$$
\text { Universidade de São Paulo }
$$

Faculdade de Zootecnia e Engenharia de Alimentos

\title{
ESTIMATIVAS DE PARÂMETROS GENÉTICOS DE CARACTERÍSTICAS DE CARCAÇAS MEDIDAS POR ULTRA-SONOGRAFIA E DE DESENVOLVIMENTO PONDERAL EM BOVINOS DA RAÇA SANTA GERTRUDIS
}

\section{JOSÉ HENRIQUE HIPPÓLITO KARSBURG}

Dissertação de Mestrado apresentada à Comissão de Pós-Graduação da Faculdade de Zootecnia e Engenharia de Alimentos da USP em 15 de Agosto de 2003, como parte dos requisitos para a obtenção do Título de Mestre em Zootecnia, na área de Concentração de Qualidade e Produtividade Animal.

Orientador: Prof.Dr. José Bento Sterman Ferraz 


\section{FICHA CATALOGRÁFICA}

preparada pela

Biblioteca da Faculdade de Zootecnia e Engenharia de Alimentos da Universidade de São Paulo 
"De tudo ficam três coisas:

A certeza de que estamos sempre começando, a certeza de que é preciso continuar, a certeza de que seremos interrompidos antes de terminar.

Portanto devemos:

Fazer da interrupção um novo caminho, da queda um passo mais firme, do medo uma escada, do sonho uma ponte, da procura um encontro".

Fernando Pessoa

"Nesta jornada terrena aprende muito quem anda e sempre que a alma se agranda a estrada fica pequena. Falta distância de pago e sobra cavalo, mesmo quando avisto a estância, as léguas que faltam, imagino um angico queimando nas brasas, fogueando a saudade com a paz no galpão e a alma da gente se sente nas casas. Continuo guardando bem meus silêncios porque eles sabem que são só meus, mas as vezes quase já não cabem na casa grande do coração".

Gujo Teixeira 


\section{Dedico:}

Ao meu querido e amado Pai, Alcebíades, que continua abrindo mão dos seus sonhos para que eu possa realizar os meus.

A minha querida e amada mãe Elizabeth, a qual sempre foi a minha maior incentivadora nesta e em outras fases.

Aos meus irmãos Luciana, Renato e Alcebíades Filho, pelo carinho e pela torcida. 
Ofereço este Trabalho: À Helena, pelo carinho, dedicação, companhia e compreensão neste período. 


\section{AGRADECIMENTOS}

A Deus pela vida e por permitir esta conquista.

Ao Prof. Dr. José Bento Sterman Ferraz, pelos ensinamentos, orientação e confiança na realização deste trabalho.

Ao Prof. Dr. Joanir Pereira Eler, pelos ensinamentos e estimulo, os quais contribuem em muito para meu crescimento profissional.

Ao amigo Saulo da Luz e Silva, pela oportunidade, pelas discussões de idéias e pelos bons momentos compartilhados.

Ao Prof. Gerson Barreto Mourão, pela significativa contribuição na elaboração deste trabalho.

Aos pós-graduandos do GMA, Sancho, Ivan, Brumatti, Elisângela, Augusto, Érika, Marcelo, Eder, Julio, Leila, Rodrigo e Andréa, existe um provérbio que diz: trabalhe e estude com campeões - eles vão lhe ensinar a ser campeão. Obrigado pelo apoio e pela ajuda fundamental. 
À minha avó Lina, minha tia Olinda, meu tio Eurico e minhas primas Jerusa e Laura, pelas orações e pela torcida.

À extensão da minha família Carla, Marcelo e ao meu querido afilhado Vitor Hugo, espero agora ter mais tempo para ele.

Aos Meus Irmãos, não de sangue, mas de Fé Gordo, Jeovane, Kako e Rogério.

À Raquel, pelos momentos juntos, pelo incentivo e pelas saudades.

Aos Meus Amigos, de Uruguaiana (Nica, Pony, Nelsinho, Preto, Nico, Pedrinho, Melissa, Tiago, Silvana, Duda, Loli, Bebe, Leandro, Perereca, Birinha, entre outros), da USP (Maurício, chorão, Luciane, Laura, Rot, feio, Frederico, minhoca, Sandro, Goiano, Angélica, entre outros). Meus amigos são todos assim... metade loucura, metade santidade. Escolho-os não pela pele, mas pela pupila... Tem que ter brilho questionador e tonalidade inquietante. Fico com aqueles que fazem de mim "louco" e "santo". Deles não quero resposta, quero meu avesso. Que me tragam dúvidas e angústias.

Aos conterrâneos Bugio, Isabeli e Evelize, que como eu se atreveram a matear longe das casas. 
Aos Professores e Funcionários da Faculdade de Zootecnia e Engenharia de Alimentos da Universidade de São Paulo.

A todos os colegas de pós-graduação pelos ensinamentos e alegrias compartilhadas.

A ABCSG e aos criadores que cederam os dados e animais para que eu pudesse transformar idéias em conhecimentos.

Aos animais experimentais, sob o nosso controle, eles crescem, dependem e confiam. Respeito haja, enquanto vivos, pois não será em vão seu sacrifício (SAMPAIO, 1998).

E a todos que direta ou indiretamente contribuíram e torceram para que este trabalho pudesse ser realizado, muito obrigado. 


\section{ÍNDICE GERAL}

Página

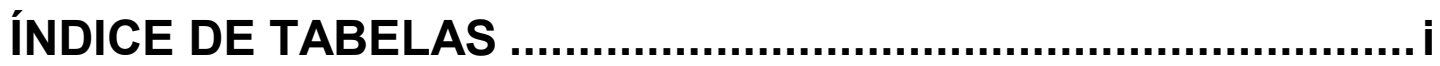

ÍNDICE DE FIGURAS

ÍNDICE DE FIGURAS …….............................................

LISTA DE ABREVIATURAS........................................... vii

LISTA DE ABREVIATURAS............................................. vii

LISTA DE SÍMBOLOS........................................................... ix

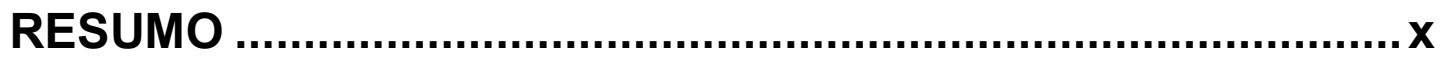

ABSTRACT

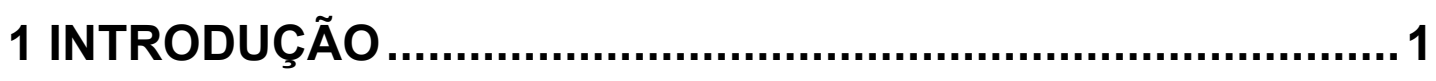

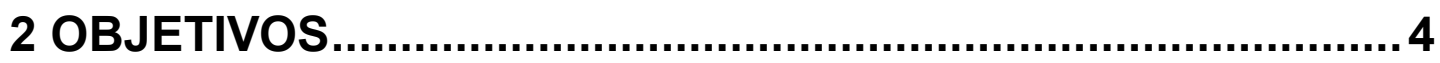

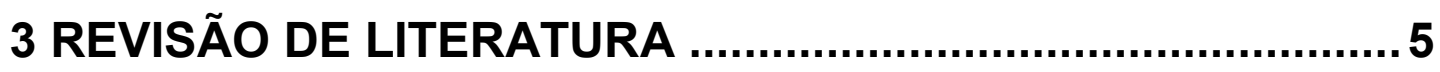

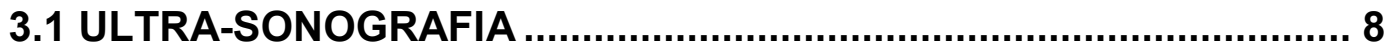

3.1.1 Ultra-sonografia para Predição de Características de Carcaça.. 10

3.1.2 Ultra-Sonografia para Estimação de Parâmetros Genéticos ...... 12

3.1.3 Precisão das Medidas Realizadas por Ultra-sonografia ............... 15

3.2 CARACTERÍSTICAS DE DESENVOLVIMENTO PONDERAL.......... 17

3.3 ESTIMAÇÃO DE PARÂMETROS GENÉTICOS …............................. 18

3.4 METODOLOGIA DE MODELOS MISTOS ...................................... 20

4 MATERIAL E MÉTODOS ..................................................... 24

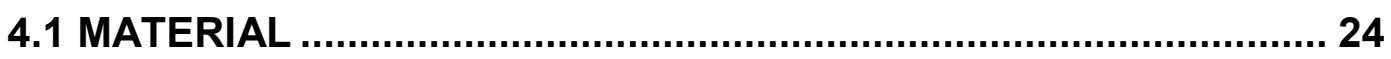

4.1.1 Formação do Banco de Dados .................................................. 26

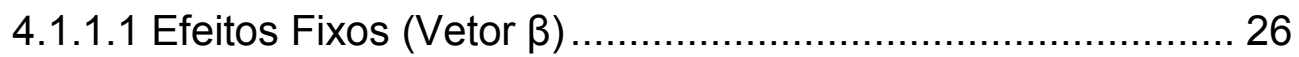

4.1.1.2 Efeitos Genéticos (Vetor $\mu$ ) ............................................ 28

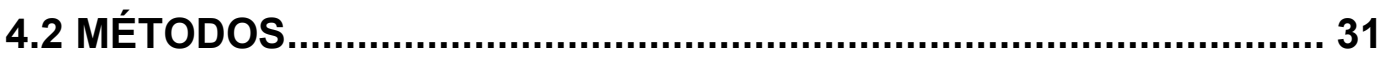


4.2.1 Ajuste dos Dados por Funções Polinomiais 32

4.2.1.1 Cálculo Dos Fatores De Correção................................... 35

4.2.2 Análise Genética - Estimação de Parâmetros Genéticos .......... 35

4.2.3 Estimação de Componentes de (Co)Variância......................... 40

5. RESULTADOS E DISCUSSÃO ......................................... 41

5.1 CaRacterísticas de CarcaÇa Ajustadas para Idade por Polinômios SEgmentAdOS 41

5.2 Características de Desenvolvimento Ponderal Ajustadas por PolinÔMIOS SEgMENTADOS.................................................................... 47

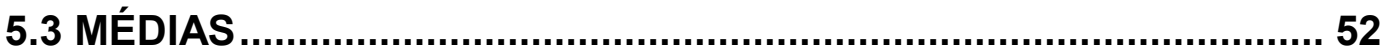

5.4 HERDABILIDADES ..................................................................... 53

5.4.1 Herdabilidades das Características de Carcaça ....................... 56

5.4.2 Herdabilidades das Características de Desenvolvimento Ponderal 61

5.5 CORRELAÇÕES GENÉTICAS 64

5.5.1 Correlações Genéticas de AOL com Característica de Desenvolvimento Ponderal 65

5.5.2 Correlações Genéticas de EGS com Característica de Desenvolvimento Ponderal. 66

5.5.3 Correlações Genéticas de PESDES com Característica de Carcaça e demais Características de Desenvolvimento Ponderal ...... 68

6 CONCLUSÕES E IMPLICAÇÕES ...................................... 70 7 REFERÊNCIAS BIBLIOGRÁFICAS ....................................... 72 


\section{ÍNDICE DE TABELAS}

Tabela 1 - Correlações entre medidas de área de olho de lombo (AOL) e espessura de gordura subcutânea (EGS) obtidas por ultrasonografia e na carcaça segundo alguns autores. 12

Tabela 2 - Coeficientes de herdabilidade das medidas de área de olho de lombo e espessura de gordura subcutânea (EGS) obtidas por ultra-sonografia segundo alguns autores.

Tabela 3 - Número de observações $(\mathrm{N})$, média $(\bar{X})$, desvio-padrão (DP), valores mínimos (MIN) e máximos (MAX) das características mensuradas por ultra-sonografia. Pirassununga, São Paulo. 2003 24

Tabela 4 - Número de observações por grupo de manejo, aos 120 dias de idade (gm120), grupo de manejo na desmama (gmdes), grupo de manejo aos 12 meses de idade (gm12) e grupo de manejo aos 18 meses de idade (gm18), de acordo com o regime alimentar. Pirassununga, São Paulo. 2003 25

Tabela 5 - Classes segundo as idades das mães ao parto (CIV), em meses. Pirassununga, São Paulo. 2003 27

Tabela 6 - Descrição do arquivo de dados para as características de área de olho de lombo (AOL), de espessura de gordura subcutânea (EGS), dos pesos ao nascimento (PESNAS), aos 120 dias de idade (PES120), na desmama (PESDES), aos 12 meses de idade (PES12), aos 18 meses de idade (PES18) e aos 24 meses de idade (PES24), do perímetro escrotal aos 18 meses de idade (PE18). Pirassununga, São Paulo. 2003 29 
Tabela 7 - Estatísticas das idades dos animais para as características de área de olho de lombo (AOL), de espessura de gordura subcutânea (EGS), dos pesos ao nascimento (PESNAS), aos 120 dias de idade (PES120), na desmama (PESDES), aos 12 meses de idade (PES12), aos 18 meses de idade (PES18) e aos 24 meses de idade (PES24), do perímetro escrotal aos 18 meses de idade (PE18). Pirassununga, São Paulo. 2003...... 30

Tabela 8 - Descrição do comportamento e dos modelos de polinômios segmentados que descrevem as características de AOL, EGS e de desenvolvimento ponderal em função da idade. Pirassununga, São Paulo. 2003 34

Tabela 9 - Valores de freqüências (FREQ), de médias ${ }^{11}$, de erros padrão (EP), de fatores de correção multiplicativos (FC), por classes de idades $(\mathrm{Cl})$ para $\mathrm{AOL}$ e EGS mensuradas por ultrasonografia. Pirassununga, São Paulo. 2003 43

Tabela 10 - Valores de freqüências (FREQ), de médias ${ }^{11}$, de erros padrão (EP), de fatores de correção multiplicativos (FC), por classes de idades $(\mathrm{Cl})$ para $\mathrm{AOL}$ e EGS mensuradas por ultrasonografia. Pirassununga, São Paulo. 2003. (continuação)... 44

Tabela 11 - Parâmetros das funções de ajuste, (erros padrão), coeficientes de determinação $\left(R^{2}\right)$ e de variação $(C V)$, e Quadrado Médio do Erro (QME) obtidos pelo polinômio segmentado e pelos polinômios ordinários para AOL. Pirassununga, São Paulo. 2003 45

Tabela 12 - Parâmetros das funções de ajuste, (erros padrão), coeficientes de determinação $\left(R^{2}\right)$ e de variação $(C V)$, e Quadrado Médio do Erro (QME) obtidos pelo polinômio segmentado e pelos polinômios ordinários para EGS. Pirassununga, São Paulo. 2003 46 
Tabela 13 - Parâmetros das funções de ajuste, (erros padrão), coeficientes de determinação $\left(R^{2}\right)$ e de variação $(C V)$, e Quadrado Médio do Erro (QME) obtidos pelo polinômio segmentado e pelos polinômios ordinários para PES120. Pirassununga, São Paulo. 2003

Tabela 14 - Parâmetros das funções de ajuste, (erros padrão), coeficientes de determinação $\left(R^{2}\right)$ e de variação $(C V)$, e Quadrado Médio do Erro (QME) obtidos pelo polinômio segmentado e pelos polinômios ordinários para PESDES. Pirassununga, São Paulo. 2003

Tabela 15 - Parâmetros das funções de ajuste, (erros padrão), coeficientes de determinação $\left(R^{2}\right)$ e de variação $(C V)$, e Quadrado Médio do Erro (QME) obtidos pelo polinômio segmentado e pelos polinômios ordinários para PES12. Pirassununga, São Paulo. 2003 49

Tabela 16 - Parâmetros das funções de ajuste, (erros padrão), coeficientes de determinação $\left(R^{2}\right)$ e de variação $(C V)$, e Quadrado Médio do Erro (QME) obtidos pelo polinômio segmentado e pelos polinômios ordinários para PES18. Pirassununga, São Paulo. 2003 50

Tabela 17 - Parâmetros das funções de ajuste, (erros padrão), coeficientes de determinação $\left(R^{2}\right)$ e de variação $(C V)$, e Quadrado Médio do Erro (QME) obtidos pelo polinômio segmentado e pelos polinômios ordinários para PES24. Pirassununga, São Paulo. 2003

Tabela 18 - Parâmetros das funções de ajuste, (erros padrão), coeficientes de determinação $\left(R^{2}\right)$ e de variação $(C V)$, e Quadrado Médio do Erro (QME) obtidos pelo polinômio segmentado e pelos polinômios ordinários para PE18. Pirassununga, São Paulo. 2003 
Tabela 19 - Estimativa dos componentes de variância, covariância e parâmetros genéticos para as características de carcaça, de desenvolvimento ponderal e de perímetro escrotal em análises uni-característica, pelo método de máxima verossimilhança restrita (REML). Pirassununga, São Paulo, 2003. 55 


\section{ÍNDICE DE FIGURAS}

Figura 1 - Freqüência de distribuição das classes de idade para as medidas de ultra-sonografia. 32

Figura 2 - Valores de herdabilidade para efeito genético aditivo direto $\left(h_{a}^{2}\right)$ e fração da variância fenotípica devido aos efeitos residuais $\left(\mathrm{e}^{2}\right)$ para área de olho de lombo, estimados em análises unicaracterística e bi-característica. Pirassununga, São Paulo. 2003

Figura 3 - Valores de herdabilidade e proporção dos efeitos residuais $\left(\mathrm{e}^{2}\right)$ para espessura de gordura subcutânea, estimados em análises uni-característica e bi-característica. Pirassununga, São Paulo. 2003 58

Figura 4 - Comparação da variação das estimativas de herdabilidade de área de olho de lombo obtidas em análises uni e bicaracterísticas. Pirassununga, São Paulo. 2003

Figura 5 - Comparação da variação das estimativas de herdabilidade de espessura de gordura subcutânea obtidas em análises uni e bicaracterísticas. Pirassununga, São Paulo. 2003. 59

Figura 6 - Valores de herdabilidade para efeitos genéticos aditivos diretos $\left(h^{2}\right)$ e para efeitos genéticos aditivos maternos $\left(h^{2}\right)$, fração da variância fenotípica devido ao ambiente permanente da vaca, $\left(c^{2}\right)$ e proporção dos efeitos residuais $\left(\mathrm{e}^{2}\right)$ para PESDES, estimados em análises uni-característica. Pirassununga, São Paulo. 2003

Figura 7 - Comparação da variação da estimativa de herdabilidade de PESDES obtida em análises uni e bi-características. Pirassununga, São Paulo. 2003. 63

Figura 8-Correlações genéticas entre AOL e características de desenvolvimento ponderal. Pirassununga, São Paulo. 2003 .... 65 
Figura 9 - Correlações genéticas entre EGS e características de desenvolvimento ponderal. Pirassununga, São Paulo. 2003 ....66

Figura 10 -Correlações genéticas entre PESDES, características de carcaça e demais características de desenvolvimento ponderal. Pirassununga, São Paulo. 2003 ......................................... 69 


\section{LISTA DE ABREVIATURAS}

\begin{tabular}{ll} 
Al & - Average Information \\
AOL & - Área De Olho De Lombo \\
BLUE & - Melhor Estimador Linear Não Viesado \\
BLUP & - Melhor Preditor Linear Não Viesado \\
CIV & - Classe De Idade Da Mãe Ao Parto \\
CV & - Coeficiente De Variação \\
DF & - Derivative Free \\
DP & - Desvio Padrão \\
EGS & - Espessura De Gordura Subcutânea \\
FC & - Fator De Correção \\
GC & - Grupo Contemporâneo \\
GLM & - General Linear Models \\
GM & - Grupo De Manejo \\
ID & - Idade \\
L & - Linear \\
M & - Média \\
MIN & - Mínimo \\
\hline
\end{tabular}




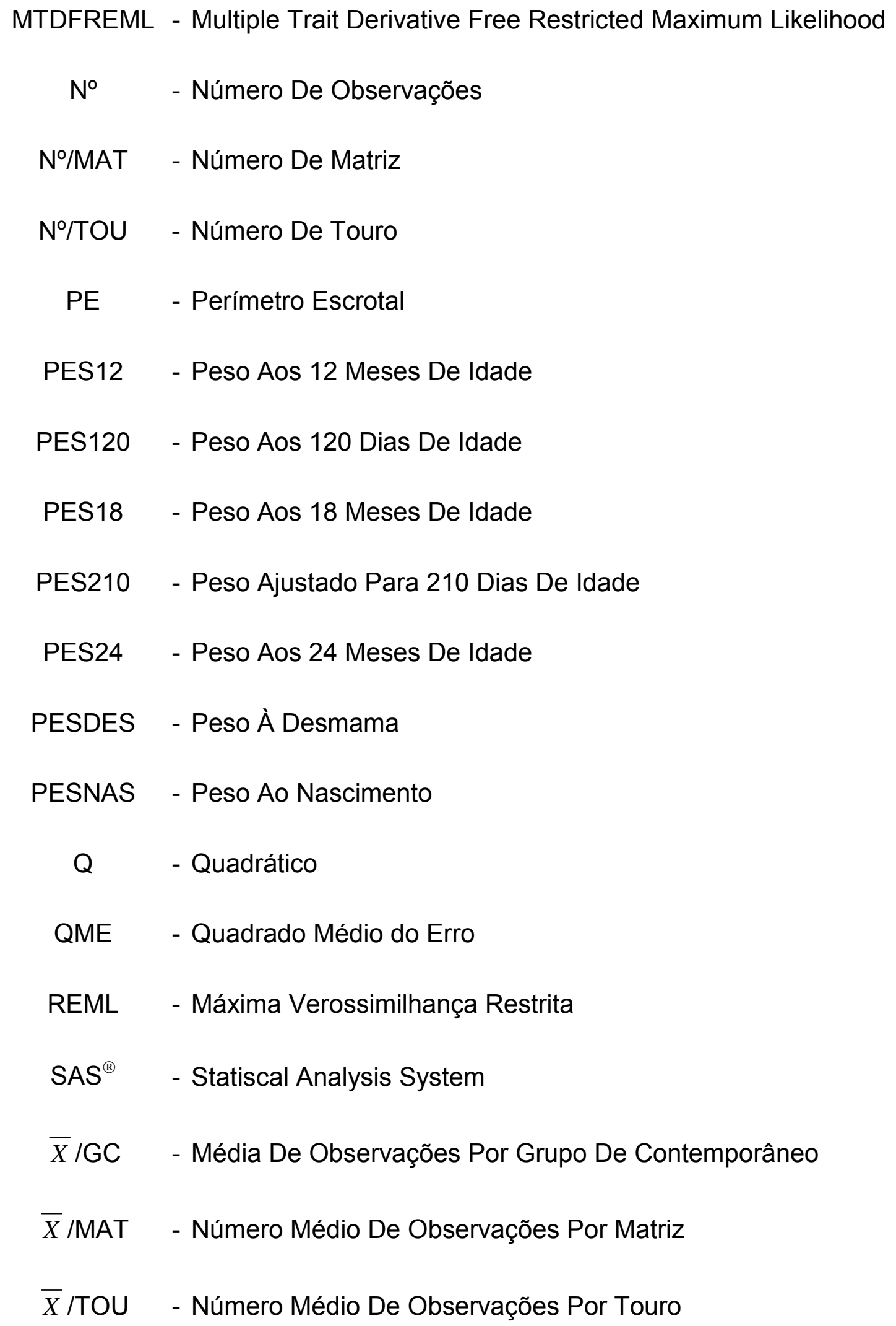




\section{LISTA DE SÍMBOLOS}

$$
\begin{aligned}
& \text { Kg - Kilograma } \\
& \% \quad \text { - Porcentagem } \\
& \bar{X} \quad \text { - Média } \\
& \sigma_{a}^{2} \quad \text { - Variância Genética Aditiva Direta } \\
& \sigma_{m}^{2} \quad \text { - Variância Genética Aditiva Materna } \\
& \sigma_{a m} \quad \text { - Covariância Entre Os Efeitos Genéticos Aditivos Diretos E Maternos } \\
& \sigma_{c}^{2} \quad \text { - Variância Devido Ao Ambiente Permanente Da Vaca } \\
& \sigma_{e}^{2} \quad \text { - Variância Residual } \\
& \sigma_{p}^{2} \quad \text { - Variância Fenotípica } \\
& \sigma_{p} \quad \text { - Desvio-Padrão Fenotípico } \\
& h_{a}^{2} \text { - Estimativa Do Coeficiente De Herdabilidade Para Os Efeitos }
\end{aligned}
$$




\section{RESUMO}

KARSBURG, J.H. ESTIMATIVAS DE PARÂMETROS GENÉTICOS DE CARACTERÍSTICAS DE CARCAÇAS MEDIDAS POR ULTRASONOGRAFIA E DE DESENVOLVIMENTO PONDERAL EM BOVINOS DA RAÇA SANTA GERTRUDIS. Pirassununga, 2003. 96p. Dissertação (Mestrado) - Faculdade de Zootecnia e Engenharia de Alimentos, Universidade de São Paulo.

O presente trabalho teve por objetivo estimar parâmetros genéticos de características de carcaça medidas por ultra-sonografia e de desenvolvimento ponderal em bovinos da raça Santa Gertrudis. O conjunto de dados é proveniente de 12 fazendas participantes do Programa de Melhoramento Animal da ABSG. As características analisadas foram, área de olho de lombo, espessura de gordura subcutânea, peso ao nascimento, peso aos 120 dias de idade, peso a desmama, peso aos 12 meses de idade, peso aos 18 meses de idade, peso aos 24 meses de idade e perímetro escrotal aos 18 meses de idade. Os dados foram pré-ajustados para o efeito de idade pela metodologia de polinômios segmentados. Os componentes de (co)variância foram estimados por máxima verossimilhança restrita utilizando-se o software MTDFREML. As estimativas de herdabilidade foram obtidas em análises uni-característica, e em análises bi-características, as quais geraram estimativas de correlações genéticas das características de AOL, EGS com as características de desempenho ponderal. As estimativas

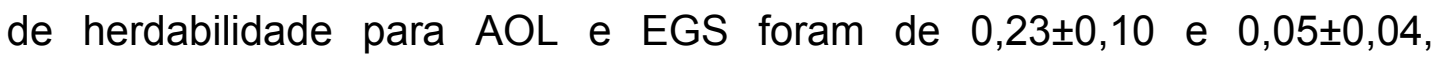
respectivamente. Os parâmetros encontrados neste trabalho são estimativas para uma amostra da população da raça Santa Gertrudis e sugerem-se estudos adicionais, para confirmar as estimativas de parâmetros genéticos para estimativas de carcaça obtidas por ultra-sonografia, para esta raça.

Palavras-chave: Ultra-som, avaliação de carcaças, Santa Gertrudis, Polinômios Segmentados, Parâmetros Genéticos. 


\begin{abstract}
KARSBURG, J.H. ESTIMATIVE OF GENETIC PARAMETERS FOR CARCASS TRAITS MEASURED BY ULTRASOUND AND TRAITS OF PONDERAL DEVELOPMENT IN SANTA GERTRUDIS BEEF CATTLE.
\end{abstract}

The present study has as objectives to estimate genetic parameters of carcass traits measured by ultrasound and traits of ponderal development in Santa Gertrudis beef cattle. All data set evaluated was originated from 12 farms participating of the Animal Breeding Program conduced by Grupo de Melhoramento Animal of the Universidade de Sao Paulo. The traits analyzed were rib eye area (REA), fat thickness (FAT), birth weight, weight at 120 days, weaning weight, weight at 12, 18 and 24 months and scrotal circumference at 18 months of age. The data were pre-adjusted for age effect by segmented polynomials methodology. The co-variance components were estimated by Restricted Maximum Likelihood using the MTDFREML software. The estimates of heritability were obtained from univariate analysis, while the genetic correlations between REA and FAT with traits of ponderal development were calculated from bivariate analysis. The heritability estimated for REA and FAT were of $0.23 \pm 0.10$ and $0.05 \pm 0.04$, respectively. All genetic parameters reported in this present study are estimated from a population sampling of Santa Gertrudis animals, being suggested additional research for genetic parameters evaluation of carcass traits measured by ultrasound. In the breed.

Keywords: Ultrasound, Carcass Evaluation, Santa Gertrudis, Segmented Polynomial, Genetic Parameters. 


\section{INTRODUÇÃO}

A ênfase dada à seleção em programas de melhoramento genético de bovinos de corte incluiu, até o momento, basicamente avaliações voltadas aos pesos em determinadas idades e de algumas características relacionadas à reprodução. Recentemente, a intensificação dos sistemas de produção, a demanda por eficiência, as tendências do mercado e o desejo dos criadores de tomar decisões embasadas num conjunto de características agregadas ao valor econômico da produção, estão possibilitando a incorporação de uma série de características qualitativas, a saber: maciez, percentual de gordura, área de músculos em determinados cortes, relação ossos / músculos / gordura, nos programas de melhoramento genético de bovinos de corte.

A eficiência e a lucratividade de um sistema tornaram-se objetivos primordiais e, conceitos tão relevantes, anteriormente ignorados, como melhoramento genético, nutrição, eficiência reprodutiva e qualidade do produto final, tornaram-se freqüentes na linguagem do produtor e motivos de sobrevivência na atividade.

Nas últimas décadas a genética, aplicada diretamente em procedimentos de seleção, tem permitido a elevação dos índices de produtividade a partir da escolha dos melhores genótipos e da adequação às condições ambientais relacionadas ao processo produtivo.

A busca de animais geneticamente superiores tornou-se imperativa. Nesse contexto, a condução de um programa de melhoramento genético é importante para a produção bovina no país FERRAZ, (2000), assim como, a identificação dos melhores reprodutores se torna indispensável para se otimizar o ganho genético dos rebanhos. 
Com aproximadamente 167 milhões de cabeças (ANUALPEC, 2003), cuja grande maioria é composta de zebuínos e seus mestiços, o Brasil aparece com o maior rebanho comercial do mundo. Estes animais são criados quase que exclusivamente em pastagem e sem receber qualquer tipo de alimentação que possa comprometer a saúde humana.

Os avanços tecnológicos em instrumentação permitem a realização de medições em animais vivos com maior precisão e de modo mais freqüente. Dessa forma é possível incluir características mais estreitamente ligadas aos objetivos dos programas de melhoramento. O êxito destes programas, neste início do milênio, está vinculado ao estabelecimento de objetivos e metas bem definidos. Esses devem ser coerentes com a estrutura de mercado vigente e certamente adaptados às condições ambientais e sociais. Desta forma, continua sendo fundamental definir o objetivo final de um programa de melhoramento genético e o que se entende por critérios de seleção.

Para produção pecuária de bovinos de corte ser eficiente é necessário produzir uma carcaça que atenda às especificações do mercado interno e externo. A seleção faz parte desta estratégia, pois permite mudanças nas características de carcaças assegurando bom retorno econômico ao sistema de produção empregado.

Para os segmentos envolvidos na cadeia de produção de carne, a importância do conhecimento das características quantitativas e qualitativas das carcaças é fundamental. Determinar a composição da carcaça e o grau de acabamento dos animais tem significado especial na eficiência do desempenho de animais de diferentes taxas de crescimento e tamanhos à maturidade. Permitindo a otimização dos recursos alimentares para cada genótipo. 
A raça Santa Gertrudis, é considerada a primeira raça sintética nas Américas, sendo desenvolvida nos anos 20 pelo capitão Richard King no "King Ranch" em Kingsville, Texas, EUA, a partir do cruzamento entre o gado Brahman (Bos taurus indicus) e o Shorthon (Bos taurus taurus), CARTWRIGHT (1978). Desenvolvida com o intuito de melhorar a produção de carne bovina em áreas tropicais e subtropicais, foi introduzida no Brasil em 1953, sendo proveniente dos Estados Unidos. O crescimento do número de animais ocorreu devido ao aumento das importações, mas principalmente, devido aos cruzamentos absorventes, no qual os criadores utilizaram vacas de várias raças zebuínas, na maioria das vezes Nelore.

A medição de animais vivos utilizando a ultra-sonografia tem como objetivo disponibilizar informações qualitativas e quantitativas precisas e objetivas da composição corporal de animais vivos. Essas informações visam à predição das diferenças genéticas entre os indivíduos e a identificação de reprodutores geneticamente superiores para características indicadoras de qualidade e produtividade de carcaça. 


\section{OBJETIVOS}

Os objetivos deste trabalho foram:

1 - Obter medidas de área de olho de lombo (AOL) e espessura de gordura subcutânea (EGS) em bovinos da raça Santa Gertrudis, utilizando a tecnologia de ultra-sonografia "real time".

2 - Estimar componentes de variância e covariância para AOL e EGS obtidas por ultra-sonografia utilizando a metodologia de modelos mistos (modelo animal).

3 - Estimar correlações genéticas entre as medidas de AOL e EGS e as características de desenvolvimento ponderal: peso ao nascimento (PESNAS), peso aos 120 dias de idade (PES120), peso a desmama (PESDES), peso aos 12 meses de idade (PES12), peso aos 18 meses de idade (PES18), peso aos 24 meses de idade (PES24) e perímetro escrotal aos 18 meses (PE18). 


\section{REVISÃO DE LITERATURA}

Nas últimas décadas, tem sido discutido a respeito da qualidade da carne e de seus subprodutos. O objetivo é satisfazer os requisitos mínimos exigidos pelo consumidor, a razão de ser da cadeia da carne.

A carcaça bovina tem se tornado importante objeto de estudo no contexto nacional e sua mensuração oferece grande oportunidade de melhorar a eficiência produtiva, por meio da aplicação dos princípios de melhoramento genético, aliados as tecnologias atualmente disponíveis de avaliação do animal vivo.

O crescimento e o desenvolvimento de bovinos de corte e os mecanismos que controlam essas mudanças vem sendo intensamente pesquisados nas ultimas décadas (BERG \& BUTERFIELD, 1979; LEME, 1993; LANNA \& PACKER, 1998; LUCHIARI FILHO, 2000).

Está claro que a maior parte das atividades desenvolvidas por produtores dentro de um sistema de criação de bovinos de corte busca maximizar a eficiência no processo de desenvolvimento animal. A meta é superar os pontos atuais da curva de crescimento. Diversos fatores genéticos e ambientais, assim como, suas interações podem alterar a eficiência do crescimento, bem como a composição e a distribuição dos tecidos corporais. Entre os principais fatores destacam-se peso, idade, nutrição, genética (raça, tamanho corporal, sexo, maturidade sexual e a manipulação do genoma). 
Segundo OWENS et al. (1993), o conhecimento do genótipo animal permite que se avalie detalhadamente o desenvolvimento e o crescimento dos bovinos. Assim, fatores importantes como precocidade, eficiência produtiva e taxa de maturação, entre outros, podem ser trabalhados adequadamente. Entretanto, a compreensão da relação dessas variáveis, com a finalidade de predizer acuradamente o grau de desenvolvimento e 0 crescimento dos animais como forma de apoio a decisões em sistemas de produção animal, requer ainda grande esforço por parte da pesquisa experimental.

SILVA (2001) afirma que animais que depositam maiores quantidades de carne magra na carcaça apresentam melhor eficiência de conversão alimentar, ou seja, utiliza menores quantidades de matéria seca para formar cada unidade de ganho de peso, o que reflete positivamente em economia de alimento, em eficiência de crescimento e composição química dos tecidos depositados.

O termo precocidade de terminação é utilizado para denotar animais que atingem composição corporal da carcaça adequada ao abate a uma idade jovem, ou seja, maior quantidade de músculo possível, menor quantidade de osso, e mínima quantidade de gordura, suficiente para não haver perdas na qualidade da carcaça (BERG \& BUTERFIELD, 1979). Esta composição, definida pelas exigências do mercado consumidor, pode ser estimada pela deposição de gordura corporal. Segundo MAVROGENIS et al. (1979), estes tecidos têm diferentes taxas de crescimento, que se alteram ao longo do desenvolvimento animal.

A taxa de maturação, segundo LANNA \& PACKER (1998), representa a rapidez com que $\mathrm{o}$ animal atinge determinada proporção do seu peso adulto e pode definir o animal precoce. Essa característica é a determinante primária da idade em que se inicia a fase de deposição de gordura, sendo que raças de maturação precoce são conhecidas por rápida deposição de gordura. 
A composição genética do animal é talvez o fator mais importante na regulação da taxa de maturação. Segundo OWENS (1993), animais de pequeno porte à maturidade e, conseqüentemente, mais precoces, iniciam o processo de deposição de tecido adiposo mais cedo, no entanto, provavelmente tem menor proporção de músculos na carcaça quando comparados com animais de grande porte à maturidade, que devido ao prolongamento do período de deposição muscular, necessitam de maior tempo para atingir o mesmo grau de acabamento nas mesmas condições de alimentação.

A utilização de instrumentos de alta tecnologia permitem medições precisas de componentes do tecido animal e composição da carcaça, os quais são difíceis de serem obtidas por inspeção visual ou palpação no animal vivo (MILLER, 2001). Assim, a ultra-sonografia, surge como técnica viável (FROST et al., 1997), acurada e de custo aceitável para esta função (HOUGHTON \& TURLINGTON, 1992).

$\mathrm{Na}$ era das alianças mercadológicas existe a necessidade da indústria pecuária, em todos os seus segmentos, dispor de informações genéticas sobre características ligadas à qualidade de carcaça. Segundo BERTRAND, (2000), muitas associações de gado de corte nos Estados Unidos desenvolveram ou estão desenvolvendo programas de avaliação genética de carcaças baseados em informações de medidas de ultra-sonografia em animais jovens criados em pastagens, confinados ou na combinação de ambos os regimes alimentares. Ainda segundo o autor, pesquisas tem sido desenvolvidas em setores públicos e privados visando desenvolver tecnologias baseadas no uso do DNA e marcadores moleculares para utilizar em programas de melhoramento de carcaça em gado de corte.

Com a expectativa de aumento das exportações de carne brasileira in natura e industrializada existe grande interesse no desenvolvimento de sistemas de avaliação e classificação para carne bovina, bem como, o uso de técnicas eficientes para identificar características indicadoras de qualidade de carcaça que permitam selecionar reprodutores para tais características. 


\subsection{ULTRA-SONOGRAFIA}

A possibilidade de utilização do ultra-som para análise de tecidos em animais é possível devido à diferença de impedância acústica existente entre os diferentes tecidos, ou seja, a resistência que determinados tecidos oferecem à passagem de ondas sonoras de alta freqüência. De acordo com THWAITES (1984), os tecidos mais densos oferecem maior resistência, refletindo maiores quantidades de ondas. Essas ondas são captadas por cristais, que possuem propriedade de transformar energia elétrica em energia mecânica e vice e versa (propriedade piezoelétrica). A velocidade do som varia de acordo com a temperatura e tipo de tecido, sendo maior no tecido muscular do que no tecido adiposo (ROBINSON et al. 1992).

Segundo THWAITES (1984), a técnica de ultra-sonografia está disponível, para a avaliação de carcaça e composição corporal de suínos, ovinos e bovinos.

Vários pesquisadores têm utilizado medidas obtidas por ultra-som para estimar parâmetros genéticos de características de carcaça em programas de melhoramento animal (WILSON et al., 1993; ROBINSON et al., 1998; IOWA STATE UNIVERSITY \& AMERICAN ANGUS ASSOCIATION, 1999; REVERTER et al., 2000; FIGUEIREDO, 2001; entre outros). O desenvolvimento muscular e o grau de acabamento em animais in vivo como estimativa da composição de carcaça (STOUFFER et al., 1961; KEMPSTER et al., 1981; FAULKNER et al., 1990; WILSON, 1995; SILVA, 2001; SUGUISAWA, 2002, entre outros), assim como, o rendimento de cortes cárneos comerciais antes do abate (WALDNER et al., 1992; JOHNSON et al., 1997; HASSEN et al., 1999b; MAY et al., 2000, entre outros). Porém no Brasil, somente o desenvolvimento de um eficiente programa de tipificação de carcaças, que beneficie e remunere o pecuarista pela entrega de um produto de melhor qualidade, é que fomentará o uso da ultra-sonografia em programas seleção para qualidade de carne. 
Segundo SUGUISAWA (2002), a aplicação prática e experimental à qual a ultra-sonografia se destina sofre mudanças regionais de acordo com o mercado e com o perfil do consumidor. Em países onde a prioridade é à busca de animais com alta deposição de gordura intramuscular, a ultrasonografia auxilia a detecção do ponto ideal de abate dos bovinos evitando o excesso de gordura subcutânea e o tempo de permanência dos animais no confinamento, tornando a atividade menos onerosa e mais eficiente. Além disso, em programas de terminação de bovinos destes países à ultrasonografia já tem sido utilizada para prever a quantidade de músculo e gordura e a composição química da carcaça antes do abate, e também na predição do período necessário destes animais em confinamento para atingir determinado grau de acabamento (BRETHOUR, 2000a).

O uso da ultra-sonografia para predizer a percentagem de gordura intramuscular da carne, embora não muito convincente para alguns pesquisadores (HOUGHTON \& TURLINGTON, 1992) está sendo cada vez mais pesquisada e vem demonstrando resultados satisfatórios (BRETHOUR, 2000b; HASSEN et al., 2001).

Segundo BUSBOOM et al. (2000), a precisão e a repetibilidade das medidas é influenciada por variáveis importantes como o conhecimento e experiência do técnico, tipo de equipamento, transdutores utilizados, software de interpretação de imagens e os parâmetros das características estudadas.

Para que as medidas de ultra-som possam ser utilizadas como preditoras de AOL e EGS, as medidas devem ser exatas (acuradas), precisas e repetíveis. A exatidão e a precisão não são necessariamente a mesma coisa. A precisão implicaria não somente em uma classificação correta, mas que as medidas feitas sejam as mesmas em uma comparação objetiva. Conseqüentemente as medidas podem ser exatas (acuradas), mas não precisas. Para finalidade da predição genética, os animais necessitam somente serem classificados corretamente. Para predição de composição corporal ou ponto ideal de abate, as medidas devem também ser precisas. 
Para medição de AOL e EGS pesquisas indicam claramente que ao se trabalhar com técnicos qualificados o ultra-som se torna útil para coletar informações de carcaça em bovinos.

\subsubsection{Ultra-sonografia para Predição de Características de} Carcaça

Segundo FISHER (1997), a ultra-sonografia passou a ser estudada como técnica para a predição da composição de carcaça em bovinos de corte a partir de 1950, sendo considerada como uma das tecnologias mais baratas e de mais fácil aplicação. Explica-se assim o esforço de muitos pesquisadores em tornar a ultra-sonografia viável para esta função.

Atualmente muitas são as pesquisas que utilizam a ultra-sonografia para avaliação e predição de características de carcaças em bovinos de corte (PERKINS et al., 1992a,b; WILSON, 1995; SILVA, 2001), demonstrando que a avaliação com ultra-som para medir a AOL, a EGS e a porcentagem de gordura intramuscular possui precisão e repetibilidade aceitável (ROBINSON et al., 1992; HERRING et al., 1998; WILSON et al., 1998).

Segundo BERTRAND (2000), em países onde existem programas de tipificação eficientes e onde a indústria frigorífica remunera o produtor pela qualidade e por rendimento de carcaça, muitas associações de raças estão se beneficiando das medidas de ultra-sonografia, e outras associações estão tentando decidir quais seriam as melhores maneiras de se utilizar estas medidas em seus programas de melhoramento genético.

PERKINS et al. (1992a) realizaram medidas de ultra-som na região entre a $12^{\circ}$ e a $13^{\circ}$ costelas em 495 machos confinados e 151 novilhas, 24 horas antes do abate, com objetivo de avaliar a acurácia das medidas de ultra-som para AOL e EGS na predição de medidas destas características nas carcaças. De acordo com os resultados, os autores concluíram que as medidas de EGS e AOL podem ser preditores relativamente acurados das medidas reais na carcaça em gado de corte. 
Outras pesquisas demonstram que as medidas de AOL e EGS feitas por ultra-sonografia são suficientemente acuradas para a predição da composição da carcaça de bovinos (FAULKNER et al., 1990; WILSON et al., 1993; BERGEN et al., 1996). Há ainda estudos que desaconselham o uso das medidas de AOL e EGS para predição da composição de carcaça (FORREST et al., 1968; PRYANTO et al., 1997). Atualmente, é de consenso geral que a AOL obtida por ultra-sonografia é uma medida consolidada como indicador de rendimento de carcaça e tem tido ampla utilização em estudos de composição corporal (PERRY \& FOX,1990; BERGEN et al., 1996; LUCHIARI FILHO, 2000; BANKS et al, 2001; SULLIVAN \& MILLER, 2001).

A Tabela 1 apresenta estimativas de correlações entre as medidas de AOL e EGS realizadas por ultra-sonografia e as obtidas no animal postmortem, observa-se existir grande variação entre os resultados.

Segundo BANG et al. (1994), a correlação genética entre peso corporal do animal vivo e EGS medida por ultra-som, foi de 0,78 para 42 touros pesando entre 260 e $650 \mathrm{~kg}$. Esta mesma correlação, na carcaça, foi de 0,77 , demonstrando a acurácia da medida de ultra-som.

Apesar das medidas de AOL e EGS feitas por ultra-sonografia utilizadas nas equações de predição da composição de carcaça serem acuradas (SILVA, 2001; SUGUISAWA, 2002), torna-se evidente a necessidade de mais estudos nesta área para obtenção de metodologias mais adequadas e de maior aplicação prática. 
Tabela 1 - Correlações entre medidas de área de olho de lombo (AOL) e espessura de gordura subcutânea (EGS) obtidas por ultrasonografia e na carcaça segundo alguns autores.

\begin{tabular}{lcc}
\hline \multicolumn{1}{c}{ Autor } & \multicolumn{2}{c}{ Correlações } \\
\cline { 2 - 3 } & AOL & EGS \\
\hline STOUFFER et al. (1989) & 0,76 & 0,86 \\
PERRY et al. (1990) & 0,90 & 0,96 \\
PERKINS et al. (1992a) & 0,60 & 0,75 \\
PERKINS et al. (1992b) & 0,82 & 0,86 \\
WALDNER et al. (1992) & 0,73 & 0,86 \\
HASSEN et al. (1999a) & 0,48 & 0,70 \\
MAY et al. (2000) & 0,61 & 0,81 \\
RIBEIRO et al. (2000) & 0,51 & 0,43 \\
SILVA (2001) & 0,74 & 0,87 \\
SUGUISAWA (2002) & 0,68 & 0,82 \\
\hline
\end{tabular}

Recentes estudos têm mostrado também que características de $\mathrm{AOL}$ e EGS medidas por ultra-sonografia em touros e em fêmeas possuem correlações genéticas altas e positivas com características de carcaça em animais abatidos, (MOSER et al., 1998; REVERTER et al., 2000; DEVITT AND WILTON 2001), concluindo os pesquisadores que isso é um fator importante e deve ser levado em conta para efetivar a técnica de ultrasonografia como preditora da composição corporal em animais vivos.

\subsubsection{Ultra-Sonografia para Estimação de Parâmetros Genéticos}

Segundo SHEPARD et al. (1996), a AOL e a EGS medidas por ultrasom $\mathrm{e}$ as mesmas medidas feitas na carcaça são suficientemente correlacionadas, o que possibilita seu uso em programas de melhoramento genético (PERKINS et al., 1992a,b; SMITH et al., 1992).

Alguns resultados de estudos de parâmetros genéticos para AOL e EGS medidas por ultra-som têm evidenciado variabilidade genética suficiente para serem incorporados em um programa de melhoramento genético (Tabela 2), concordando com valores obtidos em estudos anteriores com medidas de carcaça no animal post-mortem. 
JOHNSON et al. (1993) estudando 2.101 animais da raça Brangus, estimaram, pelo método de máxima verossimilhança restrita (REML) parâmetros genéticos para medidas de ultra-som de AOL e EGS entre a $12^{\circ}$ e a $13^{\text {a }}$ costelas, avaliadas a uma idade e um peso constante. Os referidos autores demonstraram que os resultados alcançados com a seleção utilizando medidas de ultra-som a uma idade constante teriam um ganho maior que a seleção baseada em um peso constante.

Tabela 2 - Coeficientes de herdabilidade das medidas de área de olho de lombo (AOL) e espessura de gordura subcutânea (EGS) obtidas por ultra-sonografia segundo alguns autores.

\begin{tabular}{lcc}
\hline \multicolumn{1}{c}{ Fonte } & \multicolumn{2}{c}{ Herdabilidade } \\
\cline { 2 - 3 } & AOL & EGS \\
\hline ROBINSON et al. (1993) & 0,21 & 0,30 \\
SHEPARD et al. (1996) & 0,11 & 0,56 \\
MOSER et al. (1998) & 0,29 & 0,11 \\
REVERTER et al. (2000) & 0,37 & 0,47 \\
DEVITT \& WILTON (2001) & 0,45 & 0,41 \\
FIGUEIREDO (2001) & $0,19-0,41$ & $0,04-0,19$ \\
CREWS \& KEMP (2001) & 0,54 & 0,46 \\
KEMP et al. (2002) & 0,29 & 0,39 \\
RILEY et al. (2002) & 0,44 & 0,63 \\
CREWS \& KEMP (2002) & 0,61 & 0,50 \\
\hline
\end{tabular}

CREWS et al. (2002), em estudo realizado para avaliar a inclusão de dados de ultra-sonografia em programas de melhoramento genético, comparou a diferença esperada na progênie (DEP'S) gerada através de três diferentes metodologias e fontes de informação: (1) somente os dados de carcaça foram avaliados; (2) somente os dados dos animais vivos foram avaliados (touros e fêmeas) e (3) ambos os dados foram avaliados. Os autores reportaram estimativas de herdabilidades para as medidas de AOL e EGS in vivo e na carcaça de moderada a alta $(0,38$ a 0,69$)$, respectivamente, de acordo com os parâmetros encontrados na literatura (KOOTS et al., 1994a; REVERTER et al., 2000). 
Com o objetivo de estimar parâmetros genéticos para medidas de ultra-sonografia em animais de sobreano da raça Brangus, STELZLENI et al. (2002), estimaram herdabilidade para AOL e EGS de 0,31 e 0,26 respectivamente, e valores de correlações genéticas moderadas de 0,44 e 0,42 de peso ao sobreano com AOL e EGS, respectivamente. Os autores concluíram que medidas de ultra-som ao sobreano podem ser usadas como uma ferramenta de seleção na produção de bovinos para a melhoria de características de carcaça.

Com a possibilidade de aplicação da ultra-sonografia no estudo de composição de carcaça de bovinos, a observação de correlações genéticas favoráveis entre mensurações de AOL e EGS e outras características economicamente relevantes, aliada às estimativas moderadas ou altas de herdabilidade dessas características, os produtores passaram a dispor de informações mais confiáveis para selecionar seus animais precocemente para características de carcaça.

Em programas de melhoramento genético, estas medidas são importantes por apresentarem correlação favorável com capacidade de deposição muscular, precocidade de terminação e também por apresentarem valores de herdabilidade estimada de moderada a alta, sugerindo que possam ser modificadas por seleção, (IOWA STATE UNIVERSITY \& AMERICAN ANGUS ASSOCIATION, 1999).

Entretanto, para que os dados de ultra-sonografia sejam incluídos em um programa de avaliação genética, o desenvolvimento de estratégias de ajuste a uma determinada idade ou peso e possíveis diferenças nos componentes de variância devido à raça e sexo devem ser considerados (HASSEN et al. 1999a). Logicamente, a seleção baseada em característica medidas por ultra-som em animais a uma idade jovem poderia permitir, mais rapidamente, o progresso genético e econômico.

WALDNER et al. (1992), relataram que medidas de AOL obtidas por ultra-som ajustadas para 12 meses e EGS ajustadas para 12 ou 16 meses realizadas por técnicos qualificados são precisas o bastante para classificar os animais vivos. 
A incorporação, em um índice de seleção, das medidas de AOL e EGS feitas em animais jovens pode afetar de forma positiva a tendência genética das características de crescimento nos programas de melhoramento genético, influenciando o intervalo de gerações, a exatidão e também a intensidade de seleção (DEVITT \& WILTON, 2001). Desta maneira, a utilização do ultra-som como ferramenta nos programas de melhoramento genético de bovinos de corte no Brasil se apresenta como uma alternativa muito promissora para o melhoramento das características de carcaça e desenvolvimento ponderal.

Em nossos diferentes sistemas de criação a ultra-sonografia pode contribuir de forma positiva para os programas de melhoramento genético nas diferentes raças de bovinos de corte, disponibilizando informações, a uma idade jovem, de animais para as características de carcaça, auxiliando os produtores na identificação e seleção de animais superiores para estas características dentro de rebanho e de dentro de raças.

\subsubsection{Precisão das Medidas Realizadas por Ultra-sonografia}

O sistema utilizado para a captura e interpretação das imagens feitas por ultra-som pode ter um impacto significativo na qualidade, precisão e repetibilidade das estimativas de mensurações de características de carcaça feitas por ultra-sonografia.

Em um estudo avaliando a precisão de dois diferentes equipamentos, HERRING et al. (1998), concluíram que o Aloka 550V foi superior na exatidão e repetibilidade quando comparado com o Aloka 210DX, para medidas de AOL. CHARAGU et al. (2000) concluíram que existem diferenças entre o sexo do animal e o tipo de equipamento para as medidas de AOL e EGS. Com relação ao sexo, ambas as máquinas tiveram precisão similar em bovinos bem acabados e com maiores AOL, mas houve diferença significativa em animais mais magros e com $\mathrm{AOL}$ menores. 
BRETHOUR (1992) determinou a repetibilidade de medidas de EGS em 217 animais e constatou que as medidas de ultra-som podem ser mais precisas que medidas de carcaças para estimar a EGS em gado de corte. Também ROBINSON et al. (1992) ao avaliarem as medidas de carcaças em animais vivos por ultra-som e a eficiência dos técnicos que manipulam o aparelho, confirmaram a efetividade na predição de medidas de carcaça, além do seu uso potencial em programas de seleção.

Embora a técnica de ultra-sonografia para mensuração da AOL e EGS esteja praticamente consolidada no meio cientifico, várias pesquisas demonstram resultados discrepantes na sua exatidão. Alguns autores sugerem que as medidas de ultra-sonografia de EGS são exatas, apesar da predição da AOL ainda ser inconsistente (BRETHOUR et al., 1992; ROBINSON et al., 1992; BUSBOOM et al., 2000; MAY et al., 2000,). Outros autores consideram que a técnica de ultra-sonografia só parece ser exata para determinar a AOL (MERCADANTE et al., 1999; PRADO et al., 2001). Alguns trabalhos indicam ainda que a ultra-sonografia em tempo real pode subestimar a AOL (HENDERSON-PERRY et al., 1989; ROBINSON et al.,1992). RENAND e FISHER (1997), ao compararem quatro métodos de avaliação de carcaças, concluíram que as medidas de ultra-som são mais eficientes para predição de gordura nas carcaças dos animais. 


\subsection{CARACTERÍSTICAS DE DESENVOLVIMENTO PONDERAL}

O peso ao nascer (PESNAS) é a primeira informação após o nascimento do animal, indicando seu vigor e desenvolvimento pré-natal. É uma característica que sofre média ação genética aditiva, tem relativamente pequena influencia dos fatores genéticos e ambientais que atuam sobre a mãe, antes e durante a gestação e está relacionado com o próprio período de gestação. Pode ser considerado importante indicador da facilidade de parto.

O peso aos 120 (PES120) é mensurado quando o animal ainda depende quase que totalmente de suas mães e, portanto este peso permite avaliar a habilidade materna da matriz. Em geral, este período coincide com o pico de lactação das matrizes. O peso a desmama (PESDES) é uma característica de fácil obtenção, servindo para avaliar tanto o potencial genético do indivíduo para crescimento quanto à habilidade materna da matriz. O peso aos 12 meses de idade (PES12), reflete o potencial que o animal tem para crescer em ambiente independente dos cuidados maternos, potencial de ganho de peso no período pós-desmama e, em raças precoces, reflete o potencial do indivíduo em ganhar peso e a precocidade de crescimento tanto das fêmeas e como dos machos.

O peso aos 18 meses (PES18) é uma medida de extrema importância, pois determina o desenvolvimento do próprio animal, sendo pouco influenciado pelos efeitos maternos. Mede o potencial de desenvolvimento do animal em diferentes ambientes. O peso do animal ao sobreano reflete o potencial de ganho de peso até o abate. O peso aos 24 meses de idade é considerado um indicador do tamanho adulto do animal, reflete o potencial peso dos animais adultos e tem relação com os custos de manutenção em matrizes e com a velocidade de crescimento animal. 
O perímetro escrotal (PE), mensurado nos machos na época da pesagem aos 18 meses de idade, é correlacionado com idade à puberdade, qualidade e quantidade de sêmen, fertilidade, desenvolvimento ponderal e precocidade sexual das filhas e irmãs dos touros.

O uso desta característica para compor os critérios de seleção em bovinos de corte tem sido prática comum na maioria dos programas de melhoramento genético em todo o mundo. A seleção para PE, no entanto, não deve ser vista como substituição para a seleção direta sobre o desempenho reprodutivo das matrizes.

Os critérios de seleção de bovinos de corte tem se baseado, quase que exclusivamente, em pesos corporais em diferentes idades ou função destes pesos, como ganhos médios diários ou dias para atingir determinado peso e em perímetro escrotal pós desmama. Na proposição de inclusão das características de medidas de carcaça obtidas por ultra-sonografia, como AOL e EGS, nos critérios de seleção de bovinos de corte, é necessário o conhecimento prévio das correlações entre estas medidas e as características de desenvolvimento ponderal.

\subsection{ESTIMAÇÃO DE PARÂMETROS GENÉTICOS}

O desempenho dos animais, também denominado de fenótipo ( $F)$, é o resultado do patrimônio genético que o animal possui, o genótipo $(G)$, somado aos efeitos de meio ambiente $(A)$, existindo ainda, uma interação entre os efeitos de genótipo e de meio ambiente (GA). Alguns animais podem ser superiores a outros em determinado ambiente, mas podem se tornar inferiores àqueles em ambientes diferentes. Sendo assim, o desempenho animal, seja qual for à característica avaliada pode ser expresso como: $F=G+A+G A$. A equação mostra que o fenótipo, medido nos animais, não demonstra diretamente sua qualidade ou potencialidade genética. Esse fenótipo, essa produção ou essa medida é sempre influenciado pelo ambiente e pela interação genótipo ambiente. 
Nos indivíduos, apenas os valores fenotípicos podem ser medidos diretamente, mas é o seu valor genético que determina sua influência na geração seguinte. Por definição, se um indivíduo possui no valor fenotípico unidades acima da média da população espera-se que ele possua no valor genético, unidades acima da média dessa população, entretanto, isto depende do valor da herdabilidade da característica em questão. Por essa razão, a maior importância da herdabilidade no estudo genético dos caracteres quantitativos é o seu papel preditivo, dado que a herdabilidade é a correlação do valor fenotípico e do valor genético.

Como não se pode conhecer com exatidão o valor genético dos animais, utiliza-se de técnicas de estimação desses valores. A estimação dos valores genéticos é diretamente dependente da estimação dos componentes de variância e covariância das características, os quais são essenciais em programas de melhoramento animal, pois fornecem informações fundamentais sobre a natureza genética das características em uma certa população.

As estimativas de parâmetros genéticos e o estudo das correlações genéticas entre características de carcaça e desempenho ponderal são parte importante de um estudo amplo que visa à determinação dos critérios de seleção e a predição dos efeitos da seleção de uma característica, bem como, seu impacto sobre outras características de interesse econômico. Neste contexto, o coeficiente de herdabilidade é um parâmetro indispensável na predição do mérito genético dos animais e na predição da resposta à seleção (VAN MELIS, 2002). O coeficiente de herdabilidade é um parâmetro característico de determinada população e pode sofrer alterações ao longo do tempo, em conseqüência da seleção e das decisões de manejo. $O$ coeficiente de correlação genética também é um parâmetro genético importante, pois estabelece a força do relacionamento de uma característica em relação à outra, informando se determinada característica pode ou não ser influenciada pelas decisões de seleção em outra. 
Alem da predição do valor genético dos animais, é importante também a acurácia associada a este valor, que é dependente da qualidade e da quantidade de informação disponível. Em geral, quanto maior o número de informações de desempenho dos animais e suas progênies, e, mais próximo o parentesco entre os animais com informação disponível e o animal avaliado, maior a acurácia de predição do valor genético deste animal.

\subsection{METODOLOGIA DE MODELOS MISTOS}

O melhoramento genético das espécies zootécnicas é baseado em razões de componentes de (co)variância, como os coeficientes de herdabilidade $\left(h^{2}\right)$ correlação genética $\left(r_{g}\right)$ e repetibilidade $(R)$. Os componentes de variância são estimados por métodos que evoluíram à medida que novas técnicas computacionais e novas teorias foram desenvolvidas. O desenvolvimento desses métodos são baseados em conceitos fundamentais de probabilidade, cálculo diferencial e álgebra de matrizes (FERRAZ, 1993).

O termo modelo animal foi proposto por QUAAS \& POLLACK (1980) e atualmente designa uma série de diferentes modelos que têm em comum o fato de considerarem, na solução do sistema de equações utilizado na predição dos efeitos aleatórios, a matriz de parentesco com todas as informações conhecidas, inclusive dos animais que não tenham registro de produção. Desta forma, ele requer o uso da matriz de parentesco $(A)$ e de sua inversa $\left(A^{-1}\right)$. Por esta razão a metodologia ganhou importância prática com o desenvolvimento do método de obtenção de $\mathrm{A}^{-1}$ diretamente de uma lista de pedigrees, tornando-a computacionalmente aplicável a grandes conjuntos de dados (ELER, 1994). 
A avaliação genética sob modelo animal tem como base estatística às equações de modelos mistos (HENDERSON, 1963, 1975). A melhor predição linear não viesada - BLUP (Best Linear Unbiased Predictor) (HENDERSON, 1949; HENDERSON et al., 1959), utilizando modelos mistos sob modelo animal se tornou rapidamente o método preferido pelos geneticistas para se estimar os parâmetros genéticos (HENDERSON, 1988).

Segundo NELSEN et al., (1986), o método de estimação pode ser um fator importante na obtenção dos parâmetros genéticos, juntamente com o estabelecimento de um modelo matemático que descreva corretamente os dados, pela inclusão de fatores importantes, como a raça (SCHAEFFER \& WILTON, 1981; DE ROSE et al., 1988; TRUS \& WILTON, 1988), o sexo (KOCH et al., 1973), o manejo (TESS et al., 1984) e a origem dos dados (DIJKSTRA et al., 1987; WRITH et al., 1987).

A estimação de componentes de variância e covariância através da máxima verossimilhança restrita, utilizando-se o software MTDFREML Multiple Trait Derivative Free Restricted Maximum Likelihood (BOLDMAN \& VAN VLECK, 1991), é o método mais adequado para avaliação de dados não balanceados comumente utilizados em melhoramento animal.

$\mathrm{Na}$ estimação por REML geralmente assume-se uma distribuição normal multivariada. Para um determinado modelo de análise, calcula-se a probabilidade de que o conjunto de dados tenha sido retirado de uma população com determinados valores paramétricos. De acordo com SEARLE et al. (1992) as estimativas obtidas por máxima verossimilhança são então, por definição, os valores dos parâmetros para os quais a probabilidade de ocorrência é máxima, sendo os componentes obtidos por processo iterativo (cálculos repetidos). Cada efeito é estimado a partir de registros de produção pré-ajustados para todos os outros efeitos. $O$ processo revisa repetidamente a estimativa de cada feito até que não ocorram mais mudanças nos valores obtidos, sendo esta a solução final (ELER, 1995). 
O método de máxima verossimilhança restrita é iterativo e exige a normalidade dos dados, considera a perda dos graus de liberdade devido aos efeitos fixos, fornecendo estimadores não viciados e de variância mínima para dados balanceados.

Para dados desbalanceados, o método fornece estimativas viesadas. Entretanto, segundo HARVILLE (1977), SEARLE et al., (1992), dada as propriedades dos estimadores REML, eles têm sido preferidos quando os dados são desbalanceados combinando informações de forma maximizada e corrigindo os efeitos devido à seleção quando não se tem uma amostra aleatória dos dados dos rebanhos.

GRASER et al., (1987) propuseram um algoritmo livre de derivadas para análise de dados sob modelos mistos unicaráter, onde o efeito animal era o único efeito aleatório. Este algoritmo baseava-se no principio de que maximizar uma função é o mesmo que minimizar uma função de seu logaritmo, dado pela expressão [-2log(função)] e na utilização repetida da eliminação Gaussiana nas equações de modelos mistos para avaliação do log da função de verossimilhança (FERRAZ, 1993). MEYER (1988 a,b; 1989 $b, c$ e 1991) aperfeiçoaram a metodologia e desenvolveram o DFREML ("Derivative-free REML"), um sistema de programas em Fortran, que visa à estimação de componentes de variância, com utilização do método REML.

A partir da observação de que as matrizes de parentesco utilizadas em dados de programas de melhoramento animal são em geral muito esparsas (maioria dos elementos iguais a zero) e que a utilização de técnicas especiais para matrizes esparsas poderia agilizar muito $\mathrm{O}$ processamento dos dados em DFREML, BOLDMAN \& VAN VLECK (1991) adaptaram o programa original de MEYER ao programa SPARSPAK (GEORGE et al., 1980), que através da reordenação dos dados e utilização da fatoração de Cholesky (conceito semelhante ao de "raiz quadrada" de uma matriz), reduziu a necessidade de recursos computacionais e tornou o DFREML mais rápido que a versão original. 
Houve ainda outra modificação para fornecer um arquivo com soluções para as covariáveis, efeitos fixos e valores genéticos diretos e maternos, na dependência do modelo utilizado, tornando possível a utilização destes programas para o estudo de efeitos fixos (FERRAZ, 1993). O desenvolvimento desses algoritmos está diretamente relacionado ao progresso alcançado na avaliação genética pelo BLUP (ELER, 1994).

No método REML a idéia é calcular os estimadores de máxima verossimilhança para os componentes de (co)variância eliminando ou minimizando os efeitos de caráter não genético que possam influenciar nas estimativas nas análises.

O objetivo principal dos modelos animais é chegar a um modelo que descreva da melhor forma possível, a real situação biológica para predição de valores genéticos aditivos e estimação dos componentes de variância (FERRAZ, 1993). Recentemente vem sendo sugerida outras metodologias para obtenção de parâmetros genéticos, como o método R (VAN MELLIS, 2002) e análises Bayesianas (SILVA et al., 2001), porém existe a necessidade desses novos métodos computarem os componentes de (co)variância para não tornarem a discussão restrita, principalmente em relação aos coeficientes de correlação genética obtidas por estas metodologias. 


\section{MATERIAL E MÉTODOS}

\subsection{MATERIAL}

As informações de ultra-sonografia analisadas no presente trabalho foram obtidas entre Janeiro de 2001 a Dezembro de 2002 em 907 animais, da raça Santa Gertrudis, provenientes de 12 fazendas participantes do Programa de Melhoramento Animal da ABSG - Associação Brasileira de Santa Gertrudis. Foram mensurados animais nascidos nas safras de $1999 \mathrm{e}$ 2000 com idade variando de 10 a 24 meses.

Os registros de desempenho ponderal dos animais, ate 24 meses de idade, foram obtidos dos arquivos de dados das fazendas e compõem o banco de dados deste programa, desenvolvido no Laboratório de Melhoramento Animal "Prof. Dr. Gordon Dickerson", do Departamento de Ciências Básicas da Faculdade de Zootecnia e Engenharia de Alimentos da Universidade de São Paulo. Na Tabela 3 estão apresentadas as estatísticas descritivas das características avaliadas por ultra-sonografia e o intervalo de idade em que os animais foram analisados.

Tabela 3 - Número de observações (N), média $(\bar{X})$, desvio-padrão (DP), valores mínimos (MIN) e máximos (MAX) das características mensuradas por ultra-sonografia. Pirassununga, São Paulo. 2003

\begin{tabular}{cccccc}
\hline Variável & $N$ & $\bar{X}$ & $D P$ & $M I N$ & $M A X$ \\
\hline AOL $\left(\mathrm{cm}^{2}\right)$ & 907 & 46,5 & 13,12 & 18,2 & 101,5 \\
EGS $(\mathrm{mm})$ & 907 & 0,6 & 1,13 & 0,0 & 7,0 \\
ID (dias) & 907 & 465,4 & 65,2 & 147,0 & 1253,0 \\
\hline
\end{tabular}

AOL - Área de Olho de Lombo; EGS - Espessura de Gordura Subcutânea; ID - Idade dos animais no momento da avaliação. 
Os grupos de manejo foram formados por animais criados em três diferentes regimes alimentares, em que, (1) animais criados exclusivamente em pastagem, (2) em pastagem com suplementação e, (3) animais confinados. A Tabela 4 apresenta a descrição do arquivo com as informações de grupo de manejo nas diferentes idades e nos diferentes regimes alimentares.

O grupo de manejo possui importante função para formação dos grupos de contemporâneos, permitindo agrupar indivíduos criados sobre a mesma condição de alimentação. $O$ banco de dados estudado apresentava muitos animais sem essa informação, assim como dados de desempenho ponderal inconsistentes, e assim foi necessário restringir valos discrepantes de mínimo e máximos nas características analisadas. Nas Tabelas 6 e 7 são descritos detalhadamente os arquivos de dados utilizados para estimação dos parâmetros genéticos para as características medidas por ultrasonografia e de desenvolvimento ponderal.

Tabela 4 - Número de observações por grupo de manejo, aos 120 dias de idade (gm120), grupo de manejo na desmama (gmdes), grupo de manejo aos 12 meses de idade (gm12) e grupo de manejo aos 18 meses de idade (gm18), de acordo com o regime alimentar. Pirassununga, São Paulo. 2003

\begin{tabular}{|c|c|c|c|c|}
\hline $\begin{array}{c}\text { Regime } \\
\text { alimentar }\end{array}$ & Gm120 & Gmdes & Gm12 & Gm18 \\
\hline 1 & 3663 & 3391 & 3688 & 3854 \\
\hline 2 & 1774 & 1767 & 1591 & 1463 \\
\hline 3 & 103 & 382 & 261 & 223 \\
\hline $\mathrm{N}^{\circ}$ animais & 5540 & 5540 & 5540 & 5540 \\
\hline
\end{tabular}




\subsubsection{Formação do Banco de Dados}

A estruturação do banco de dados foi efetuada de forma a se obter um conjunto que permitisse a realização das análises necessárias para a determinação dos ajustes e a estimação dos parâmetros genéticos das características.

A digitação e a consistência dos dados foram feitas utilizando-se o software FoxPro 2.6 da Microsoft. O banco de dados formado foi utilizado para as análises preliminares em $\mathrm{SAS}^{\circledR}$ e posteriormente nas análises em MTDFREML. Foram incluídos no arquivo os animais que apresentavam as informações de AOL e EGS, assim como todos os irmãos completos e meioirmãos, totalizando 5.879 animais, gerando um arquivo de pedigree com 11.394 animais.

\subsubsection{Efeitos Fixos (Vetor $\beta$ )}

Os efeitos fixos incluídos nos modelos para análise genética foram grupo de contemporâneo (GC) e classe de idade da mãe ao parto (CIV), definida conforme a Tabela 5.

Os GC's formaram-se pela concatenação dos fatores não genéticos que estariam influenciando as características em questão. As análises foram processadas utilizando-se o pacote estatístico SAS ${ }^{\circledR}(2001)$, procedimento GLM (SAS, 8.02). Inicialmente as variáveis, rebanho, ano de nascimento, estação de nascimento, sexo e grupos de manejo nas diferentes idades estudadas foram analisadas como classificatórias visando definir seu comportamento, sendo que aquelas que apresentaram significância estatística $(P<0,05)$ formaram os Grupos de Contemporâneos.

Os Grupos de Contemporâneos que continham menos de três animais, assim como valores extremos para as características, considerados inconsistentes, foram descartados das análises posteriores. 
Tabela 5 - Classes segundo as idades das mães ao parto (CIV), em meses. Pirassununga, São Paulo. 2003

\begin{tabular}{ccc}
\hline CIMP & $\begin{array}{c}\text { Idade da mãe ao parto } \\
\text { (meses) }\end{array}$ & $\begin{array}{c}\text { Número de } \\
\text { observações em cada } \\
\text { classe de idade }\end{array}$ \\
\hline $\mathbf{1}$ & Até 27 & 259 \\
$\mathbf{2}$ & de 28 a 36 & 580 \\
$\mathbf{3}$ & de 37 a 48 & 749 \\
$\mathbf{4}$ & de 49 a 60 & 731 \\
$\mathbf{5}$ & de 61 a 108 & 2623 \\
$\mathbf{6}$ & de 109 a 144 & 701 \\
$\mathbf{7}$ & Mais que 145 & 236 \\
\hline
\end{tabular}

Os efeitos fixos considerados para cada característica foram:

> Peso ao nascimento (PESNAS): grupo de contemporâneos, que inclui os efeitos de (rebanho + sexo + ano de nascimento + estação de nascimento) e classe de idade da mãe ao parto;

Peso aos 120 dias (PES120): grupo de contemporâneos (rebanho + sexo + ano de nascimento + grupo de manejo aos 120 dias) e classe de idade da mãe ao parto;

$>$ Peso a desmama (PESDES): grupo de contemporâneos (GC120 + grupo de manejo a desmama) e classe de idade da mãe ao parto;

$>\quad$ Peso aos 12 meses (PES12): grupo de contemporâneos (GCdes + estação de nascimento + grupo de manejo aos 12 meses de idade) e classe de idade da mãe ao parto;

Peso aos 18 meses (PES18): grupo de contemporâneos (GC12 + grupo de manejo aos 18 meses de idade);

$>\quad$ Peso aos 24 meses (PES24): grupo de contemporâneos (rebanho + sexo + ano de nascimento + gm120 + gmdes + gm12 + gm18 + gm24 meses de idade); 
$>$ Perímetro Escrotal aos 18 meses (PE18): grupo de contemporâneos (rebanho + ano de nascimento + gm120 + gmdes + gm12 + gm18 meses de idade);

> Área de Olho de Lombo (AOL): grupo de contemporâneo (rebanho + sexo + ano de nascimento + gmdes + gm12 + gm18 meses de idade);

> Espessura de Gordura Subcutânea (EGS): grupo de contemporâneo (rebanho + sexo + ano de nascimento + gm120 + gm12 + gm18 meses de idade).

\subsubsection{Efeitos Genéticos (Vetor $\mu$ )}

Para as características de AOL, EGS, PES18, PES24 e PE18, foi incluído apenas o efeito genético aditivo direto no vetor de efeitos aleatórios e para PESNAS, PES120, PESDES e PES12 foram incluídos os efeitos genéticos aditivos diretos, efeito genético aditivo materno e efeito de ambiente permanente da vaca no vetor de efeitos aleatórios nos modelos de análise genética. 
Tabela 6 - Descrição do arquivo de dados para as características de área de olho de lombo (AOL), de espessura de gordura subcutânea (EGS), dos pesos ao nascimento (PESNAS), aos 120 dias de idade (PES120), na desmama (PESDES), aos 12 meses de idade (PES12), aos 18 meses de idade (PES18) e aos 24 meses de idade (PES24), do perímetro escrotal aos 18 meses de idade (PE18). Pirassununga, São Paulo. 2003

\begin{tabular}{|c|c|c|c|c|c|c|c|c|c|}
\hline \multicolumn{10}{|c|}{ Características } \\
\hline & $\begin{array}{l}\mathrm{AOL} \\
\left(\mathrm{cm}^{2}\right)\end{array}$ & $\begin{array}{l}\text { EGS } \\
(\mathrm{mm})\end{array}$ & $\begin{array}{c}\text { PESNAS } \\
(\mathrm{Kg})\end{array}$ & $\begin{array}{c}\text { PES120 } \\
\text { (Kg) }\end{array}$ & $\begin{array}{c}\text { PESDES } \\
(\mathrm{Kg})\end{array}$ & $\begin{array}{c}\text { PES12 } \\
\text { (Kg) }\end{array}$ & $\begin{array}{c}\text { PES18 } \\
(\mathrm{Kg})\end{array}$ & $\begin{array}{l}\text { PE18 } \\
\text { (cm) }\end{array}$ & $\begin{array}{c}\text { PES24 } \\
(\mathrm{Kg})\end{array}$ \\
\hline $\bar{X}$ & 47,46 & 0,95 & 36,17 & 133,24 & 209,54 & 318,07 & 403,44 & 34,22 & 463,73 \\
\hline DP & 12,20 & 1,81 & 6,11 & 27,32 & 44,78 & 76,98 & 101,06 & 3,99 & 112,40 \\
\hline CV $(\%)$ & 25,71 & 190,48 & 16,90 & 20,51 & 21,37 & 24,20 & 25,05 & 11,66 & 24,24 \\
\hline MIN & 19,70 & 0,095 & 15,00 & 54,20 & 81,89 & 107,16 & 137,13 & 21,00 & 213,62 \\
\hline MAX & 101,54 & 14,02 & 72,00 & 219,00 & 397,45 & 575,15 & 736,05 & 47,00 & 855,33 \\
\hline \multicolumn{10}{|c|}{ Dados } \\
\hline $\mathrm{N}^{\mathrm{O}}$ & 871 & 871 & 2938 & 3740 & 4975 & 3383 & 2552 & 764 & 1245 \\
\hline GC & 105 & 105 & 277 & 444 & 618 & 718 & 593 & 195 & 277 \\
\hline $\bar{X} / \mathrm{GC}$ & 8,30 & 8,30 & 10,60 & 8,42 & 8,05 & 4,71 & 4,30 & 3,92 & 4,49 \\
\hline No/TOU & 119 & 119 & 129 & 173 & 204 & 176 & 160 & 98 & 119 \\
\hline $\bar{X} /$ TOU & 7,32 & 7,32 & 22,68 & 21,50 & 24,25 & 19,08 & 15,84 & 7,75 & 10,37 \\
\hline No/MAT & 753 & 753 & 1930 & 2237 & 2639 & 1944 & 1646 & 612 & 987 \\
\hline $\bar{X} / \mathrm{MAT}$ & 1,16 & 1,16 & 1,52 & 1,66 & 1,87 & 1,73 & 1,54 & 1,24 & 1,25 \\
\hline
\end{tabular}

$\overline{\bar{X}}$ - Média; DP - desvio padrão; CV - coeficiente de variação, em \%; Min. - valor mínimo; Max. - valor máximo; № número de observações; GC - número de grupo contemporâneos; $\bar{X} / G C$ - média de observações por grupo de contemporâneo; No/TOURO - número de touros; $\bar{X}$ /TOURO - número médio de observações por touro; No/MATRIZ número de matrizes; $\bar{X}$ /MATRIZ - número médio de observações por matriz. 
Tabela 7 - Estatísticas das idades dos animais para as características de área de olho de lombo (AOL), de espessura de gordura subcutânea (EGS), dos pesos ao nascimento (PESNAS), aos 120 dias de idade (PES120), na desmama (PESDES), aos 12 meses de idade (PES12), aos 18 meses de idade (PES18) e aos 24 meses de idade (PES24), do perímetro escrotal aos 18 meses de idade (PE18). Pirassununga, São Paulo. 2003

\begin{tabular}{cccccccccc}
\hline \multicolumn{10}{c}{ Características } \\
\hline & $\begin{array}{c}\text { AOL } \\
\left(\mathbf{c m}^{\mathbf{2}}\right)\end{array}$ & $\begin{array}{c}\text { EGS } \\
\mathbf{( m m )}\end{array}$ & $\begin{array}{c}\text { PESNAS } \\
\mathbf{( K g )}\end{array}$ & $\begin{array}{c}\text { PES120 } \\
\mathbf{( K g )}\end{array}$ & $\begin{array}{c}\text { PESDES } \\
\mathbf{( K g )}\end{array}$ & $\begin{array}{c}\text { PES12 } \\
\mathbf{( K g )}\end{array}$ & $\begin{array}{c}\text { PES18 } \\
\mathbf{( K g )}\end{array}$ & $\begin{array}{c}\text { PE18 } \\
(\mathbf{c m})\end{array}$ & $\begin{array}{c}\text { PES24 } \\
(\mathbf{K g})\end{array}$ \\
\hline $\bar{X}$ & 481,39 & 481,39 & - & 121,45 & 206,61 & 359,69 & 534,19 & 529,50 & 716,85 \\
DP & 309,53 & 309,53 & - & 24,85 & 31,48 & 31,13 & 41,65 & 40,51 & 40,02 \\
CV & 64,30 & 64,30 & - & 20,46 & 15,24 & 8,65 & 7,80 & 7,65 & 5,58 \\
MIN & 210,00 & 210,00 & - & 75,00 & 149,00 & 293,00 & 454,00 & 450,00 & 650,00 \\
MAX & 992,00 & 992,00 & - & 145,00 & 291,00 & 450,00 & 650,00 & 647,00 & 799,00 \\
\hline
\end{tabular}

$\bar{X}$ - Média; DP - desvio padrão; CV - coeficiente de variação, em \%; Min. - valor mínimo; Max. - valor máximo. 


\subsection{MÉTODOS}

As informações de AOL e EGS foram coletadas em animais vivos, na região entre a $12^{\mathrm{a}}$ e a $13^{\mathrm{a}}$ costelas, por ultra-sonografia, sendo efetuada uma coleta por animal.

Para tomada das imagens de ultra-som foi utilizado um equipamento de ultra-som ${ }^{1}$, acoplado a um transdutor de arranjo linear ASP com freqüência de $3,5 \mathrm{MHz}$ e $17,8 \mathrm{~cm}$ de comprimento e uma guia acústica para melhor adaptação à anatomia do corpo do animal.

Após a imobilização do animal em um tronco de contenção, localizouse por meio de palpação, o local anatômico para a tomada da imagem. Sobre o local da medida foi colocado óleo vegetal como acoplante acústico. Todas imagens de AOL e EGS obtidas foram armazenadas em um notebook para posterior interpretação. Para a interpretação das imagens de ultra-som foi utilizado o software Eview ${ }^{\circledR}$ (Piemedical Inc.).

Para determinar a AOL $\left(\mathrm{cm}^{2}\right)$, as imagens foram traçadas contornando a área do músculo longissimus dorsi. A EGS estimada em milímetros $(\mathrm{mm})$ foi medida a $2 / 3$ da borda lateral do mesmo músculo. $\mathrm{O}$ procedimento de coleta e interpretação das medidas devem ser adotados como forma de padronizar as estimativas destas características, minimizando possíveis erros de predição.

A idade do animal por ocasião da mensuração por ultra-sonografia foi outro fator não genético importante nas análises. Para estas características foram criadas classes de idade $(\mathrm{Cl})$ com a finalidade de melhor distribuir as freqüências das observações. Estas diferiam em 15 dias, a partir de 230 até 730 dias, conforme a Figura 1.

\footnotetext{
${ }^{1}$ Pie medical, modelo Scanner 200 VET.
} 


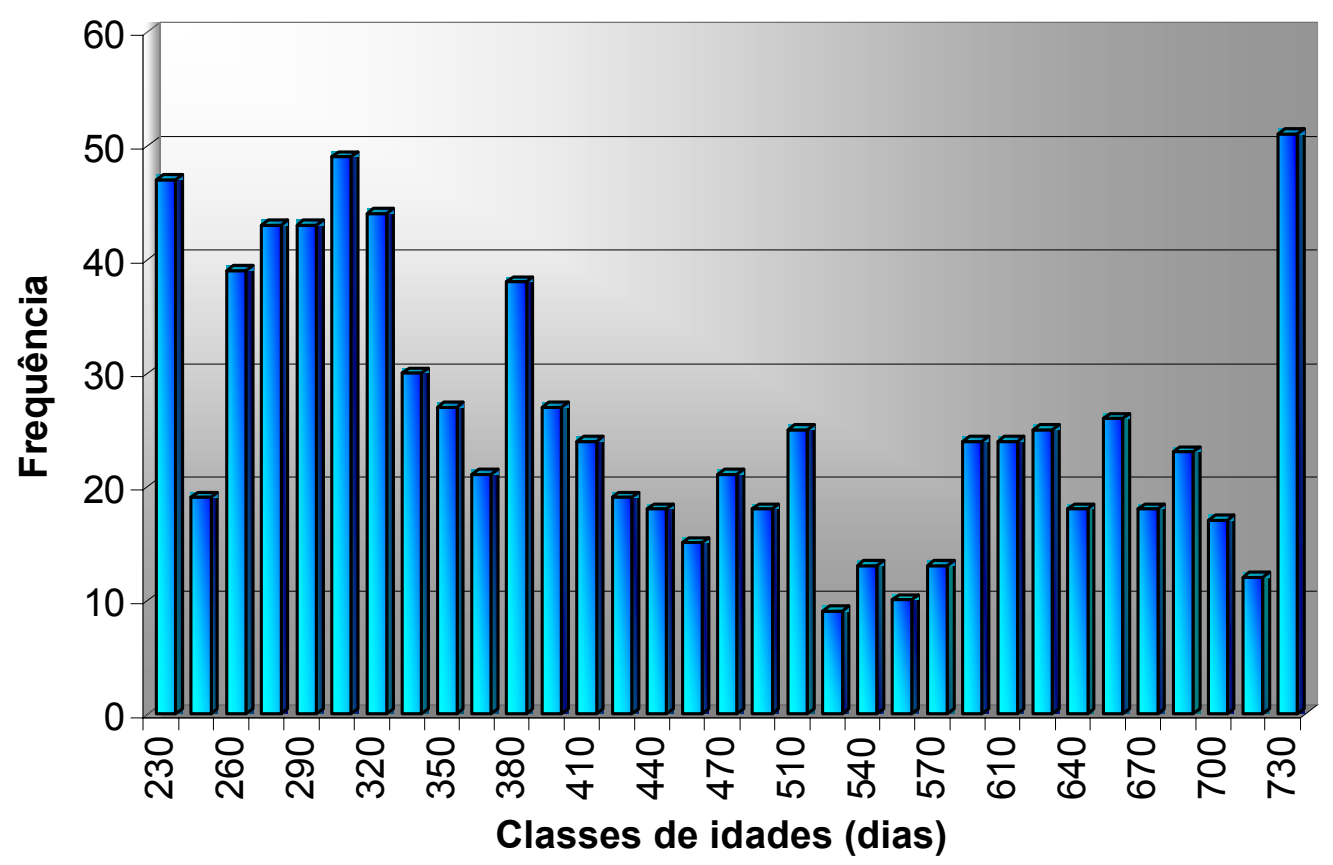

Figura 1 - Freqüência de distribuição das medidas de ultra-sonografia nas classes de idade.

Segundo PAZ (1999), como recomendação prática, ao se trabalhar com pequeno número de observações nas classes nos pontos mais extremos, a melhor estratégia seria utilizar os fatores de correção dos pontos próximos com maiores números de observações.

\subsubsection{Ajuste dos Dados por Funções Polinomiais}

Para que animais possam ser comparados e distinguidos na seleção de rebanhos, é necessário que os efeitos de ambiente sobre as características de interesse sejam minimizados. Os avanços no desenvolvimento de algoritmos e recursos computacionais têm permitido ajustar os dados de desempenho para que seja possível a comparação entre reprodutores. 
Os polinômios segmentados tem sido utilizados em estudos de curvas de crescimento de bovinos de corte, aves, curvas de produção de leite e ovos e para estimação dos fatores de correção para os efeitos fixos (SCHENKEL, 1989; PELICIONI, 2000).

O objetivo do uso da metodologia de polinômios segmentados foi ajustar os dados das características de AOL e EGS medidas por ultrasonografia e das características de desenvolvimento ponderal e calcular os fatores de correção (FC) para o efeito de idade na época de mensuração.

$\mathrm{Na}$ determinação dos segmentos que compõem a função, primeiramente utilizou-se o diagrama de pontos, na forma de um gráfico de dispersão, com o objetivo de identificar, por inspeção visual, as regiões onde ocorrem as mudanças de comportamento da distribuição dos valores fenotípicos, regiões estas que continham os pontos de junção (K) entre os segmentos.

As análises de regressão foram realizadas por técnicas não lineares, através do método de Gauss-Newton utilizando-se o procedimento NLIN (SAS, 2001). A estimação dos parâmetros foi realizada iterativamente, juntamente com a definição dos modelos polinomiais, tendo como critério de escolha o menor quadrado médio do erro (QME) e os coeficientes de determinação $\left(R^{2}\right)$ dos diferentes modelos, procedendo-se, então, à estimação dos parâmetros do modelo.

A AOL e EGS foram pré-ajustadas para o efeito de idade aos 555 dias. O valor foi adotado por representar o pico da curva de crescimento dos bovinos dessa raça expressando o potencial de desenvolvimento desses animais e por ser medida padrão freqüentemente encontrada na literatura para esta finalidade. 
Diferentes modelos polinomiais foram comparados com a finalidade de definir qual apresentava melhor ajuste para as características estudadas. As funções polinomiais (Polinômios Segmentados) utilizadas no presente estudo são descritas na Tabela 8. Para a AOL, o modelo proposto neste trabalho, pela observação dos resultados das análises de regressão, pelo $Q M E$ e pelo $R^{2}$, foi o modelo composto de quatro segmentos quadráticos $(Q-$ $\mathrm{Q}-\mathrm{Q}-\mathrm{Q})$. Para EGS o modelo sugerido e que proporcionou melhor ajuste foi o modelo com dois segmentos quadráticos (Q-Q).

Tabela 8 - Descrição do comportamento e dos modelos de polinômios segmentados que descrevem as características de AOL, EGS e de desenvolvimento ponderal em função da idade. Pirassununga, São Paulo. 2003

\begin{tabular}{|c|c|c|}
\hline Característica & $\begin{array}{c}\text { Comportamento } \\
\text { da } \\
\text { característica }\end{array}$ & Descrição dos Modelos \\
\hline $\mathrm{AOL}$ & $Q-Q-Q-Q$ & $\mathrm{~b} 0+\mathrm{b} 1^{*} \mathrm{ci}+\mathrm{b} 2^{*} \mathrm{ci}^{* *} 2+\mathrm{b} 3^{*} \mathrm{z} 1+\mathrm{b} 4^{*} \mathrm{z} 2+\mathrm{b} 5^{*} \mathrm{z} 3$ \\
\hline EGS & $Q-Q$ & $\mathrm{~b} 0+\mathrm{b} 1^{*} \mathrm{ci}+\mathrm{b} 2^{*} \mathrm{ci}^{* *} 2+\mathrm{b} 3^{*} \mathrm{z} 1$ \\
\hline PES120 & L-Q-Q & b0+b1*idade120+b2*z1+b3*z2 \\
\hline PESDES & Q-L-Q & $\mathrm{b} 0+\mathrm{b} 1^{*}$ idadedes+b2*(idadedes) ${ }^{2}+\mathrm{b} 3^{*} \mathrm{z} 1+\mathrm{b} 4^{*} \mathrm{z} 2$ \\
\hline PES12 & $Q-Q-Q$ & $\mathrm{~b} 0+\mathrm{b} 1{ }^{*}$ idade $12+\mathrm{b} 2^{*}(\text { idade } 12)^{2}+\mathrm{b} 3^{*} \mathrm{z} 1+\mathrm{b} 4^{*} \mathrm{z} 2$ \\
\hline PES18 & $Q-Q-Q$ & $\mathrm{~b} 0+\mathrm{b} 1{ }^{*}$ idade $18+\mathrm{b} 2^{*}(\text { idade } 18)^{2}+\mathrm{b} 3^{*} \mathrm{z} 1+\mathrm{b} 4{ }^{*} \mathrm{z} 2$ \\
\hline PES24 & $Q-Q-Q$ & b0+b1*idade24+b2*(idade24) $)^{2}+b 3^{*} z 1+b 4^{*} z 2$ \\
\hline PE18 & L-Q & $\mathrm{b} 0+\mathrm{b} 1{ }^{*}$ idadePE $18+\mathrm{b} 2^{*} \mathrm{z} 1$ \\
\hline
\end{tabular}

Em que: $Z_{i}=0$ se Idade $\leq K_{i}$, senão $Z_{i}=\left(\text { Idade ou } C l-K_{i}\right)^{2}$ se Idade $>K_{i}$; Sendo, $\mathrm{Cl}=$ classe de idade do animal na mensuração do ultra-som; Idade = idade do animal na medida dos pesos e do perímetro escrotal;

$\mathrm{K}_{\mathrm{i}}$ = "nó" ou ponto de junção entre os segmentos do polinômio;

$b_{0}, b_{1}, b_{2}, b_{3} b_{4} b_{5}=$ parâmetros a serem estimados;

Para comparar os resultados obtidos por polinômios segmentados e polinômios ordinários utilizou-se uma Regressão Linear e uma regressão quadrática simples para os dois efeitos estudados ( $\mathrm{Cl}$ e Idade na medida) sobre a AOL, EGS, PESNAS, PES120, PESDES, PES12, PES18, PES24 e PE18. 


\subsubsection{Cálculo Dos Fatores De Correção}

Segundo MILLER, (1973), a utilização de fatores de correção multiplicativos, quando se trabalha com grandes variações nas produções dos rebanhos, apresenta menores vícios quando comparados aos fatores aditivos.

Os fatores de correção (FC) das características analisadas para as idades dos animais à mensuração foram calculados utilizando-se as soluções obtidas para cada efeito no ajuste dos polinômios segmentados anteriormente estimados, sendo o mesmo dado por:

$$
F C=\frac{X_{\text {base }}}{X_{\text {pred }}}
$$

Em que:

FC = fator de correção;

$\mathrm{X}_{\text {base }}=$ média predita da característica na idade padrão de ajuste, obtida utilizando a metodologia dos polinômios segmentados.

$\mathrm{X}_{\text {pred }}=$ média predita da característica nas diferentes idades, obtida utilizando a metodologia dos polinômios segmentados.

\subsubsection{Análise Genética - Estimação de Parâmetros Genéticos}

A metodologia utilizada para análise genética foi a de modelos mistos, com utilização do modelo animal (HENDERSON, 1963; HENDERSON, 1975). 
Para características controladas por grande número de loci agindo aditivamente, o uso do modelo animal incluindo a matriz de relações aditivas entre os animais (matriz de parentesco) leva em consideração as mudanças na média e variância genéticas devido à seleção, já que os valores genéticos são expressos como funções lineares dos valores genéticos dos animais da população base e da amostragem mendeliana, que não são afetados pela seleção (KENNEDY et.al., 1988).

Primeiramente foram processadas análises uni-características para AOL, EGS, PESNAS, PES120, PESDES, PES12, PES18, PES24 e PE18. As análises bi-características foram realizadas para se obter as estimativas de herdabilidade e os parâmetros de correlações genéticas entre duas características. Para estas análises utilizou-se o PESDES como característica âncora, sendo esta avaliada com PESNAS, PES120, PES12, PES18, PES24, PE18, AOL e EGS. As características AOL e EGS foram também analisadas com as características de desenvolvimento ponderal de PESDES, PES12, PES18, PES24, PE18.

Em análises multi-características, a inclusão das matrizes de variâncias e covariâncias genéticas e residuais leva em consideração os efeitos do descarte seqüencial dos animais (QUAAS, \& POLLACK, 1980).

Para estimação dos parâmetros genéticos das características de desempenho ponderal e das medidas feitas por ultra-sonografia, o modelo matemático geral que expressa o desempenho de cada animal utilizado nas análises uni-característica, pode ser explicado pelo seguinte modelo linear misto na forma matricial.

$$
Y=X \beta+Z \mu+S m+W p e+e \text {, em que: }
$$

$\mathrm{Y}=$ Vetor das variáveis dependentes (PESNAS, PES120, PESDES, PES12, PES18, PES24, PE18, AOL e EGS);

$\beta=$ Vetor dos efeitos fixos (GC's e CIV); 
$\mu=$ Vetor de efeitos aleatórios de valor genético aditivo direto do animal;

$\mathrm{m}=$ Vetor de efeitos aleatórios de valor genético materno (somente PESNAS, PES120, PESDES, PES12 );

pe $=$ Vetor dos efeitos aleatórios de ambiente permanente (somente PESNAS, PES120, PESDES, PES12 );

$e=$ Vetor de efeitos aleatórios residuais.

$X, Z, S$ e $W=$ são matrizes de incidência relacionando as observações $(Y)$ aos seus respectivos efeitos fixos $(\beta)$, genético aditivo direto do animal $(\mu)$, genético aditivo materno $(\mathrm{m})$ e de ambiente permanente (pe).

É assumido que,

$\operatorname{Var}\left[\begin{array}{l}a_{1} \\ a_{2} \\ p e \\ e\end{array}\right]=\left[\begin{array}{cccc}A \sigma_{a_{1}}^{2} & A \sigma_{a_{1} a_{2}} & 0 & 0 \\ A \sigma_{a_{1} a_{2}} & A \sigma_{a_{2}}^{2} & 0 & 0 \\ 0 & 0 & I \sigma_{p e}^{2} & 0 \\ 0 & 0 & 0 & I \sigma_{e}^{2}\end{array}\right]$

em que:

$a_{1}\left(a_{2}\right)=$ vetor dos efeitos aleatórios de valor genético aditivo direto e materno;

pe = vetor dos efeitos aleatórios de ambiente permanente;

e = vetor dos efeitos aleatórios residuais.

$\mathrm{A}=$ matriz de parentesco entre todos os animais, incluindo parentes sem registros de produção;

$\sigma_{a 1}^{2}\left(\sigma_{a 2}^{2}\right)=$ variância genética aditiva dos efeitos aleatórios direto e materno;

$\sigma_{\mathrm{a} 1}\left(\sigma_{\mathrm{a} 2}\right)=$ covariância genética aditiva entre os efeitos aleatórios direto e materno;

$\sigma_{p e}^{2}=$ variância devido ao efeito de ambiente permanente; 
$\sigma_{e}^{2}=$ variância residual

A variância residual de y é dada por:

$$
\operatorname{var}[y]=[Z S]\left[\begin{array}{cc}
A \sigma_{a_{1}}^{2} & A \sigma_{a_{1} a_{2}}^{2} \\
A \sigma_{a_{1} a_{2}}^{2} & A \sigma_{a_{2}}^{2}
\end{array}\right]\left[\begin{array}{c}
Z^{\prime} \\
S^{\prime}
\end{array}\right]+\mathrm{W} I \sigma_{p e}^{2} \mathrm{~W}^{\prime}+I \sigma_{e}^{2}
$$

As soluções para os efeitos fixos $(\beta)$ são BLUE, melhor estimador linear não viesado de funções estimáveis, e, as soluções para os efeitos aleatórios $(\mu)$, são BLUP, melhor preditor linear não viesado desses efeitos. "Best" no sentido de minimização dos erros de predição; "Unbiased" porque a esperança da estimativa é igual à esperança do parâmetro e "Linear" porque usam funções lineares das observações.

O BLUE de b e o BLUP de $\mu, \mathrm{m}$ e pe são obtidos pela solução das seguintes equações de modelos mistos:

$$
\left[\begin{array}{cccc}
X^{\prime} X & X^{\prime} Z & X^{\prime} S & X^{\prime} W \\
Z^{\prime} X & Z^{\prime} Z+A^{-1} \alpha_{1} & Z^{\prime} S+A^{-1} \alpha_{2} & Z^{\prime} W \\
S^{\prime} X & S^{\prime} Z+A^{-1} \alpha_{2} & S^{\prime} S+A^{-1} \alpha_{3} & S^{\prime} W \\
W^{\prime} X & W^{\prime} Z & W^{\prime} S & W^{\prime} W+I \alpha_{4}
\end{array}\right]\left[\begin{array}{c}
b^{\circ} \\
\hat{u} \\
\hat{m} \\
\hat{p} e
\end{array}\right]=\left[\begin{array}{c}
X^{\prime} y \\
Z^{\prime} y \\
S^{\prime} y \\
W^{\prime} y
\end{array}\right]
$$

As equações de modelos mistos são obtidas minimizando-se os erros de predição e as variâncias amostrais das estimativas dos efeitos fixos, com a condição de que a predição seja não viesada. Portanto as equações são obtidas pela maximização da função densidade de probabilidade da distribuição conjunta do vetor das observações (y) e o vetor de efeitos aleatórios dos valores genéticos aditivo direto dos animais $(\mu)$. 
Para análises genéticas bi-característica, foi utilizado o seguinte modelo matemático genérico na forma matricial:

$$
\left[\begin{array}{l}
y_{1} \\
y_{2}
\end{array}\right]=\left[\begin{array}{cc}
X_{1} & 0 \\
0 & X_{2}
\end{array}\right]\left[\begin{array}{l}
b_{1} \\
b_{2}
\end{array}\right]+\left[\begin{array}{cc}
Z_{1} & 0 \\
0 & Z_{2}
\end{array}\right]\left[\begin{array}{l}
\mu_{1} \\
\mu_{2}
\end{array}\right]+\left[\begin{array}{cc}
S_{1} & 0 \\
0 & S_{2}
\end{array}\right]\left[\begin{array}{l}
m_{1} \\
m_{2}
\end{array}\right]+\left[\begin{array}{cc}
W_{1} & 0 \\
0 & W_{2}
\end{array}\right]\left[\begin{array}{l}
p e_{1} \\
p e_{2}
\end{array}\right]+\left[\begin{array}{l}
e_{1} \\
e_{2}
\end{array}\right]
$$

em que:

$\mathrm{y}_{1}=$ vetor dos registros da característica 1 (PESDES considerada a característica âncora, AOL e EGS);

$\mathrm{y}_{2}=$ vetor dos registros da característica 2, (PESNAS, PES120, PES12, PES18, PES24, PE18, AOL e EGS);

$b_{1}=$ vetor de efeitos fixos para a característica 1 (GC e CIV);

$\mathrm{b}_{2}=$ vetor de feitos fixos para a característica 2 (GC e CIV);

$\mathrm{u}_{1}=$ vetor de efeitos aleatórios de valor genético direto para a característica 1 ;

$\mathrm{u}_{2}=$ vetor de efeitos aleatórios de valor genético direto para a característica 2;

$\mathrm{m}_{1}=$ vetor de efeito aleatório genético materno para a característica 1 ;

$\mathrm{m}_{2}=$ vetor de efeito aleatório genético materno para a característica 2;

$\mathrm{pe}_{1}=$ vetor de efeito aleatório permanente de ambiente para a característica 1;

$\mathrm{pe}_{2}=$ vetor de efeito aleatório permanente de ambiente para a característica 2;

$\mathrm{e}_{1}\left(\mathrm{e}_{2}\right)=$ vetor dos efeitos residuais;

$X_{1}\left(X_{2}\right), Z_{1}\left(Z_{2}\right), S_{1}\left(S_{2}\right), W_{1}\left(W_{2}\right)$ são matrizes de incidência relacionando os registros das características $\left(\mathrm{y}_{1}, \mathrm{y}_{2}\right)$ aos seus respectivos efeitos fixos $\left(\beta_{1}\right.$, $\left.\beta_{2}\right)$, genético aditivo direto do animal $\left(\mu_{1}, \mu_{2}\right)$, genético aditivo materno $\left(m_{1}\right.$, $m_{2}$ ) e de ambiente permanente $\left(p_{1}, p_{2}\right)$, respectivamente. 


\subsubsection{Estimação de Componentes de (Co)Variância}

Para estimação dos componentes de variância das características analisadas foram considerados apenas os animais de pais conhecidos.

As estimativas de componentes de (co)variância para as características avaliadas neste estudo foram obtidas pelo programa MTDFREML - Multiple Trait Derivative Free Restricted Maximum Likelihood (BOLDMAN et al., 1993) que usa técnicas de matrizes esparsas através da incorporação do SPARSPACK (GEORGE et al., 1980) e fatoração de Choleski para obter o logaritmo do determinante da matriz dos coeficientes e a soma de quadrados generalizada dos resíduos. O procedimento usa um modelo animal que não só ajusta, por regressão, o efeito genético aditivo direto para animais com informações de desempenho, mas também para os pais incluídos na análise através de informações de genealogia.

A otimização da função de verossimilhança é obtida por um algoritmo conhecido como "downhill simplex" (NELDER \& MEAD, 1965). O MTDFREML utiliza este algoritmo para localizar o mínimo do logaritmo da função de verossimilhança em modelos com múltiplos parâmetros. Os componentes de (co)variância que minimizam a função são estimativas de máxima verossimilhança (MERCADANTE, 1995).

O critério de convergência assumido neste trabalho foi quando a variância da simplex alcançou $1 \times 10^{-9}$. Isto ocorre quando a variação do valor do log da função do ciclo anterior e do presente ciclo for menor que $1 \mathrm{x}$ $10^{-9}$. Como há possibilidade de se obter máximos locais ao invés do máximo global (PRES et al., 1986), várias reinicializações foram executadas no sentido de se assegurar à convergência no máximo global da função de verossimilhança, Para essas reinicializações os "prior's" iniciais de componentes de (co)variância foram os obtidos da análise anterior. 


\section{RESULTADOS E DISCUSSÃO}

\subsection{Características de Carcaça Ajustadas para Idade por Polinômios Segmentados}

Há problemas nas avaliações do mérito genético dos animais se considerarmos as medidas de ultra-sonografia na forma absoluta, uma vez que as comparações entre indivíduos são influenciadas pelas diferenças entre as idades na mensuração, portanto, precisam ser ajustadas para este efeito.

Quando se trabalha com dados ajustados para uma idade ou peso padrão a resposta à seleção tende a ser maior uma vez que a variância fenotípica diminui. FIGUEIREDO (2001) afirma ainda que é possível uma maior resposta à seleção quando se utiliza as medidas de ultra-sonografia ajustadas para uma idade padrão em comparação com as ajustadas para um peso padrão.

Por estes motivos as características de carcaça foram ajustadas pela metodologia de polinômios segmentados, sendo comparados diferentes modelos polinomiais a fim de se aferir qual ajustava-se melhor ao banco de dados analisado.

Para a AOL o modelo proposto neste trabalho, pela observação dos resultados das análises de regressão, pelo menor quadrado médio do erro (QME) e pelo maior coeficiente de determinação $\left(R^{2}\right)$ foi o modelo com quatro segmentos quadráticos (Q-Q-Q-Q). Para EGS o modelo sugerido e que proporcionou melhor ajuste foi o modelo com dois segmentos quadráticos $(\mathrm{Q}-\mathrm{Q})$. 
Nas tabelas 9 e 10 são mostrados os valores de freqüência, médias observadas, desvios padrão, erros padrão e os fatores de correção resultantes da aplicação do modelo definido para o ajuste de AOL e EGS em função da $\mathrm{Cl}$ dos animais avaliados. Verifica-se que no presente estudo as medidas de AOL e EGS apresentaram grande variação de 18,20 a 101,53 $\mathrm{cm}^{2}$ e 0,0 a $7,02 \mathrm{~mm}$, respectivamente.

As médias e as amplitudes dos valores ajustados para a AOL e a EGS foram 56,91 (19,70 a 108,58) e 1,52 (0,0092 a 9,9133), respectivamente, com a fixação do valor de idade aos 555 dias no modelo. A amplitude de variação do FC para o efeito da $\mathrm{Cl}$ foi de 0,8891 a 1,2355 para AOL é, de 0,9246 a 3,2061 para EGS. 
Tabela 9 - Valores de freqüências (FREQ), de médias ${ }^{11}$, de erros padrão (EP), de fatores de correção multiplicativos (FC), por classes de idades (Cl) para AOL e EGS mensuradas por ultra-sonografia. Pirassununga, São Paulo. 2003

\begin{tabular}{|c|c|c|c|c|c|c|c|c|c|c|c|}
\hline \multicolumn{7}{|c|}{ Área de Olho de Lombo $\left(\mathrm{cm}^{2}\right)$} & \multicolumn{5}{|c|}{ Espessura de Gordura Subcutânea (mm) } \\
\hline $\mathrm{Cl}$ & FREQ & $\mathrm{AOL}_{\text {obs }}$ & EP & $\mathrm{AOL}_{\mathrm{esp}}$ & $\mathrm{AOL}_{\mathrm{AJ} 555}$ & $\mathrm{FC}$ & $\mathrm{EGS}_{\mathrm{obs}}$ & EP & $\mathrm{EGS}_{\mathrm{esp}}$ & $\mathrm{EGS}_{\text {AJ555 }}$ & $\mathrm{FC}$ \\
\hline $230-245$ & 47 & 39,87 & 1,74 & 40,55 & 46,41 & 1,1700 & 0,17 & 0,26 & 0,31 & 0,56 & 3,0521 \\
\hline $245-260$ & 19 & 41,69 & 1,75 & 39,35 & 50,01 & 1,2074 & 0,54 & 0,62 & 0,30 & 1,73 & 3,1557 \\
\hline $260-275$ & 39 & 38,43 & 1,93 & 38,58 & 47,01 & 1,2332 & 0,21 & 0,29 & 0,29 & 0,71 & 3,2061 \\
\hline $275-290$ & 43 & 37,73 & 2,16 & 38,23 & 46,58 & 1,2455 & 0,32 & 0,38 & 0,29 & 1,04 & 3,1978 \\
\hline $290-305$ & 43 & 39,40 & 1,98 & 38,31 & 48,54 & 1,2437 & 0,34 & 0,36 & 0,30 & 1,09 & 3,1319 \\
\hline $305-320$ & 49 & 37,62 & 1,78 & 38,80 & 45,76 & 1,2278 & 0,39 & 0,30 & 0,31 & 1,21 & 3,0152 \\
\hline $320-335$ & 44 & 39,61 & 1,97 & 39,72 & 47,07 & 1,1988 & 0,28 & 0,30 & 0,33 & 0,81 & 2,8589 \\
\hline $335-350$ & 30 & 41,40 & 1,77 & 40,94 & 47,73 & 1,1631 & 0,47 & 0,44 & 0,35 & 1,29 & 2,6759 \\
\hline $350-365$ & 27 & 42,28 & 2,86 & 42,07 & 47,43 & 1,1319 & 0,23 & 0,28 & 0,38 & 0,60 & 2,4790 \\
\hline $365-380$ & 21 & 43,82 & 1,93 & 43,09 & 48,00 & 1,1051 & 0,25 & 0,32 & 0,41 & 0,59 & 2,2786 \\
\hline $380-385$ & 38 & 46,23 & 1,98 & 44,00 & 49,60 & 1,0822 & 0,41 & 0,29 & 0,45 & 0,88 & 2,0828 \\
\hline $395-410$ & 27 & 41,55 & 1,65 & 44,79 & 43,79 & 1,0629 & 0,33 & 0,30 & 0,49 & 0,63 & 1,8970 \\
\hline $410-425$ & 24 & 45,52 & 3,05 & 45,47 & 47,25 & 1,0467 & 0,35 & 0,25 & 0,54 & 0,61 & 1,7243 \\
\hline $425-440$ & 19 & 46,15 & 2,70 & 46,03 & 47,32 & 1,0334 & 1,09 & 0,47 & 0,60 & 1,72 & 1,5673 \\
\hline $455-470$ & 15 & 47,36 & 3,51 & 46,83 & 47,74 & 1,0149 & 0,55 & 0,35 & 0,70 & 0,75 & 1,3382 \\
\hline
\end{tabular}

1/médias observadas ( $\mathrm{AOL}_{\mathrm{obs}}$ e $\mathrm{EGS}_{\mathrm{obs}}$ ), esperadas $\left(\mathrm{AOL} \mathrm{L}_{\mathrm{esp}}, \mathrm{EGS}_{\mathrm{esp}}\right.$ ) e ajustadas para $\mathrm{Cl} 555$ dias de idade $\left(\mathrm{AOL} \mathrm{L}_{\mathrm{AJ55}}\right.$, $\mathrm{EGS}_{555}$ ). 
Tabela 10 - Valores de freqüências (FREQ), de médias ${ }^{11}$, de erros padrão (EP), de fatores de correção multiplicativos (FC), por classes de idades $(\mathrm{Cl})$ para AOL e EGS mensuradas por ultra-sonografia. Pirassununga, São Paulo. 2003. (continuação)

\begin{tabular}{|c|c|c|c|c|c|c|c|c|c|c|c|}
\hline \multicolumn{7}{|c|}{ Área de Olho de Lombo $\left(\mathrm{cm}^{2}\right)$} & \multicolumn{5}{|c|}{ Espessura de Gordura Subcutânea (mm) } \\
\hline $\mathrm{Cl}$ & FREQ & $A O L_{o b s}$ & EP & $A O L_{e s p}$ & $\mathrm{AOL}_{\mathrm{AJ} 555}$ & $\mathrm{FC}$ & $E_{G S}$ & EP & $E_{G S}$ esp & $\mathrm{EGS}_{\mathrm{AJ} 555}$ & $\mathrm{FC}$ \\
\hline $470-495$ & 21 & 48,42 & 3,13 & 47,05 & 48,58 & 1,0093 & 0,97 & 0,43 & 0,74 & 1,22 & 1,2561 \\
\hline $495-510$ & 18 & 48,05 & 1,62 & 47,18 & 48,07 & 1,0053 & 0,71 & 0,32 & 0,81 & 0,83 & 1,1509 \\
\hline $525-540$ & 9 & 41,03 & 2,72 & 46,94 & 41,26 & 1,0080 & 0,76 & 0,56 & 0,88 & 0,81 & 1,0614 \\
\hline $540-555$ & 13 & 42,98 & 2,64 & 46,96 & 43,21 & 1,0063 & 1,11 & 0,60 & 0,91 & 1,15 & 1,0277 \\
\hline $555-570$ & 10 & 56,91 & 6,10 & 47,20 & 56,91 & 1,0000 & 1,52 & 0,32 & 0,93 & 1,52 & 1,0000 \\
\hline $570-595$ & 13 & 46,37 & 2,57 & 47,67 & 45,91 & 0,9894 & 0,64 & 0,23 & 0,96 & 0,63 & 0,9774 \\
\hline $595-610$ & 24 & 49,63 & 2,72 & 48,97 & 47,83 & 0,9630 & 0,86 & 0,29 & 0,98 & 0,82 & 0,9495 \\
\hline $610-625$ & 24 & 47,01 & 2,93 & 50,06 & 44,32 & 0,9426 & 0,65 & 0,23 & 1,00 & 0,62 & 0,9381 \\
\hline $625-640$ & 25 & 56,26 & 3,06 & 51,29 & 51,77 & 0,9212 & 1,25 & 0,31 & 1,00 & 1,17 & 0,9302 \\
\hline $640-655$ & 18 & 48,73 & 2,03 & 52,24 & 44,03 & 0,9047 & 0,93 & 0,32 & 1,01 & 0,86 & 0,9257 \\
\hline $655-670$ & 26 & 53,99 & 2,61 & 52,83 & 48,24 & 0,8929 & 0,79 & 0,24 & 1,01 & 0,74 & 0,9246 \\
\hline $670-685$ & 18 & 55,28 & 3,27 & 53,09 & 49,15 & 0,8855 & 0,82 & 0,24 & 1,01 & 0,77 & 0,9268 \\
\hline $685-700$ & 23 & 53,56 & 2,26 & 52,99 & 47,70 & 0,8821 & 1,52 & 0,37 & 1,00 & 1,42 & 0,9323 \\
\hline $700-715$ & 17 & 47,01 & 1,77 & 52,55 & 42,22 & 0,8828 & 0,80 & 0,24 & 0,99 & 0,76 & 0,9413 \\
\hline $715-730$ & 12 & 62,48 & 3,06 & 51,77 & 56,97 & 0,8876 & 1,28 & 0,35 & 0,98 & 1,22 & 0,9539 \\
\hline-730 & 51 & 50,63 & 1,40 & 50,63 & 47,20 & 0,8966 & 0,87 & 0,17 & 0,96 & 0,85 & 0,9706 \\
\hline
\end{tabular}

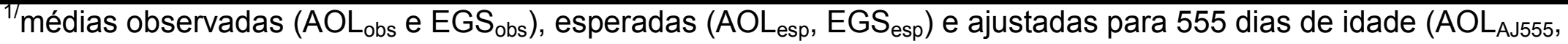

$\left.\mathrm{EGS}_{555}\right)$; 
Os resultados das estimativas dos parâmetros obtidos pelo polinômio segmentado e pelos polinômios ordinários para AOL e EGS estão apresentados nas Tabelas 11 e 12 .

A AOL foi modelada por uma função composta por quatro segmentos quadráticos e seis parâmetros livres, os nós para esta função foram aos 324 dias $\left(K_{1}\right), 518$ dias $\left(K_{2}\right)$ e 616 dias $\left(K_{3}\right)$, os quais após sucessivas análises, fazendo-se variar o valor dos "nós", iterativamente, proporcionaram menor QME $(138,94)$ e o melhor $R^{2}(16,91 \%)$, quando comparados com os polinômios ordinários.

$\mathrm{O}$ ajuste de $\mathrm{AOL}$ pelo polinômio segmentado diferiu numericamente dos ajustes por polinômio ordinário. A equação de predição para descrever a $\mathrm{AOL}$ ajustada em função da $\mathrm{Cl}$ foi:

$$
\mathrm{AOL}_{\text {aj }}=111.7-0.5251 \mathrm{CI}+0.000938 \mathrm{CI}^{2}-0.00119 \mathrm{Z}_{1}+0.000762 \mathrm{Z}_{2}-0.00128 \mathrm{Z}_{3}
$$

Tabela 11 - Parâmetros das funções de ajuste, (erros padrão), coeficientes de determinação $\left(R^{2}\right)$ e de variação $(C V)$, e Quadrado Médio do Erro (QME) obtidos pelo polinômio segmentado e pelos polinômios ordinários para AOL. Pirassununga, São Paulo. 2003

\begin{tabular}{crrr}
\hline AOL & Polinômio Q-Q-Q-Q & Reg Linear & Reg Quadrática \\
\hline $\mathrm{B}_{0}$ & $111,7(31,04649)^{* *}$ & $30,86(1,20951)^{* *}$ & $25,85(4,33)^{*}$ \\
$\mathrm{~B}_{1}$ & $-0,52(0,20828)^{*}$ & $3,18^{-02}\left(2,54^{-03}\right)^{* *}$ & $5,51^{-02}\left(1,97^{-02}\right)^{* *}$ \\
$\mathrm{~B}_{2}$ & $9,38^{-04}\left(3,4^{-0,3}\right)^{* *}$ & - & $-2,47^{-05}\left(2,05^{-05}\right) \mathrm{ns}$ \\
$\mathrm{B}_{3}$ & $-1,19^{-03}\left(4,1^{-04}\right)^{* *}$ & - & - \\
$\mathrm{B}_{4}$ & $7,62^{-03}\left(3,3^{-04}\right)^{*}$ & - & - \\
$\mathrm{B}_{5}$ & $-1,28^{-02}\left(5,7^{-03}\right)^{*}$ & - & - \\
$\mathrm{K}_{1}$ (dias) & 324 & - & - \\
$\mathrm{K}_{2}$ (dias) & 518 & - & - \\
$\mathrm{K}_{3}$ (dias) & 616 & - & - \\
$\mathrm{R}^{2}(\%)$ & 16,91 & 15,72 & 15,86 \\
CV (\%) & 26,13 & 26,26 & 26,25 \\
$\mathrm{QME}$ & 138,94 & 140,28 & 140,20 \\
\hline
\end{tabular}

Níveis de significância: ${ }^{*}(P<0,05),{ }^{* *}(P<0,01)$, ns (não significativo).

A EGS foi modelada como polinômio segmentado de efeito Quadratico-Quadratico, o nó para esta função foi estimado aos 420 dias $\left(\mathrm{K}_{1}\right)$. A equação de predição para descrever a EGS ajustada em função da $\mathrm{Cl}$ foi: 


$$
\mathrm{EGS}_{\mathrm{aj}}=1.1430974-0.006357 \mathrm{CI}+0.00001187 \mathrm{CI}^{2}-0.00001955 Z_{1}
$$

Tabela 12 - Parâmetros das funções de ajuste, (erros padrão), coeficientes de determinação $\left(R^{2}\right)$ e de variação $(C V)$, e Quadrado Médio do Erro (QME) obtidos pelo polinômio segmentado e pelos polinômios ordinários para EGS. Pirassununga, São Paulo. 2003

\begin{tabular}{crrr}
\hline EGS & \multicolumn{1}{c}{ Polinômio Q-Q } & \multicolumn{1}{r}{ Reg.Linear } & \multicolumn{1}{r}{ Reg.Quadrática } \\
\hline $\mathrm{B}_{0}$ & $1,14(1,04) \mathrm{ns}$ & $-0,17(0,11) \mathrm{ns}$ & $-0,49\left(3,9^{-02}\right) \mathrm{ns}$ \\
$\mathrm{B}_{1}$ & $-6,4^{-03}\left(5,72^{-02}\right) \mathrm{ns}$ & $1,74^{-03}\left(2,3^{-04}\right)^{* *}$ & $3,3^{-03}\left(1,8^{-03}\right) \mathrm{ns}$ \\
$\mathrm{B}_{2}$ & $1,18^{-04}\left(7,83^{-05}\right) \mathrm{ns}$ & - & $-1,58^{-05}\left(1,86^{-05}\right) \mathrm{ns}$ \\
$\mathrm{B}_{3}$ & $-1,95^{-04}\left(1,11^{-04}\right) \mathrm{ns}$ & - & - \\
$\mathrm{K}_{1}$ (dias) & 420 & - & - \\
$\mathrm{R}^{2}(\%)$ & 6,80 & 6,37 & 6,45 \\
CV (\%) & 176,37 & 176,56 & 176,59 \\
QME & 1,16 & 1,19 & 1,16 \\
\hline
\end{tabular}

Níveis de significância:* $(\mathrm{P}<0,05),{ }^{* *}(\mathrm{P}<0,01)$, ns (não significativo).

Para EGS o ajuste pelo polinômio segmentado (Q-Q) não diferiu da regressão por polinômio ordinário, entretanto, o ajuste pelo polinômio segmentado foi preferido, pois proporcionou melhor $\mathrm{R}^{2}(6,80 \%)$ comparado com a regressão linear $(6,37 \%)$ e a regressão quadrática $(6,45 \%)$. O modelo proposto apresentou baixa capacidade de ajuste dos dados, possivelmente em decorrência do comportamento da característica. $O \mathrm{R}^{2}$ reduzido pode ter ocorrido pela alta variabilidade ou pela instabilidade apresentada pela EGS. A instabilidade pode ser observada pelo alto coeficiente de variação apresentado. Verificou-se também que não ocorreu aderência da curva ajustada em função da distribuição das médias, refletindo em baixo $\mathrm{R}^{2}$.

Para que se tenha maior precisão nas funções de ajuste e nas estimativas dos fatores de correção, os dados deveriam estar mais bem distribuídos com relação às idades para $A O L$ e EGS, minimizando os possíveis problemas de concentração ou dispersão imprópria dos dados. 


\subsection{Características de Desenvolvimento Ponderal Ajustadas por Polinômios Segmentados}

Diferentes modelos polinomiais foram testados para as características de desenvolvimento ponderal a fim de se aferir qual ajustava melhor o banco de dados analisado.

Os resultados das estimativas dos parâmetros obtidos pelo polinômio segmentado e pelos polinômios ordinários para as características de desenvolvimento ponderal estão apresentados nas Tabelas 13 a 18 .

O peso aos 120 dias de idade foi modelado por uma função composta pelo polinômio com um segmento linear e dois segmentos quadráticos (L-Q$Q$ ), os nós para esta função foram estimados aos 131 dias $\left(K_{1}\right)$ e 147 dias $\left(\mathrm{K}_{2}\right)$. O ajuste pelo polinômio segmentado proporcionou menor QME $(790,94)$ e melhor $R^{2}(39,10 \%)$, quando comparado com as regressões pelos polinômios ordinários. O ajuste do PES120 pelo polinômio segmentado diferiu numericamente dos ajustes pelos polinômios ordinários $A$ equação de predição para descrever o PES120 ajustado em função da idade foi:

$$
\mathrm{PES} 120_{\mathrm{aj}}=33.2338+0.83467 \mathrm{Idade} 120+0.0188 \mathrm{Z}_{1}-0.0767 \mathrm{Z}_{2}
$$

Tabela 13 - Parâmetros das funções de ajuste, (erros padrão), coeficientes de determinação $\left(R^{2}\right)$ e de variação $(C V)$, e Quadrado Médio do Erro (QME) obtidos pelo polinômio segmentado e pelos polinômios ordinários para PES120. Pirassununga, São Paulo. 2003

\begin{tabular}{crrr}
\hline PES120 & Polinômio L-Q-Q & Reg Linear & Reg Quadrática \\
\hline $\mathrm{b}_{0}$ & $33,23(3,20)^{*}$ & $28,85(2,29)^{*}$ & $37,82(11,14)^{\star *}$ \\
$\mathrm{~b}_{1}$ & $0,83\left(2,8^{-02}\right)^{\star *}$ & $0,87(0,018)^{* *}$ & $0,72(0,19)^{\star}$ \\
$\mathrm{b}_{2}$ & $0,02\left(5,8^{-02}\right)^{\star *}$ & - & $6,4^{-03}\left(7,8^{-03}\right)^{\star *}$ \\
$\mathrm{~b}_{3}$ & $-0,77\left(2,1^{-02}\right)^{*}$ & - & - \\
$\mathrm{K}_{1}$ (dias) & 131 & - & - \\
$\mathrm{K}_{2}$ (dias) & 147 & - & - \\
$\mathrm{R}^{2}(\%)$ & 39,10 & 37,40 & 37,50 \\
$\mathrm{CV}(\%)$ & 20,76 & 20,79 & 20,79 \\
$\mathrm{QME}$ & 790,94 & 794,16 & 794,23 \\
\hline
\end{tabular}

Níveis de significância:* $(P<0,05),{ }^{* *}(P<0,01)$, ns (não significativo). 
O PESDES foi modelado pelo polinômio segmentado de efeito Quadratico-Linear-Quadratico (Q-L-Q) com quatro parâmetros livres, os nós para esta função foram aos 166 dias $\left(\mathrm{K}_{1}\right), 234$ dias $\left(\mathrm{K}_{2}\right)$, os quais, após sucessivas análises, fazendo-se variar o valor dos "nós", iterativamente, proporcionaram o menor QME $(1937,37)$ e o melhor $R^{2}(23,30 \%)$. O ajuste do PESDES pelo polinômio segmentado diferiu dos ajustes pelos polinômios ordinários A equação de predição para descrever o PESDES ajustado em função da idade foi:

$$
\text { PEDES }_{\mathrm{aj}}=-2.0127+0,8012 \text { Ides }+0,0015 \text { Ides }+6,6390 Z_{1}+0.0135 Z_{2}
$$

Tabela 14 - Parâmetros das funções de ajuste, (erros padrão), coeficientes de determinação $\left(R^{2}\right)$ e de variação $(C V)$, e Quadrado Médio do Erro (QME) obtidos pelo polinômio segmentado e pelos polinômios ordinários para PESDES. Pirassununga, São Paulo. 2003

\begin{tabular}{crrr}
\hline PESDES & Polinômio Q-L-Q & Reg Linear & Reg Quadrática \\
\hline $\mathrm{b}_{0}$ & $-2,01(11,87)^{*}$ & $46,18(4,20)^{* *}$ & $-77,71(21,79)^{* *}$ \\
$\mathrm{~b}_{1}$ & $0,80(0,37)^{\star *}$ & $0,76\left(2,0^{-02}\right)^{\star}$ & $2,0(0,21)^{*}$ \\
$\mathrm{~b}_{2}$ & $1,57^{-03}\left(1,3^{-03}\right)^{* *}$ & - & $3,0^{-02}\left(5,2^{-03}\right)^{* *}$ \\
$\mathrm{~b}_{3}$ & $6,6(0,2)^{*}$ & - & \\
$\mathrm{b}_{4}$ & $0,01\left(4,0^{-2}\right)^{*}$ & & \\
$\mathrm{~K}_{1}$ (dias) & 166 & & \\
$\mathrm{~K}_{2}$ (dias) & 234 & & \\
$\mathrm{R}^{2}(\%)$ & 23,30 & 22,62 & 23,14 \\
CV (\%) & 21,52 & 21,62 & 21,55 \\
QME & 1937,37 & 1955,95 & 1943,19 \\
\hline
\end{tabular}

Níveis de significância: ${ }^{*}(P<0,05),{ }^{* *}(P<0,01)$, ns (não significativo).

O peso aos 12 meses de idade foi modelado por uma função composta pelo polinômio com três segmentos quadráticos (Q-Q-Q), os nós para esta função foram estimados aos 320 dias $\left(K_{1}\right)$ e 372 dias $\left(K_{2}\right)$. $O$ ajuste pelo polinômio segmentado proporcionou menor QME $(5367,90)$ e melhor $R^{2}$ $(6,58 \%)$ comparado com a regressão pelos polinômios ordinários. $O$ ajuste do PES12 pelo polinômio segmentado diferiu numericamente dos ajustes pelos polinômios ordinários $A$ equação de predição para descrever o PES12 ajustado em função da idade foi: 
PES12 $2_{\text {aj }}=1992.9+11.57$ ID12 $+0.01\left(\right.$ ID12) ${ }^{2}-0.02 Z_{1}-0.01 Z_{2}$

Tabela 15 - Parâmetros das funções de ajuste, (erros padrão), coeficientes de determinação $\left(R^{2}\right)$ e de variação (CV), e Quadrado Médio do Erro (QME) obtidos pelo polinômio segmentado e pelos polinômios ordinários para PES12. Pirassununga, São Paulo. 2003

\begin{tabular}{|c|c|c|c|}
\hline PES12 & Polinômio Q-Q-Q & Reg Linear & Reg Quadrática \\
\hline $\mathrm{b}_{0}$ & $1992,9(373,37)^{\star}$ & $103,41(14,70)^{*}$ & $-217,84(133,05)^{*}$ \\
\hline$b_{1}$ & $11,57(2,13)^{* *}$ & $0,54\left(4,0^{-02}\right)^{*}$ & $2,32(0,73)^{\star *}$ \\
\hline$b_{2}$ & $0,01\left(2,9^{-02}\right)^{\star}$ & , & $-2,4^{-02}\left(1,0^{-02}\right)^{*}$ \\
\hline$b_{3}$ & $-0,02\left(7,8^{-04}\right)^{\star}$ & - & (3) \\
\hline$b_{4}$ & $-0,01\left(5,1^{-04}\right)^{*}$ & & \\
\hline $\mathrm{K}_{1}$ (dias) & 320 & - & - \\
\hline $\mathrm{K}_{2}$ (dias) & 372 & - & - \\
\hline $\mathrm{R}^{2}(\%)$ & 6,58 & 4,70 & 5,17 \\
\hline CV (\%) & 24,47 & 24,33 & 24,65 \\
\hline QME & 5367,90 & 5530,52 & 5477,56 \\
\hline
\end{tabular}

Níveis de significância:* $(\mathrm{P}<0,05),{ }^{* *}(\mathrm{P}<0,01)$, ns (não significativo).

O peso aos 18 meses de idade foi modelado por uma função composta pelo polinômio com três segmentos quadráticos (Q-Q-Q), os nós para esta função foram estimados aos 482 dias $\left(\mathrm{K}_{1}\right)$ e 600 dias $\left(\mathrm{K}_{2}\right)$. O ajuste pelo polinômio segmentado proporcionou menor QME $(9669,89)$ e melhor $\mathrm{R}^{2}$ $(4,35 \%)$ quando comparado com as regressões pelos polinômios ordinários. O ajuste do PES18 pelo polinômio segmentado diferiu dos ajustes pelos polinômios ordinários A equação de predição para descrever o PES18 ajustado em função da idade foi:

PES $18_{\text {aj }}=10557.9-43.80 I D 18+0.04(\text { ID } 18)^{2}-0.05 Z_{1}+0.02 Z_{2}$ 
Tabela 16 - Parâmetros das funções de ajuste, (erros padrão), coeficientes de determinação $\left(R^{2}\right)$ e de variação $(C V)$, e Quadrado Médio do Erro (QME) obtidos pelo polinômio segmentado e pelos polinômios ordinários para PES18. Pirassununga, São Paulo. 2003

\begin{tabular}{crrr}
\hline PES18 & Polinômio Q-Q-Q & Reg Linear & \multicolumn{1}{c}{ Reg Quadrática } \\
\hline $\mathrm{b}_{0}$ & $10557,9(1845,21)^{*}$ & $149,27(25,13)^{*}$ & $-1267,26(260,38)^{*}$ \\
$\mathrm{~b}_{1}$ & $-43,80(6,0)^{\star *}$ & $0,49\left(4,7^{-02}\right)^{\star *}$ & $5,76(0,97)^{\star *}$ \\
$\mathrm{~b}_{2}$ & $0,04(0,05)^{*}$ & - & $-4,9^{-02}\left(9,0^{-03}\right)^{\star *}$ \\
$\mathrm{~b}_{3}$ & $-0,05(0,05)^{\star *}$ & - & - \\
$\mathrm{b} 4$ & $0,02(0,04)^{\star *}$ & - & - \\
$\mathrm{K}_{1}$ (dias) & 482 & & \\
$\mathrm{~K}_{2}$ (dias) & 600 & & \\
$\mathrm{R}^{2}(\%)$ & 4,35 & 3,49 & 4,27 \\
CV (\%) & 25,28 & 25,30 & 25,16 \\
QME & 9669,89 & 9678,39 & 9575,39 \\
\hline
\end{tabular}

Níveis de significância:* $(\mathrm{P}<0,05),{ }^{* *}(\mathrm{P}<0,01)$, ns (não significativo).

O peso aos 24 meses de idade foi modelado por uma função composta pelo polinômio com três segmentos quadráticos ( $Q-Q-Q)$, os nós para esta função foram estimados aos 677 dias $\left(\mathrm{K}_{1}\right)$ e 787 dias $\left(\mathrm{K}_{2}\right)$. O ajuste pelo polinômio segmentado proporcionou menor QME $(13085,20)$ e melhor $\mathrm{R}^{2}(3,37 \%)$ quando comparado com as regressões obtidas pelos polinômios ordinários. O ajuste do PES24 por polinômio segmentado diferiu dos ajustes pelos polinômios ordinários A equação de predição para descrever o PES24 ajustado em função da idade foi:

PES2 $_{\text {aj }}=221,94+0,0047$ ID24 $-0,035(\text { ID24 })^{2}+0.05 Z_{1}+0.02 Z_{2}$ 
Tabela 17 - Parâmetros das funções de ajuste, (erros padrão), coeficientes de determinação $\left(R^{2}\right)$ e de variação $(C V)$, e Quadrado Médio do Erro (QME) obtidos pelo polinômio segmentado e pelos polinômios ordinários para PES24. Pirassununga, São Paulo. 2003

\begin{tabular}{|c|c|c|c|}
\hline PES24 & Polinômio Q-Q-Q & Reg Linear & Reg Quadrática \\
\hline$b_{0}$ & $221,94(78,45)^{\star *}$ & $115,40(58,08)^{* *}$ & $683,55(105,84)^{*}$ \\
\hline$b_{1}$ & $4,7^{-03}\left(1,6^{-03}\right)^{\star}$ & $0,47\left(8,0^{-02}\right)^{\star *}$ & $-1,10(2,92)^{\star *}$ \\
\hline$b_{2}$ & $-3,5^{-02}\left(2,6^{-03}\right)^{* *}$ & & $-1,0^{-02}\left(2,0^{-03}\right)^{* *}$ \\
\hline$b_{3}$ & $0,05(0,05)^{*}$ & - & r \\
\hline b4 & $0,02(0,04)^{*}$ & - & - \\
\hline $\mathrm{K}_{1}$ (dias) & 677 & - & - \\
\hline $\mathrm{K}_{2}$ (dias) & 787 & _ & \\
\hline $\mathrm{R}^{\overline{2}}(\%)$ & 3,37 & 2,67 & 2,70 \\
\hline$C \vee(\%)$ & 25,08 & 25,14 & 25,15 \\
\hline QME & 13085,20 & 14752,39 & 13164,79 \\
\hline
\end{tabular}

Níveis de significância:* $(\mathrm{P}<0,05),{ }^{* *}(\mathrm{P}<0,01)$, ns (não significativo).

O perímetro escrotal aos 18 meses de idade foi modelado por uma função composta pelo polinômio com um segmento linear e um segmento quadrático (L-Q), o nó para esta função foi estimado aos 508 dias $\left(K_{1}\right)$. O ajuste pelo polinômio segmentado proporcionou menor QME $(14,94)$ e melhor $R^{2}(8,47 \%)$ quando comparado com as regressões obtidas pelos polinômios ordinários. O ajuste do PE18 pelo polinômio segmentado diferiu dos ajustes pelos polinômios ordinários $A$ equação de predição para descrever o PE18 ajustado em função da idade foi:

$$
\text { PE1 }_{\text {aj }}=8.32+0.048\left(\text { IDPE 18) }-0.0042 Z_{1}\right.
$$


Tabela 18 - Parâmetros das funções de ajuste, (erros padrão), coeficientes de determinação $\left(R^{2}\right)$ e de variação $(C V)$, e Quadrado Médio do Erro (QME) obtidos pelo polinômio segmentado e pelos polinômios ordinários para PE18. Pirassununga, São Paulo. 2003

\begin{tabular}{lrrr}
\hline PE18 & Polinômio L-Q & \multicolumn{1}{c}{ Reg Linear } & Reg Quadrática \\
\hline B $_{0}$ & $8,32(3,18)^{\star}$ & $20,49(1,85)^{\star}$ & $-71,24(20,09)^{\star}$ \\
B $_{1}$ & $4,8^{-02}\left(6,2^{-02}\right)^{\star \star}$ & $0,024\left(3,5^{-03}\right)^{\star \star}$ & $0,37(0,075)^{\star *}$ \\
B $_{2}$ & $-4,2^{-03}\left(9,0^{-04}\right)^{\star \star}$ & - & $-3,2^{03}\left(7,1^{-04}\right)^{\star \star}$ \\
K $_{1}$ (dias) & 508 & - & - \\
R $^{2}(\%)$ & 8,47 & 5,84 & 8,37 \\
CV (\%) & 11,62 & 11,78 & 11,63 \\
QME & 14,94 & 15,34 & 14,95 \\
\hline
\end{tabular}

Níveis de significância:* $(\mathrm{P}<0,05),{ }^{* \star}(\mathrm{P}<0,01)$, ns (não significativo).

A modelagem pelo polinômio segmentado para as características de desenvolvimento ponderal mostrou maior eficiência em relação ao ajuste pelos polinômios ordinários devido a melhor qualidade das curvas ajustadas. Percebe-se que as curvas ajustadas pelos polinômios segmentados acompanham a tendência das médias observadas. Verifica-se, também, que na região onde há menor dispersão das médias ocorre melhor aderência da curva ajustada.

Mesmo considerando o melhor ajuste das funções polinomiais em relação aos polinômios ordinários, existe a necessidade de analisar o quanto esta mudança proporciona alterações significativas nas avaliações genéticas.

\subsection{MÉDIAS}

Na Tabela 6, mostrada na página 29 do material e métodos, as médias encontradas, para PESNAS, PES120, PESDES, PES12 E PES18 são bem próximas das relatadas por RIBEIRO et al., (1996) e por RIBEIRO (1997), para a raça Santa Gertrudis. 
A média para $\mathrm{AOL}\left(47,46 \pm 12,20 \mathrm{~cm}^{2}\right)$, encontrada no presente estudo foi maior ao valor encontrado em animais da raça Nelore, por FIGUEIREDO (2001), para o rebanho 1 , o qual foi de $42,57 \pm 5,90 \mathrm{~cm}^{2}$ e menor ao valor encontrado para o rebanho 2 que foi de $49,23 \pm 9,92 \mathrm{~cm}^{2}$. Já a média obtida para EGS $(0,95 \pm 1,81 \mathrm{~mm})$, foi menor a descrita por FIGUEIREDO (2001), as quais foram de $2,41 \pm 0,84 \mathrm{~mm}$ e 2,10 $\pm 0,57 \mathrm{~mm}$ para o rebanho 1 e rebanho 2 respectivamente.

Com relação ao perímetro escrotal aos 18 meses a média $(34,32 \pm$ $3,99 \mathrm{~cm}$ ), foi menor às encontradas por FIGUEIREDO, (2001), para a raça Nelore as quais foram de $27,66 \pm 3,35 \mathrm{~cm}^{2}$ para o rebanho 1 e 25,29 $\pm 3,47$ $\mathrm{cm}^{2}$ para o rebanho 2 .

\subsection{HERDABILIDADES}

O coeficiente de herdabilidade é a fração da variância fenotípica que é atribuída aos efeitos genéticos aditivos. Em outras palavras, ele expressa a proporção da variância fenotípica que é atribuível ao efeito médio dos genes aditivos. A herdabilidade é uma propriedade não apenas da característica, mas também da população e das circunstâncias ambientais a que os indivíduos são submetidos. $\mathrm{O}$ valor da herdabilidade depende da magnitude de todos os componentes de variância, e assim, uma mudança nestes componentes influencia este valor.

$\mathrm{Na}$ Tabela 19 são mostrados os componentes de variância, covariância e parâmetros genéticos para as características de carcaça e de desempenho ponderal obtidos pelo método REML. Os erros padrão obtidos nas análises uni-características foram utilizados para as análises bicaracterísticas, pois o método que utiliza o algoritmo Average Information (JOHNSTON \& THOMPSON, 1995) calcula o erro padrão para análises bicaracterísticas somente quando não houver valores perdidos entre as duas características. 
Os valores de variância genética aditiva direta, variância genética aditiva materna e covariância entre os efeitos genéticos aditivo diretos e maternos para PESDES, obtidos nas análises uni-característica foram fixados nas análises bi-características. Optou-se por este procedimento porque o PESDES é a característica com maior número de informações e sendo assim, assumiu-se que estes valores seriam os mais consistentes.

As covariâncias genéticas negativas entre efeitos diretos e maternos para as características de PESNAS, PES120, PESDES e PES12 indicam um antagonismo genético entre estas fontes de variação e devem ser considerados nos programas de seleção, pois podem influenciar a tendência genética em longo prazo. 
Tabela 19 - Estimativa dos componentes de variância, covariância e parâmetros genéticos para as características de carcaça, de desenvolvimento ponderal e de perímetro escrotal em análises uni-característica, pelo método de máxima verossimilhança restrita (REML). Pirassununga, São Paulo, 2003.

\begin{tabular}{crrrrrrrrrrr}
\hline \multicolumn{1}{c}{ Componentes de variância e covariância } & \multicolumn{1}{c}{ Parâmetros genéticos } \\
\hline Análise & \multicolumn{1}{r|}{$\sigma^{2}{ }_{a}$} & \multicolumn{1}{c}{$\sigma_{m}{ }^{2}$} & \multicolumn{1}{c}{$\sigma_{a m}$} & \multicolumn{1}{c}{$\sigma_{c}{ }^{2}$} & \multicolumn{1}{c}{$\sigma_{e}{ }^{2}$} & \multicolumn{1}{c}{$\sigma_{P}{ }^{2}$} & \multicolumn{1}{c}{$h^{2}{ }_{a}$} & $h_{m}{ }_{m}$ & $r_{a m}$ & $c^{2}$ & $e^{2}$ \\
\hline PESNAS & 8,84 & 1,61 & $-1,55$ & 4,17 & 12,92 & 26,00 & $0,34 \pm 0,09$ & $0,06 \pm 0,06$ & $-0,41 \pm 0,30$ & $0,16 \pm 0,04$ & $0,50 \pm 0,07$ \\
PES120 & 48,28 & 32,04 & $-20,07$ & 49,95 & 293,99 & 404,20 & $0,12 \pm 0,04$ & $0,08 \pm 0,05$ & $-0,51 \pm 0,30$ & $0,12 \pm 0,04$ & $0,73 \pm 0,04$ \\
PESDES & 153,00 & 69,45 & $-51,65$ & 128,02 & 669,17 & 967,98 & $0,16 \pm 0,05$ & $0,07 \pm 0,04$ & $-0,50 \pm 0,25$ & $0,13 \pm 0,03$ & $0,69 \pm 0,04$ \\
PES12 & 301,96 & 156,52 & $-92,62$ & 186,51 & 1652,25 & 2204,63 & $0,14 \pm 0,06$ & $0,07 \pm 0,06$ & $-0,43 \pm 0,41$ & $0,09 \pm 0,04$ & $0,75 \pm 0,05$ \\
PES18 & 1035,48 & - & - & - & 2576,14 & 3611,62 & $0,29 \pm 0,07$ & - & - & - & $0,71 \pm 0,07$ \\
PES24 & 1847,56 & - & - & - & 3130,35 & 4977,92 & $0,37 \pm 0,11$ & - & - & - & $0,63 \pm 0,11$ \\
PE18 & 4,32 & - & - & - & 6,93 & 11,25 & $0,38 \pm 0,16$ & - & - & - & $0,62 \pm 0,16$ \\
AOL & 20,21 & - & - & - & 69,40 & 89,61 & $0,23 \pm 0,10$ & - & - & - & $0,77 \pm 0,10$ \\
EGS & 0,10 & - & - & - & 1,90 & 2,00 & $0,05 \pm 0,04$ & - & - & - & $0,95 \pm 0,04$ \\
\hline
\end{tabular}

$\sigma_{\mathrm{a}}{ }^{2}=$ variância genética aditiva direta; $\sigma_{\mathrm{m}}{ }^{2}=$ variância genética aditiva materna; $\sigma_{\mathrm{am}}=$ covariância entre os efeitos genéticos aditivos direto e materno; $\sigma_{\mathrm{c}}{ }^{2}=$ variância devido ao efeito de ambiente permanente da vaca; $\sigma_{\mathrm{e}}{ }^{2}=$ variância de ambiente; $\sigma_{\mathrm{P}}{ }^{2}$

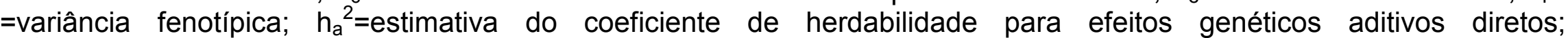
$\mathrm{h}_{\mathrm{m}}{ }^{2}=$ estimativas do coeficiente de herdabilidade para efeitos genéticos maternos; $r_{a m}$ correlação entre efeitos genéticos diretos e maternos; $c^{2}=$ fração da variância fenotípica devido ao ambiente permanente; $e^{2}=$ fração da variância fenotípica devido ao ambiente temporário, - significa que não foi incluído no modelo. 


\subsubsection{Herdabilidades das Características de Carcaça}

Os parâmetros genéticos encontrados neste trabalho para as características de AOL e EGS são estimativas de uma amostra da população de animais da raça Santa Gertrudis. O número de informações referentes às medidas de ultra-sonografia é considerado pequeno quando comparado com outras características como PES120, PESDES, PE18 entre outras.

As estimativas de herdabilidades para efeito genético aditivo direto e erros padrão obtidas neste estudo em análises uni-característica foram de $0,23 \pm 0,10$ e $0,05 \pm 0,04$ para AOL e EGS respectivamente. Estes coeficientes, os efeitos residuais e as variâncias fenotípicas estimados estão apresentados nas Figura 2 e 3.

Estes valores foram menores aos reportados por REVERTER et al., (2000) que encontraram estimativas de herdabilidade para AOL e EGS iguais a 0,37 e 0,47 respectivamente, para animais machos da raça Red Angus e 0,41 e 0,09 para machos da raça Hereford.

As herdabilidades para efeito direto encontradas para AOL e EGS foram maiores às estimativas de 0,19 e 0,04 e 0,41 e 0,19, respectivamente, encontrados por FIGUEIREDO (2001) em dois rebanhos Nelore distintos (rebanho 1 e rebanho 2).

A literatura demonstra que características de carcaças geralmente apresentam valores de herdabilidade variando de moderado a alto (KOOTS et al., 1994a; REVERTER et al., 2000) e correlações genéticas positivas com as características de crescimento no animal vivo (KOOTS et al., 1994b; CREWS \& KEMP, 1999). 
O valor de herdabilidade encontrado neste estudo para AOL encontrase dentro do intervalo dos valores reportados na literatura (ROBINSON et al. 1993; SHEPARD et al. 1996; MOSER et al. 1998; RILEY et al. 2002). Para EGS o valor de herdabilidade encontrado é menor do que a grande maioria dos trabalhos revisados na literatura (SHEPARD et al. 1996; DEVITT \& WILTON 2001; CREWS \& KEMP 2002; CREWS et al. 2003). Isto pode ter ocorrido pela assimetria da distribuição dos dados desta característica no intervalo de idade dos animais avaliados. Foi observado que uma grande quantidade de animais (62\%) apresentava valores de EGS igual a zero. Observou-se ainda que a EGS é uma variável que não apresenta uma distribuição normal em relação à idade.

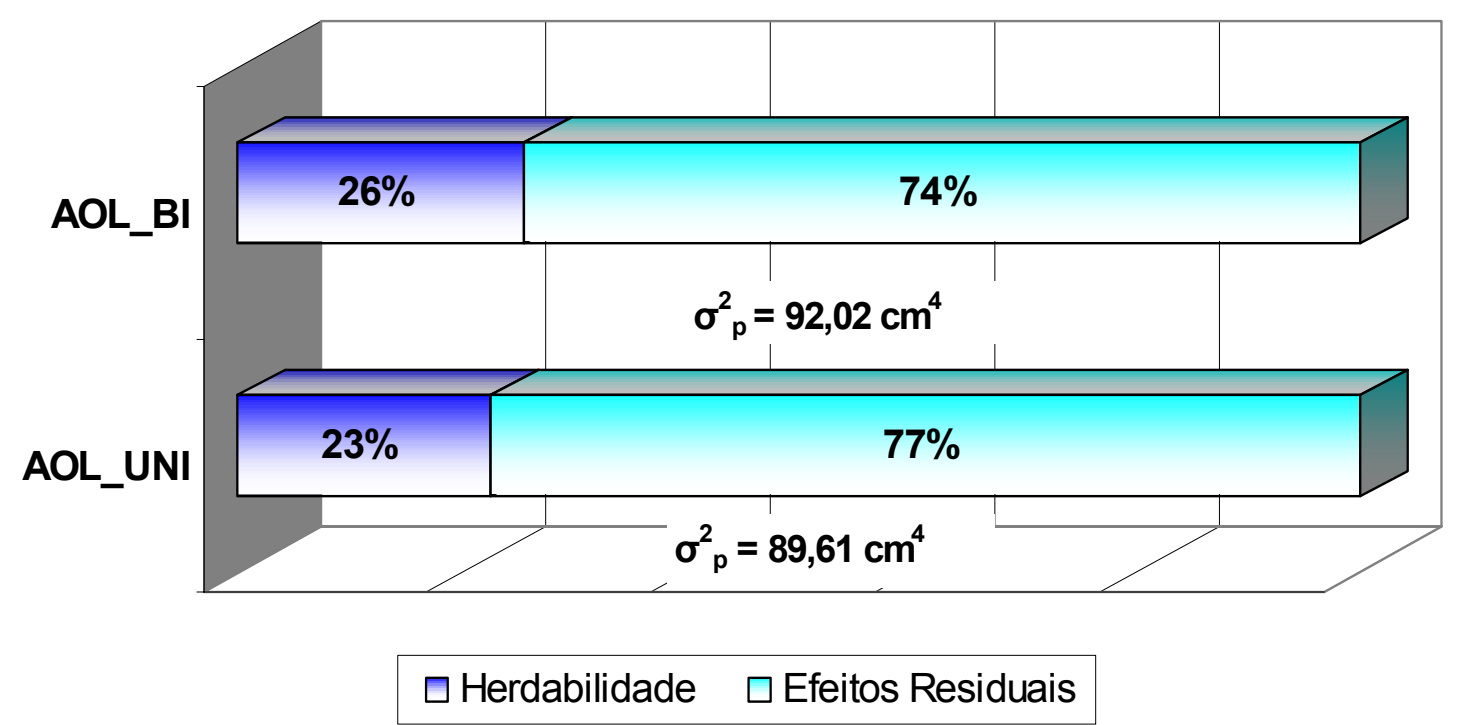

Figura 2 - Valores de herdabilidade para efeito genético aditivo direto $\left(\mathrm{h}_{\mathrm{a}}{ }^{2}\right) \mathrm{e}$ fração da variância fenotípica devido aos efeitos residuais $\left(\mathrm{e}^{2}\right)$ para área de olho de lombo, estimados em análises uni-característica e bi-característica. Pirassununga, São Paulo. 2003

Deve-se salientar, no entanto, que a falta de estudos semelhantes com animais da raça Santa Gertrudis, bem como o padrão de idade à mensuração adotado, dificultaram as comparações com dados da literatura. 


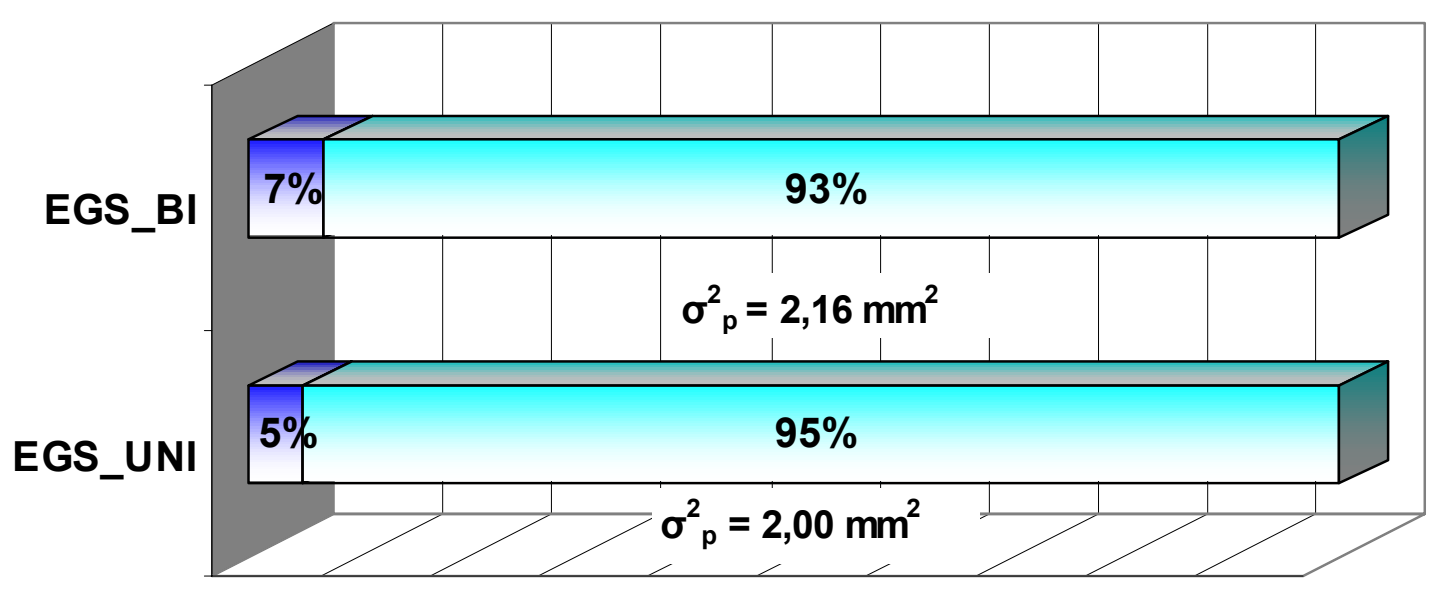

$\square$ Herdabilidade $\square$ Efeitos Residuais

Figura 3 -Valores de herdabilidade e proporção dos efeitos residuais $\left(\mathrm{e}^{2}\right)$ para espessura de gordura subcutânea, estimados em análises unicaracterística e bi-característica. Pirassununga, São Paulo. 2003

Nas figuras 4 e 5 estão os coeficientes de herdabilidade de AOL e EGS estimados em análises bi-características. Observa-se uma variação das herdabilidades estimadas. $\mathrm{O}$ que pode ser devido à diferença encontrada no número de animais do banco de dados, pois este varia conforme a característica analisada em conjunto com a AOL. As estimativas mais confiáveis devem ser as obtidas quando a $A O L$ e a EGS foram analisadas com o PESDES, pois são os valores que foram estimados com maiores conjuntos de dados. 


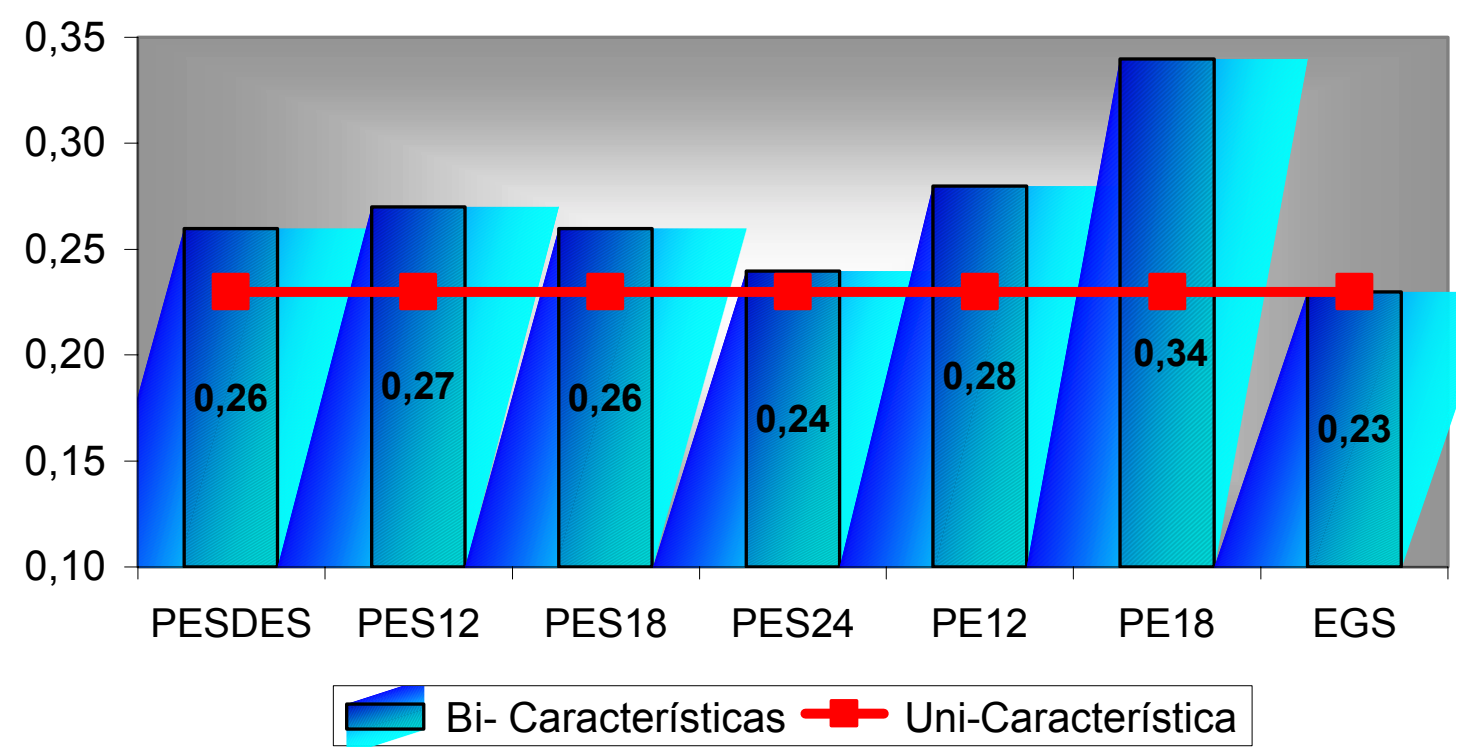

Figura 4 - Comparação da variação das estimativas de herdabilidade de área de olho de lombo obtidas em análises uni e bi-características. Pirassununga, São Paulo. 2003

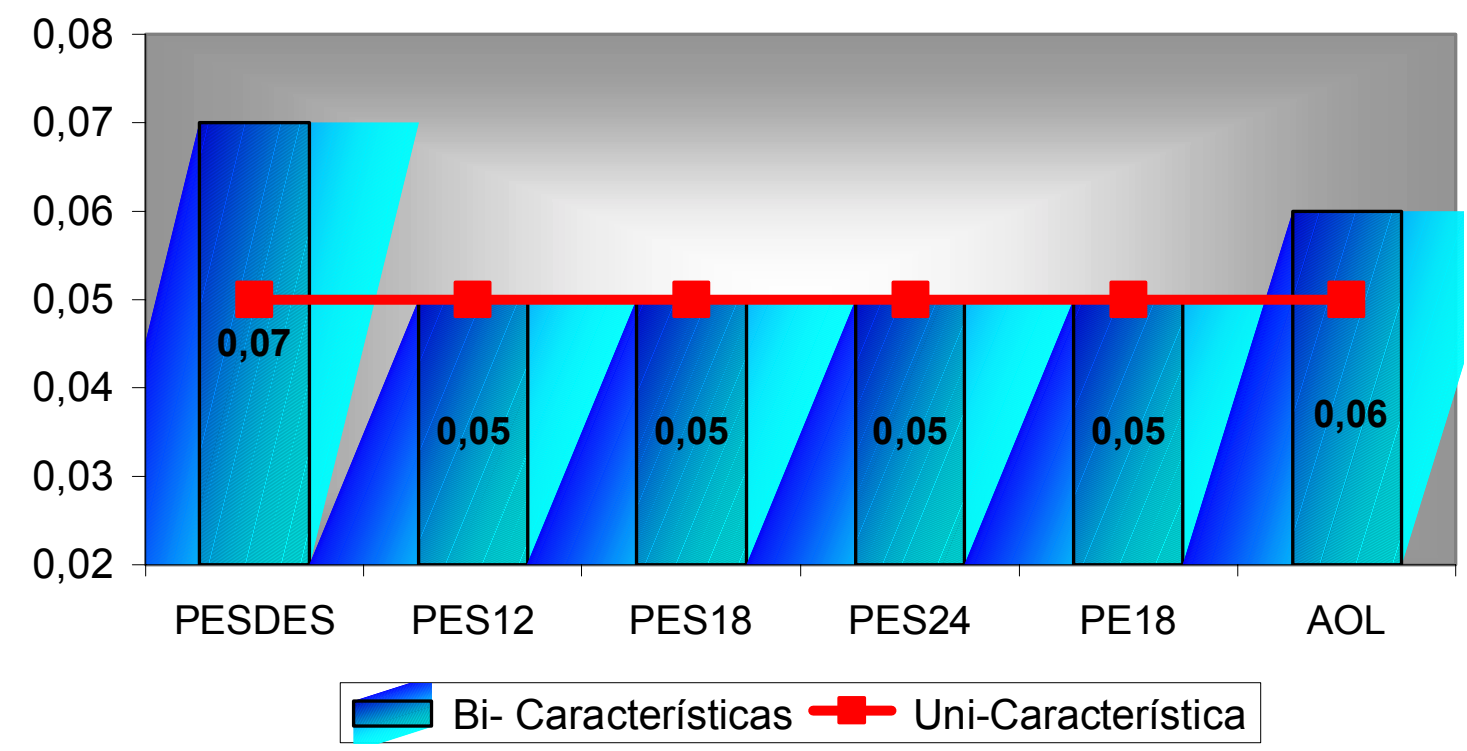

Figura 5 - Comparação da variação das estimativas de herdabilidade de espessura de gordura subcutânea obtidas em análises uni e bicaracterísticas. Pirassununga, São Paulo. 2003 
As herdabilidades encontradas na literatura para as características de carcaça medidas por ultra-sonografia são um tanto conflitantes, havendo trabalhos relatando valores de herdabilidade muito baixo para as características de AOL e EGS (TURNER et al., 1990), enquanto há outros relatando valores muito altos (WILSON et al., 1993; BANKS et ., 2001, CREWS \& KEMP, 2002).

Esta discrepância de resultados, principalmente para EGS, pode ser devido ao fato de que a maioria da literatura estrangeira trabalha com animais em regime de confinamento com elevada deposição de tecido adiposo. O que difere da realidade dos sistemas de criação brasileiros, o qual, sabe-se atualmente que existe grande interesse em determinar a exatidão da técnica de ultra-sonografia em animais criados em pastagens. Porém, neste caso, suspeita-se que animais jovens criados nessas condições dificilmente conseguem atingir peso elevado e alta deposição de gordura subcutânea.

A estimativa de herdabilidade para $\operatorname{AOL}(0,23 \pm 0,10)$ encontrada neste estudo sugere que progressos podem ser conseguidos usando a técnica de Ultra-sonografia como uma ferramenta para seleção de características de carcaça em bovinos. Porém deve ser levado em conta o baixo coeficiente de herdabilidade encontrado para EGS $(0,05 \pm 0,04)$, valor este que sugere que a característica é altamente influenciada pelo meio ambiente, em especial pelo fator nutricional e pouco influenciado pelo componente genético aditivo direto.

Naturalmente, a taxa de maturação é muito influenciada por modificações no manejo e pela nutrição, o que parece estar sendo confirmado pelo baixo coeficiente de herdabilidade.

De acordo com LANNA (1996) geralmente, a seleção para os animais mais pesados a uma idade jovem resulta em animais de maior peso à puberdade e maior peso adulto. 
O melhoramento para taxas de ganhos pode se traduzir em pressão de seleção para aumento no peso adulto. Porém deve-se ter em mente que animais de raças de médio e grande porte atingirão um nível especifico de gordura corporal a pesos mais elevados que animais de tamanho corporal pequeno. Sendo assim, animais de maior tamanho corporal só serão mais eficientes quando abatidos ao mesmo peso, pois depositam menos gordura no ganho.

Se o abate é realizado para produção de uma carcaça semelhante, animais de menor porte são mais eficientes, por atingirem a taxa de maturação mais cedo, diluindo as exigências de mantença.

Para a obtenção dos dados de AOL e EGS com ultra-som, sugere-se restringir o intervalo de idade a medição na tentativa de uniformizar melhor $\mathrm{O}$ lote de animais a serem mensurados. Neste processo o efeito de grupo de manejo também é importante e pode influenciar as características estudadas, devendo ser levado em consideração.

A continuidade das mensurações de AOL e EGS são fundamentais para um maior progresso do programa de melhoramento desta raça com ênfase no melhoramento de características de carcaça.

Mais pesquisas são necessárias, com uma amostra substancialmente maior para estimar parâmetros genéticos confiáveis de características indicadoras de qualidade e produtividade de carcaças obtidas por ultrasonografia.

\subsubsection{Herdabilidades das Características de Desenvolvimento} Ponderal

As estimativas dos componentes de (co)variância e parâmetros genéticos para as características de desenvolvimento ponderal estão descritos na Tabela 19 da página 55. 
Neste estudo a estimativa de herdabilidade para efeito direto obtida para PESNAS $(0,34 \pm 0,09)$, está dentro do intervalo descrito por AARON et al (1987), de 0,38 $\pm 0,12$ para machos, $0,24 \pm 0,10$ para fêmeas e $0,32 \pm 0,07$ para ambos sexos e maior ao valor de 0,16, encontrado por RIBEIRO (1997) ambos avaliando animais da raça Santa Gertrudis.

A herdabilidade para PESNAS foi menor ao valor encontrado por VAN MELIS (2002), PEREIRA (2001), SILVA et al. (2001) e maiores aos valores encontrados por LÔBO et al. (1994), MAGNABOSCO et al.(1998), todos avaliando rebanhos da raça Nelore.

O valor de herdabilidade para efeito materno obtido para PESNAS $(0,06 \pm 0,06)$ foi próxima ao encontrado por RIBEIRO (1997) na raça Santa Gertrudis, maior do que os valores encontrados por VAN MELIS (2002) e MAGNABOSCO et al. (1998) e similar ao valor encontrado por ELER et al. (1996), SCAPARTTI \& LÔBO (1999) e MARCONDES et al. (2000) em rebanhos Nelore.

O valor de herdabilidade encontrado para efeito genético direto para PES120 $(0,12 \pm 0,04)$, foi maior ao encontrado por RIBEIRO (1997).

Quando se busca estimar parâmetros genéticos com confiabilidade e precisão o número de informações e a correta colheita da informação são fatores essenciais.

Quanto ao PESDES os valores de herdabilidade para os efeitos genéticos aditivos diretos $\left(h^{2}=0,16 \pm 0,05\right)$ e maternos $\left(h^{2}{ }_{m}=0,07 \pm 0,04\right)$ estão apresentadas na Figura 6 . Estes resultados foram menores do que os encontrados por LÔBO et al. (2000), AARON et al. (1987), e próximos aos valores encontrados por KRIESE et al.(1991) e RIBEIRO (1997).

$O$ coeficiente de herdabilidade encontrado, quando o PESDES foi estimado em análise bi-característica, está na Figura 7. Observa-se pouca variação da herdabilidade encontrada quando o PESDES foi estimado em análises bi-características, quando comparado com a análise unicaracterística. 


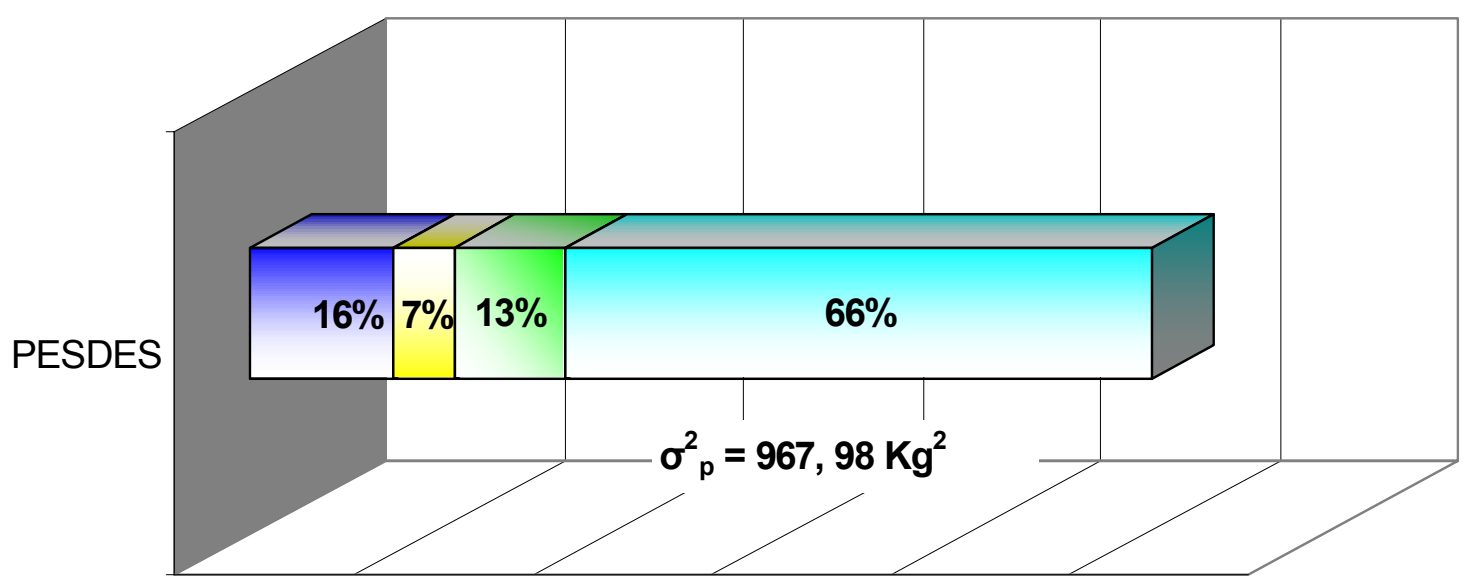

$\square$ Efeito Genético Aditivo Direto

$\square$ Efeito Genético Aditivo Materno

$\square$ Efeito do Ambiente Permanente da Vaca $\square$ Efeitos Residuais

Figura 6- Valores de herdabilidade para efeitos genéticos aditivos diretos $\left(h^{2}{ }_{a}\right)$ e para efeitos genéticos aditivos maternos $\left(h^{2}{ }_{m}\right)$, fração da variância fenotípica devido ao ambiente permanente da vaca, $\left(c^{2}\right)$ e proporção dos efeitos residuais $\left(e^{2}\right)$ para PESDES, estimados em análises uni-característica. Pirassununga, São Paulo. 2003

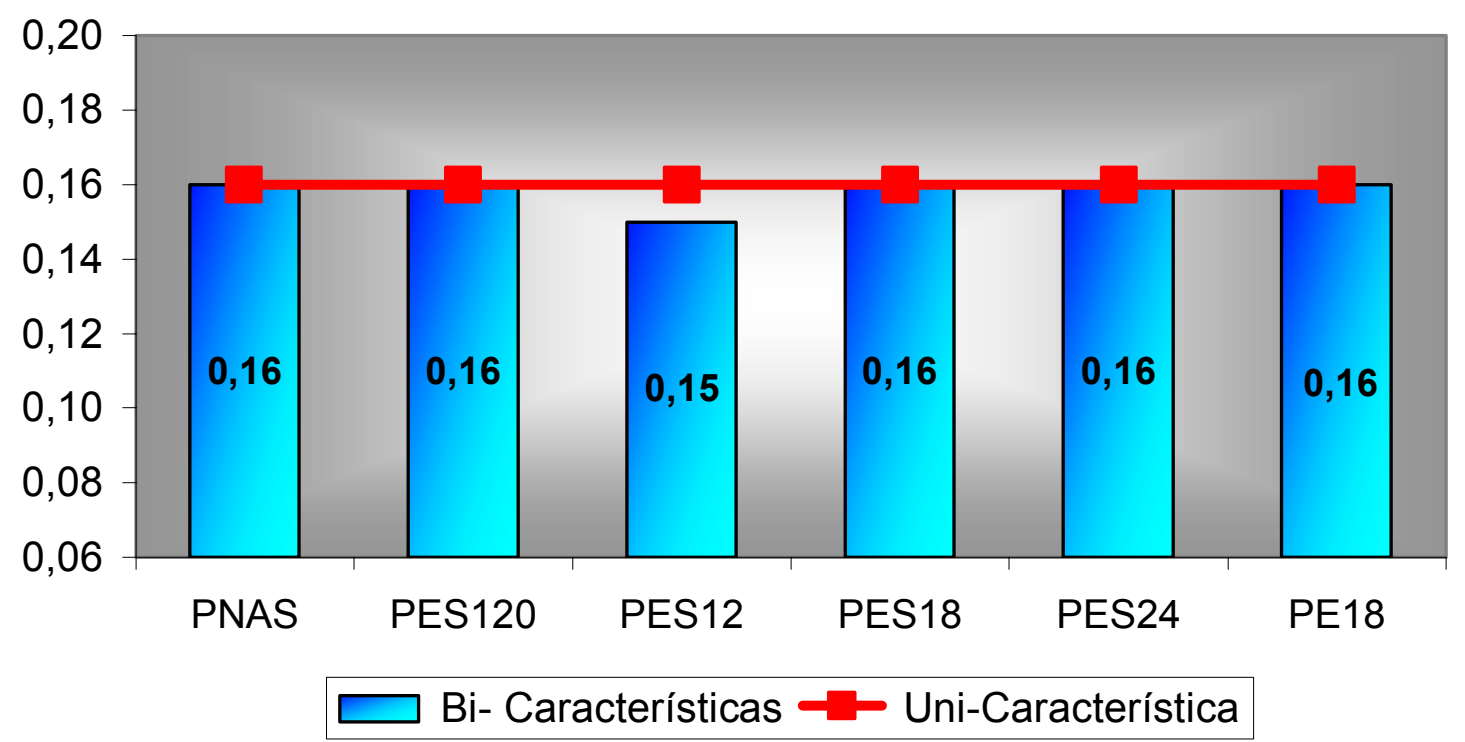

Figura 7 - Comparação da variação das estimativas de herdabilidade de PESDES obtidas em análises uni e bi-características. Pirassununga, São Paulo. 2003 
Em relação ao PES12, as estimativas de herdabilidade para os efeitos genéticos aditivos diretos $\left(h^{2}{ }_{a}=0,14 \pm 0,06\right)$ e maternos $\left(h^{2}=0,07 \pm 0,07\right)$, foram maiores aos encontrados por RIBEIRO (1997), $\left(h^{2}{ }_{a}=0,12\right.$ e $\left.^{2}{ }_{m}=0,01\right)$.

Para PES18 e PES24, os coeficientes de herdabilidades para os efeitos genéticos aditivos diretos $\left(h^{2}{ }_{a}=0,29 \pm 0,07\right.$ e $\left.0,37 \pm 0,11\right)$ foram maiores do que os encontrados por RIBEIRO (1997).

Quanto ao PE18 o coeficiente de herdabilidade para efeito genético aditivo direto $\left(h^{2}=0,38 \pm 0,16\right)$ foi maior do que o encontrado por LÔBO et al. (2000), que reportou herdabilidade de 0,31 para perímetro escrotal.

Neste estudo verificou-se que as estimativas de herdabilidade direta e materna para todas as características estudadas apresentaram valor moderado, o que indica a possibilidade de obtenção de resposta à seleção na população estudada, se estas características forem usadas como critérios de seleção. Os resultados indicam também, que, o efeito genético materno pode ser incluído no modelo de estimativa de componentes de (co) variância nos animais da raça Santa Gertrudis criados no Brasil, para as características analisadas aos 12 meses de idade.

\subsection{CORRELAÇÕES GENÉTICAS}

As análises bi-características foram realizadas com o objetivo de se estimar as correlações genéticas e para estas análises utilizou-se o PESDES como característica âncora, sendo esta avaliada com PESNAS, PES120, PES12, PES18, PES24, PE18, AOL e EGS. As características AOL e EGS foram também analisadas com as características de desenvolvimento ponderal de PESDES, PES12, PES18, PES24, PE18.

As correlações encontradas entre as características de carcaça e as demais características de desenvolvimento ponderal são apresentadas nas Figuras 8 e 9 . 
5.5.1 Correlações Genéticas de AOL com Característica de Desenvolvimento Ponderal

A Figura 8 ilustra as correlações genéticas obtidas entre $A O L$ e características de desenvolvimento ponderal.

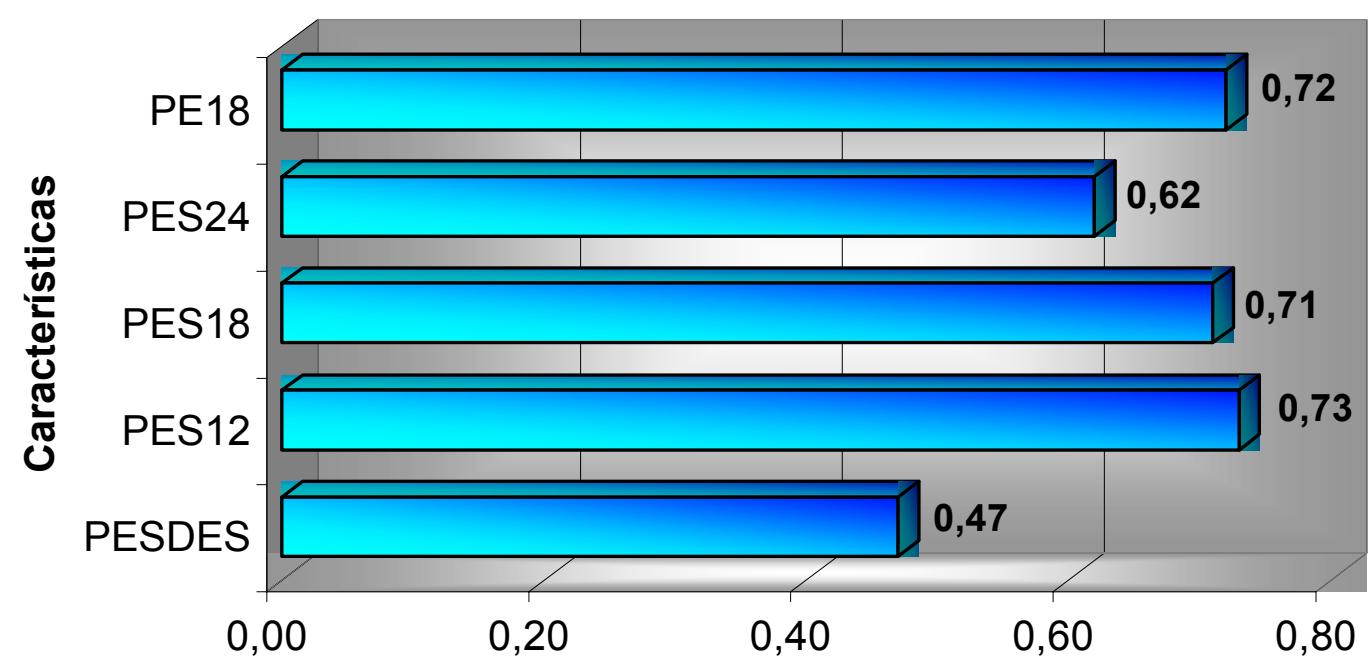

Correlações

Figura 8 - Correlações genéticas entre AOL e características de desenvolvimento ponderal. Pirassununga, São Paulo. 2003

Neste trabalho encontrou-se alta e positiva correlação genética entre $\mathrm{AOL} e$ as características de crescimento. Estes resultados indicam que, animais que apresentam PESDES, PES12, PES18, PES24 e PE18, maiores, tendem também a ter maiores $\mathrm{AOL}$ nas respectivas idades. Conseqüentemente, esses animais têm possibilidade de apresentar maior deposição de tecido muscular, proporção superior de rendimento de carcaça e da porção comestível da carcaça.

Estes resultados vão de encontro ao que a literatura aponta, ou seja, existe uma correlação genética positiva e forte entre $A O L$ e características de desenvolvimento ponderal (KOOTS et al., 1994; SHEPARD et al., 1996; MOSER et al., 1998). 
Parece ser fato que a $\mathrm{AOL}$ é geneticamente correlacionada com características de crescimento. Portanto, o uso da avaliação com ultrasonografia deve ser considerada como uma ferramenta importante nos programas de melhoramento genético de bovinos de corte.

\subsubsection{Correlações Genéticas de EGS com Característica de} Desenvolvimento Ponderal

As correlações genéticas entre EGS e características de desenvolvimento ponderal são apresentadas nas Figura 9.

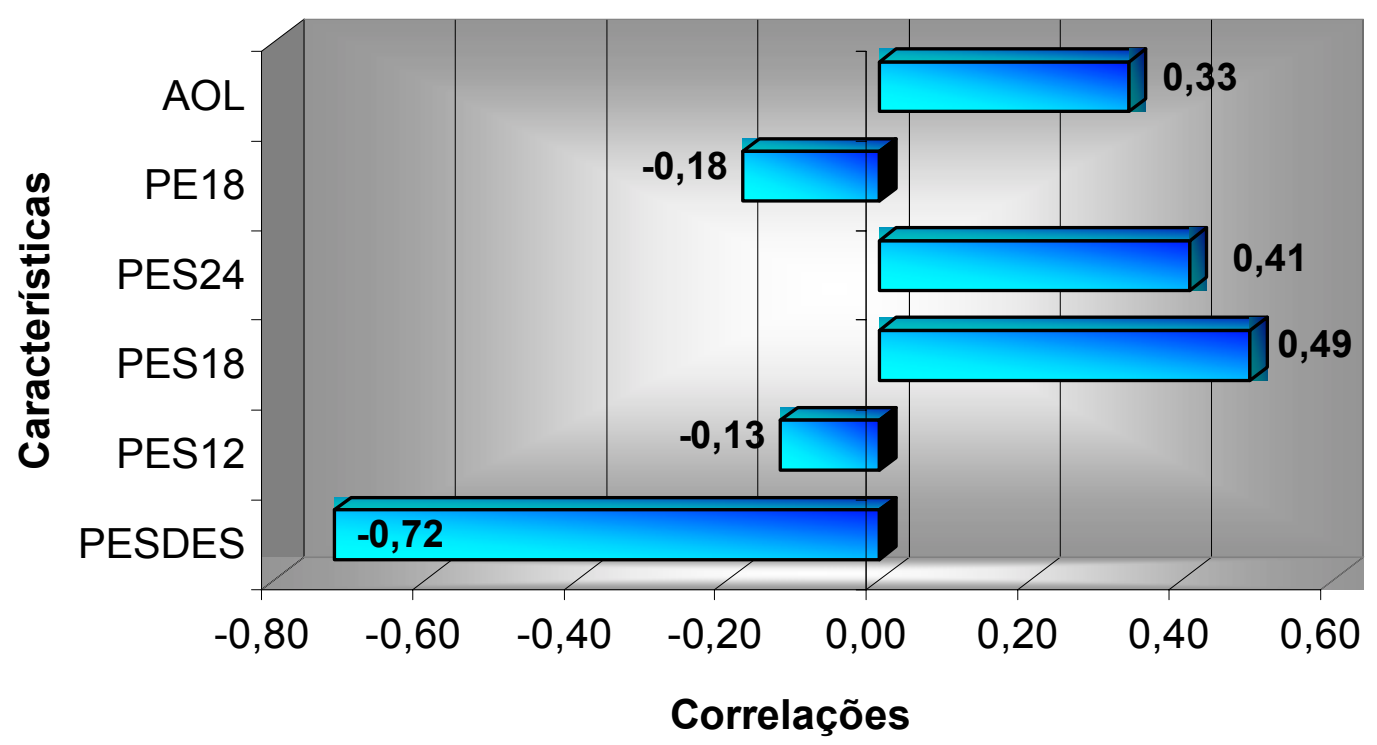

Figura 9 - Correlações genéticas entre EGS e características de desenvolvimento ponderal. Pirassununga, São Paulo. 2003

Verifica-se que existe uma grande variabilidade nas correlações encontradas entre EGS e características de desenvolvimento ponderal. Os resultados da literatura também são díspares (SHEPARD et al., 1996; MOSER et al., 1998; REVERTER et al., 2000). 
Neste trabalho a correlação entre AOL e EGS foi positiva, isto indica que para cada $\mathrm{cm}^{2}$ de crescimento da $A O L$, deve haver um aumento da EGS. O valor encontrado para esta correlação é antagônico ao valor encontrado por REVERTER et al. (2000) para a raça Hereford, e, similar ao relatado por ROBINSON et al. (1993).

A correlação genética de EGS com PES18 (0,41) e PES24 $(0,49)$ foram positivas e de média relação, sendo esses valores superiores aos encontrados por MOSER et al. (1998).

As correlações genéticas de EGS com PE18 (- 0,18) e PES12 $(-0,13)$, foram negativas de baixa magnitude e indicam que a seleção para PE18 e PES12, além de não contribuir para ganhos genéticos em EGS podem sugerir uma relação negativa entre estas características, ou seja o ganho em uma tende a diminuir a expressão de outra.

Com relação ao PESDES os resultados indicam uma correlação genética negativa de magnitude alta $(-0,72)$ com EGS. Isto pode se explicado pelo fato que na idade a desmama e sob as condições de manejo em que a maioria dos animais foi medida, estes se apresentavam em pleno desenvolvimento muscular, longe da fase de maturação.

Sob as condições deste estudo e dos dados analisados a correlação genética encontrada indica que a seleção para PESDES resulta em animais que podem apresentar menor capacidade de deposição de tecido adiposo. Ou seja, a ênfase na seleção para PESDES estaria relacionada a uma menor precocidade de terminação dos animais. Não devemos esquecer que animais de maior tamanho corporal apresentam carcaças mais magras, a um mesmo peso, que animais de menor tamanho sob uma mesma condição alimentar. 
Contudo, TEDESCHI (1996) ressalta que um fator complicador é a existência de correlação negativa entre peso adulto e taxa de maturação, ou seja, animais com elevados pesos adultos tendem a apresentar menores taxas de maturação. Todavia, para este autor, apesar da existência de uma pressão de seleção para animais de elevado peso adulto, os programas de melhoramento parecem não ter piorado a taxa de maturação, isso porque na seleção para peso à idade jovem (12-18 meses), animais que depositam gordura mais cedo têm maior mérito.

Há necessidade de se continuar às pesquisas para melhor quantificar as relações genéticas entre as medidas de carcaça e de desenvolvimento ponderal em diferentes populações, diferentes idades e diferentes regimes alimentares.

Tais estudos contribuiriam para se determinar qual a idade na mensuração das características de carcaça resultaria nas melhores correlações genéticas de desenvolvimento ponderal.

\subsubsection{Correlações Genéticas de PESDES com Característica de} Carcaça e demais Características de Desenvolvimento Ponderal

As correlações genéticas entre PESDES e características de carcaça e demais características de desenvolvimento ponderal são apresentadas nas Figura 10. 


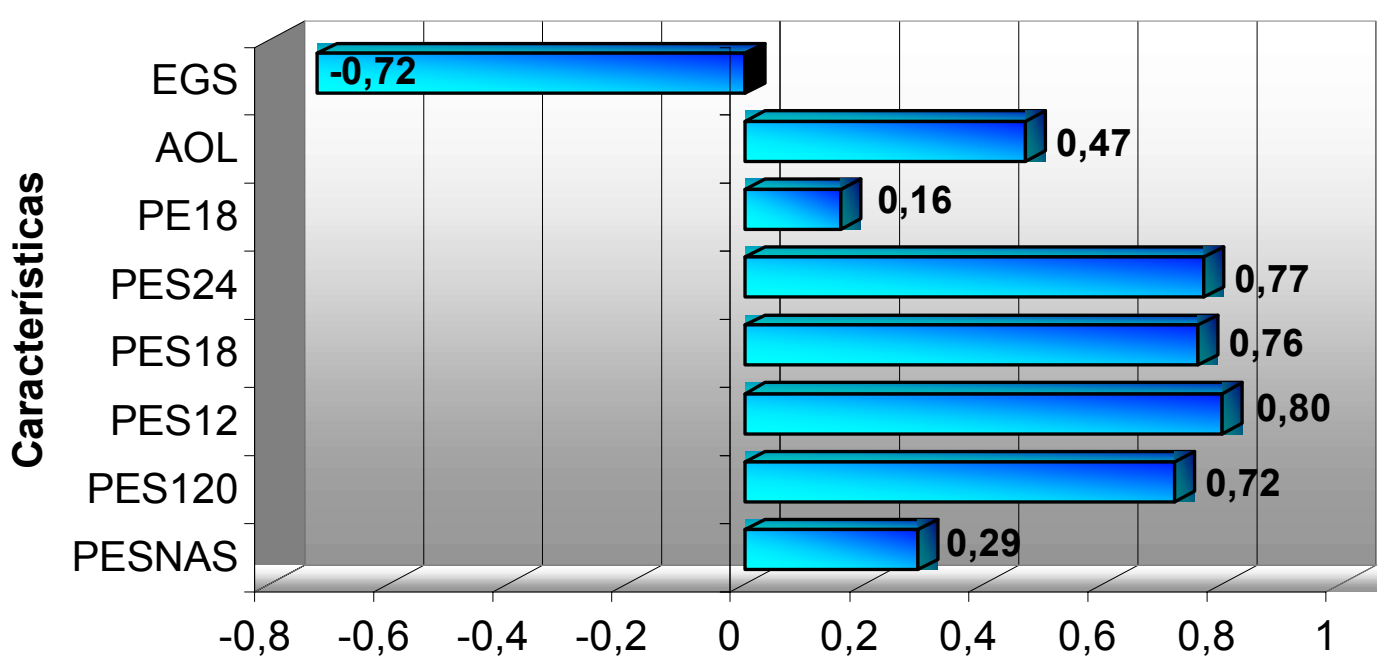

Correlações

Figura 10 - Correlações genéticas entre PESDES, características de carcaça e demais características de desenvolvimento ponderal. Pirassununga, São Paulo. 2003

A correlação genética obtida entre PESDES e PESNAS foi de 0,29. Este valor foi inferior aos valores de correlação genética de 0,62, 0,60 e 0,61encontrados por LÔBO et al. (2000), SILVA et al. (2001) e VAN MELLIS (2002), respectivamente.

Com relação aos PES120, PES12, PES18 e PES24, os resultados indicam uma correlação genética positiva de alta magnitude, $0,72,0,80,0,76$ e 0,77 , respectivamente. Estes valores indicam que a seleção para PESDES resultaria em ganhos genéticos favoráveis para os pesos citados. Além de contribuir para ganhos genéticos, os resultados sugerem uma relação positiva entre estas características, ou seja, o ganho em uma tende a aumentar a expressão de outra.

A correlação genética entre PESDES e PE18 $(0,16)$, embora positiva não sugere que expressivos ganhos com a seleção de PESDES podem ser obtidas para PE18. 


\section{CONCLUSÕES E IMPLICAÇÕES}

A técnica de ultra-sonografia real time tem avançado muito nas ultimas duas décadas, e se tornará uma importante ferramenta em todos os segmentos da industria de carne. Como uma ferramenta de pesquisa e manejo, o ultra-som poderá aumentar o entendimento em relação à curva de crescimento e desenvolvimento animal de diversas raças de bovinos de corte.

A modelagem por Polinômios Segmentados mostrou maior eficiência em relação aos Polinômios Ordinários devido a melhor qualidade das curvas ajustadas;

Os resultados do presente trabalho sugerem que o ajuste linear para AOL e EGS não elimina completamente o efeito de idade. A utilização de fatores de correção para estas características, para remover os efeitos de idade do animal pode contribuir na melhoria dos modelos de análise.

Deve se padronizar o intervalo de idade para mensuração das características de AOL e EGS aos 18 meses para a raça Santa Gertrudis, nessa faixa etária ocorre o pico de desenvolvimento muscular e, é quando a deposição de tecido adiposo aumenta.

Medidas de AOL e EGS dos animais aos 18 meses podem ser usadas como uma ferramenta de seleção na produção de bovinos para a melhoria de características de carcaça. Estas medidas levariam a uma maior precisão na seleção de touros. 
A estimativa de herdabilidade encontrada para $A O L$ neste estudo sugere que progressos podem ser conseguidos usando esta medida como uma ferramenta para seleção de características de carcaça em bovinos. Apesar da baixa estimativa de herdabilidade encontrada para EGS, esta característica mostra variabilidade genética o que sugere que mais pesquisas e maior atenção deve ser dada a esta característica em programas de melhoramento.

Os parâmetros encontrados neste trabalho são estimativas de uma amostra da população de Santa Gertrudis e mais pesquisa são necessárias, com uma amostra substancial maior para estimar parâmetros genéticos para estimativas de carcaça obtidas por ultra-sonografia. 


\section{REFERÊNCIAS BIBLIOGRÁFICAS}

AARON, D.K.; THRIFT, F.A.; PARISH, N.R. Genetic parameter estimates for preweaning growthin Santa Gertrudis cattle. J. Anim. Sci., v. 65, p. 14951499, 1987.

ALBERTA AGRICULTURAL FOOD AND RURAL DEVELOPMENT. Selection of Beef cattie breeds. http:Ilwww.agric.gov.ab.ca/livestocklbeeflbreedsl.html, (10/Dez/2001).

ANUALPEC. Anuário da pecuária brasileira. São Paulo: FNP, 2003. 392 p.

BAILEY, C.M.; JESEN, J.; ANDERSEN, B. B. Ultrasonic scanning and body measurements for predicting composition and muscle distribution in young Holstein x Friesian bulls. J. Anim. Sci., v. 63, p. 1337 - 1346, 1986.

BANG, K. S.; YOOON, J. K.; KIM, Y. K. Ultrasonic back fat measurement in Korean Native cattle. Kor. J. Anim. Sci., v. 36, n. 4, p. 409-414, 1994.

BANKS, L. R; MILLER, S. P.; WILTON, J. W. Genetic parameter estimates for traits measured on bulls in central evaluation stations. Disponível em: http://apsit.aps.uoguelph.ca/pub/jwwpapers/96beefrep6.html Acesso em: 10 out. 2001.

BERG, R.T.; BUTERFIELD, R.M. Nuevos Conceptos sobre el desarollo del ganado vacuno. Zaragoza: Acríbia, 1979. 297 p.

BERGEN, R. D.; McKINNON, J. J.; CHRISTENSEN, D. A.; KOHLE, N.; BELANGER, A. Prediction of lean yield in yearling bulls using real-time ultrasound. Can. J. Anim. Sci, v. 76, p. 305-311, 1996.

BERGMANN, J. A. G. Impacto econômico do desenvolvimento da biotecnologia. In: CONGRESSO BRASILEIRO DAS RAÇAS ZEBUÍNAS, 4., 2000, Uberaba. Anais... Uberaba, MG: CBZ, 2000. p. 260-271.

BERTRAND, J. K. Use of live animal ultrasound carcass measures in carcass evaluation of beef cattle. In: BEEF IMPROV. FED. ANN. RES. SYMP. ANNU., 34., 2002. Proceedings... Omaha, NE, 2002. p. 128-134.

BERTRAND, J. K.; MOSER, D. W.; HERRING, W. O. Beef genetic evaluation programs for carcass traits: current situation and future possibilities. J. Anim. Sci., v. 78, n. suppl. 1, p. 57, 2000. 
BOLDMAN, K. G.; VAN VLECK, L. D. Derivate-free restricted maximun likelihood estimation in animal models with sparse matrix solver. J. Dairy Sci., v. 74, p. 4337-4344, 1991.

BOLDMAN, K.G.; KRIESE, L.A.; VAN VLECK, L.D.; KACHMAN, S.D. A manual for use of MTDFREML: a set of programs to obtain estimates of variances and covariances. USDA-ARS, 1993.

BRETHOUR, J. R. Using receiver operating characteristics analysis to evaluate the accuracy in predicting future quality grade from ultrasound marbling estimates on beef calves. J. Anim. Sci, v. 78, p. 2263-2268, 2000a.

BRETHOUR, J. R. Using serial ultrasound measures to generate models of marbling and backfat thickness changes in feedlot cattle. J. Anim Sci, v. 78, p. 2055-2061,2000b.

BRETHOUR, J.R. The repeatility and accuracy of ultrasound in measuring back fat of cattle. J. Anim. Sci., v. 70, p. 1039-1044, 1992.

BUSBOOM, J. A; BRETHOUR, J. R; ELIAS-CALLES, A; GASKINS, C. T; DUCKETT, S. K. Using ultrasound for prediction feeding and marketing of cattle. Disponível em:

http://www.ansci.wsu.edu/wagyu/wagsymp/articles97/busboom.htm . Acesso em 10 fev. 2000.

CARTWRIGHT, T. C. A raça Santa Gertrudis: melhoramento genético. In: CONGRESSO INTERNACIONAL DE SANTA GERTRUDIS, 2., São Paulo, 1978. Anais... São Paulo, p. 58-70.

CHARAGU, P. K.; CREWS Jr., D. H.; KEMP, R. A.; MWANSA, P. B. Machine effects of ultrasonic prediction of backfat and ribeye area in beef bulls, steers and heifers. Can J. Anim Sci, v. 80, p. 19-24, 2000.

CREWS, D. H., Jr.; Pollak E. J.; Weaber, R. L.; Quaas, R. L.; Lipsey, R. J. Genetic parameters for carcass traits and their live animal indicators in Simmental cattle. J. Anim Sci. v. 81, p. 1427-1433, 2003.

CREWS, D. H., Jr.; KEMP, R. A. Genetic evaluation of carcass yield using ultrasound measures on young replacement beef cattle. J. Anim. Sci. v. 80, p. 1809-1818, 2002.

CREWS, D. H., Jr.; KEMP, R. A. Genetic parameters for ultrasound and carcass measures of yield and quality among replacement and slaughter beef cattle. J. Anim. Sci., v. 79, p. 3008-3020, 2001.

CREWS, D.H. Jr.; KEMP, R.A. Contribution of preweaning growth information and maternal effect for prediction of carcass trait breeding values among crossbred beef cattle. Can. J. Anim. Sci., v. 79, p. 17-25, 1999. 
DE ROSE, E.P.; WILTON, J.W.; SCHAEFFER, L.R. Estimation of variance components for trait measured on station-tested beef bulls. J. Anim. Sci, v. 66, n. 3, p. 626-634, 1988.

DEVITT, C. J. B.; WILTON, J. W. Genetic correlation estimates between ultrasound measurements on yearling bulls and carcass measurements on finished steers. J. Anim. Sci, v. 79, p. 2790-2797, 2001.

DIJKSTRA, J.; KORVER, S.; OLDENBROEK, J.K. et al. Relationship between performance test and progeny test for veal and beef production in Dutch Red and White cattle. In: Performance testing of Al bulls for efficiency and beef production in dairy and dual-purpose breeds: study commissions on cattle production and animal genetics. Wageningen, Netherlands, 27-29 Apr. 1987. p. 28-34. (EAAP Publication, 34).

ELER, J. P.; VAN VLECK, L. D.; FERRAZ, J. B. S.; LÔBO, R. B. Estimation of variances due to direct an maternal effects for growth traits of Nelore cattle. J. Anim. Sci., v. 73, p. 3253 - 3258, 1995.

ELER, J.P. Utilização de modelos animais univariado e multivariado na avaliação genética de bovinos na raça Nelore. 1994. 123 p. Tese (livredocência) - Faculdade de Zootecnia e Engenharia de Alimentos, USP, Pirassununga.

ELER, J.P.; FERRAZ, J.B.S.; SILVA, P. R. Parâmetros genéticos para peso, avaliação visual e circunferência escrotal na raça Nelore, estimado por modelo animal. Arq. Bras. Med. Vet. Zootec.,v. 48, n. 2, p. 203-213, 1996.

FAULKNER, D. B.; PARRET, D. F.; McKEITH, F. K; BERGER, L. L. Prediction of fat cover and carcass composition fTom live and carcass measurements. J. Anim. Sci., v. 68, p. 604-610, 1990.

FERRAZ J. B.; ELER J. P. Sumário de touros Nelore 2000. São José do Rio Preto: Agropecuária CFM, 2000. 55 p.

FERRAZ, J. B. S.; ELER, J. P.; RIBEIRO, P. M. T. Genetic study of Santa Gertrudis cattle in Brazil. Livest. Res. Rural Develop., v. 12, n. 2, 2000. (online).

FERRAZ, J.B.S. Aplicações de modelos animais na avaliação de parâmetros populacionais de características reprodutivas e produtivas de coelhos da raça Califórnia e Nova Zelândia branca. 1993. 123 p. Tese (Livre-Docência) - Faculdade de Zootecnia e Engenharia de Alimentos, USP, Pirassununga.

FIGUEIREDO, L. G. G. Estimativas de parâmetros genéticos de características de carcaças feitas por bovinos por ultra-sonografia em bovinos da raça Nelore. 2001. 52 p. Dissertação (Mestrado) - Faculdade de Zootecnia e Engenharia de Alimentos, USP, Pirassununga. 
FISHER, A. A review of the technique of estimating the composition of livestock using the velocity of ultrasound. Computers and Electronics in Agriculture, v. 17, p. 217-231, 1997.

FORREST, R. J. Comparison of several methods of estimating the fat and the lean composition of bovine rib cuts. Can. J. Anim Sci., v. 48, p. 103-108, 1968.

FROST, A R; SCHOFIELD, C. P.; BEAULAH, S. A; MOTTRAM, T. T.; UNES, $\mathrm{J} A$; W A THES, C. M. A review of livestock and monitoring and the need for integrated systems. Computers and Electronics in Agriculture, v. 17, p. 139-159, 1997.

GEORGE, A.; LIU, J.; NG, E. User guide for SPARSPACK: Waterloo sparse linear equations package. Canada: Univ. Waterloo, ON, Dept. Computer Sci., 1980. (CS- 78-30).

GRASER, H. U.; SMITH, S. P. TIER, B. A dirivative-free approach for estimate variance components in animal models by restricted maximun likelihood. J. Anim. Sci., v. 64, p. 1362-1370. 1987.

HARVILLE, D.A. Maximun likelihood approaches to variance component estimation and to related problems. J. Am. Stat. Assoc. v. 72, p. 320-340. 1977.

HASSEN, A.; WILSON, D. E.; ROUSE, G. H. Evaluation of carcass, live, and realtime ultrasound measures in feedlot cattle: I. assessment of sex and breed effects. J. Anim. Sci., v. 77, p. 273-282, 1999a.

HASSEN, A.; WILSON, D. E.; ROUSE, G. H. Evaluation of carcass, live, and realtime ultrasound measures in feedlot cattle: 11. effects of different age end points on the accuracy of predicting the percentage of retail product, retai! product weight, and hot carcass weight. J. Anim. Sci., v. 77, p. 283-290, 1999b.

HASSEN, A; WILSON, D. E.; AMIN, V. R; ROUSE, G. H.; HA YS, C. L Predicting percentage of intramuscular fat using two types of real- time ultrasound equipment. J. Anim Sci, v. 79, p. 11-18, 2001.

HENDERSON, C.R. Best linear unbiased prediction under a selection model. Biometrics, v. 31, p. 423-447, 1975.

HENDERSON, C.R. Estimation of changes in herd environment. J. Dairy Sci., v. 32, p. 706-711, 1949.

HENDERSON, C.R. Estimation of variance and covariance components. Biometrics, v. 9, p. 226-56, 1953. 
HENDERSON, C.R. Selection index and expected genetic advance. In: Statistical genetics and plant breeding. NAS-NRC, 1963. (Publications, 982).

HENDERSON, C.R. Theoretical basis and omputational methods for a number of different animal models. J. Dairy Sci., v. 71, suppl. 2, p. 1-16, 1988.

HENDERSON, C.R.; KEMPTHORNE, O.; SEARLE, S.R.; Von KROSIGK, C.M. The estimation of genetic and environmental trends from records subject to culling. Biometrics, v. 15, p. 192-218, 1959.

HENDERSON-PERRY, S. C.; CORAR, L. R; PERRY, R. C. The use ofultrasound in cattle to estimate subcutaneous fat thickness and ribeye area. J. of Anim Sci, v. 67, p. 433, 1989.

HERRING, W. O.; KRIESE, L. A.; BERTRAND, J. K.; CROUCH, J. Comparison of four real time ultrasound systems that predict intramuscular fat in beef cattle. J. Anim. Sci., v. 76, p. 364-370, 1998.

HOUGHTON, P. L.; TURLINGTON, L. M. Application of ultrasound for feeding and finishing animais: a review. J. Anim Sci, v. 70, p. 930- 941, 1992.

IOWA STATE UNIVERSITY / AMERICAN ANGUS ASSOCIATION. Angus carcass evaluation using ultrasound data, 1999. 8 p.

JOHNSON, E. R; PRIYANTO, R; TAYLOR, D. G. Investigations into the accuracy of prediction of beef carcass composition using subcutaneous fat thickness and carcass weight: II improving the accuracy of prediction. Meat Science, v. 46, p. 159 172, 1997.

JOHNSON, M. Z.; SCHALLES, R. R.; DIKEMAN, M. E., et al. Genetic parameter estimates of ultrasound-measured longissimus muscle area and 12 rib fat a thickness in Brangus cattle. J. Anim. Sci., v. 71, p. 2623-2630, 1993.

KEMP, D. J.; HERRING, W. O.; KAISER ,C. J. Genetic and environmental parameters for steer ultrasound and carcass traits. J. Anim Sci. v. 80, p. 1489-1496, 2002.

KEMPSTER, A. J.; OWEN, M. G. A note of the accuracy of an ultrasonic technique for selecting cattle of different breeds for slaughter at equal fatness. Anim. Prod., v. 32, p. 113-115, 1981.

KENNEDY, B.W.; SCHAEFFER, L.R.; SORENSEN, D.A. Genetic properties of animal models. J. Dairy Sci, v. 71, supl. 2, p. 17-26, 1988.

KOCH, R.M.; CUNDIFF, L.V.; GREGORY, K.E. et al. Genetic and phenotipic relations associated with preweaning and postweaning growth af Hereford bulls and heifers. J. Anim. Sci. v. 36, p. 235-239, 1973. 
KOOTS, K. R.; GIBSON, J. P.; SMITH, C.; WILTON, J. W. Analyses of published genetic parameter estimates for beef production traits. 1. heritability. Anim. Breed. Abstr., v. 62, p. 309-337, 1994a.

KOOTS, K. R.; GIBSON, J. P.; WILTON, J. W. Analyses of published genetic parameter estimates for beef production traits. 2. phenotypic and genetic correlations. Anim. Breed. Abstr., v. 62, p. 825-853. 1994b.

KRIESE, L. A.; BERTRAND, J. K.; BENYSHEK, L. L. Genetic and environmental growth trait parameter estimates for Brahman and Brahmanderivate cattle. J. Anim. Sci., v. 69, p. 2362-2370, 1991.

LANNA, D. P. D.; PACKER, I. U. Eficiência biológica e econômica em bovinos de corte. 1998. $21 \mathrm{p}$.

LANNA, D. P. D.; FOX D. G.; BOIN, C. Validation of the Cornell net carbohydrate and protein system estimates of nutrient requirements of growing and lactating Zebu, 1996.

LEME, P. R. Estimativa da composição química corporal de novilhos Nelore através do espaço de Deutério. 1993. 78 p. Tese (Doutorado) Faculdade de Ciências Agrárias e Veterinárias, Universidade Estadual Paulista "Júlio de Mesquita Filho", Jaboticabal.

LÔBO, R N. B.; MADALENA, F. E.; VIEIRA, A. R. Average estimates of genetic parameters for beef and dairy cattle in tropical regions. Anim. Breed. Abstr., v. 68, n. 6, p. 433-462, 2000.

LÔBO, R.B.; REYES, A., FERRAZ, J.B.S. et al. Bivariate animal model analysis of growth weight and scrotal circunference of Nellore cattle in Brazil. In: WORLD CONGRESS ON GENETIC APPLIED TO LIVESTOCK PRODUCTION, 5., 1994, Guelph. Proceedings... Ghelph: WCGALP, 1994. V. 17. p. 199-201.

LUCHIARI FILHO, A. Pecuária da carne bovina. 1. ed. São Paulo: o autor, 2000. $134 \mathrm{p}$.

MAGNABOSCO, C. de U.; REYES, A. de los; Mc MANUS, C. BORGES JUNIOR, M.M. Estudo genético - quantitativo de características de crescimento em bovinos da raça Nelore nos Estados Unidos da América. In: REUNIAO ANUAL DA SOCIEDADE BRASILEIRA DE ZOOTECNIA, 35., 1998, Botucatu. Anais... Botucatu: SBZ, 1998. /cd-room/.

MARCONDES, C. R.; BERGMANN, J. A. G.; ELER, J. P.et al. Análises de alguns critérios de seleção para características de crescimento da raça Nelore. Arq. Bras. Med. Vet e Zootec., v. 52, n. 1, p. 83-89, 2000. 
MAVROGENIS, A.P.; LOUCA, A. A note of some factors influencing postweaning performance of purebred and crossbred lambs. Anim. Prod. v. 29, p. 415-418, 1979.

MAY, S. G.; MIES, W. L; EDW ARDS, J. W.; HARRIS, 1. J.; MORGAN, 1. B.; GARRET, R P.; WILLIANS, F. L;. WISE, J. W.; CROSS, H. R; SAVELL, J. W. Using live estimates and ultrasound measurements to predict carcass cutability. J. Anim. Sci, v. 78, p. 1255-1261, 2000.

MERCADANTE, M. E. Z; CYRILLO, J, N.S. G.; SILVA, S. L.; RAZOOK, A. G.; FIGUEIREDO, L. A.; BONILHA NETO, L. M. Medidas de ultra-som da área de olho-de-lombo e espessura de gordura de cobertura de bovinos em prova de ganho de peso. Disponível em: http://www.sbz.org.br/eventos/portoalegre/homepagesbz/meVme1O22.htm, Acesso em: 15 nov. 1999.

MERCADANTE, M.E.Z.; LOBO, R.B.; REYES, A. de los. Parâmetros genéticos para características de crecimiento em cebuinos de carne: uma revision. Arch. Latinoam. Prod. Anim., v. 3, p. 45-89, 1995.

MEYER, K. DFREML - a set of programs to estimate variance components under individual animal model. J. Dairy Sci. v. 71, p. 33, 1988a.

MEYER, K. Estimation of variance components for individual animal models. I univariate analysis. Genet. Sel. Evol., v. 21, p. 317-340, 1989b

MEYER, K. Estimation of variance components for individual animal models. II. multivariate analysis. Genet. Sel. Evol., v. 23, p. 67-83, 1991.

MEYER, K. Programs to estimate variance components for individual models by restricted maximun likelihood. User notes. Edinburg Univ., Scotland, 1988b.

MEYER, K. Restricted maximun likelihood to estimate variance components for animal models with several random effects using a derivate-free algorithm. Genet. Sel. Evol., v. 21, p. 31, 1989c.

MILLER, P. A recent study of age adjustiment. J. Dairy Sci., v. 56, n. 7, p. 952-958, 1973.

MILLER, R. K. Avaliação instrumental da qualidade da carne. In: CONGRESSO BRASILEIRO DE CIÊNCIA E TECNOLOGIA DE CARNES, 1., 2001, São Pedro. Anais... Campinas: ITAL, 2001. p. 179-184.

MOSER , D.W.; BERTRAND, J.K.; MIZTAL, I.; KRIESE, L.A.; BENYSHEK, L.L. Genetic parameter estimates for carcass and yearling ultrasound measurements in Brangus cattle. J. Anim. Sci., v. 76, p. 2542-2548, 1998.

NELDER, J.A.; MEAD, R. A simplex method for function minimization.

Computer J., v. 5, p. 147-151, 1965. 
NELSEN, T.C.; SHORT, R.E.; URICK, J.J. et al. Heritabilities and genetic correlations of growth and reproductive measurements in Hereford bulls. $\mathbf{J}$. Anim. Sci. v. 63, p. 409-417, 1986.

OWENS, F. N.; DUBESKI, P.; HANSON, C. F. Factors that alter the growth and development ofruminants. J. Anim Sci, v. 71, p. 3138-3150, 1993.

PAZ, C.C.P.; ALBUQUERQUE, L.G.; FRIES, L.A. Efeitos ambientais sobre ganho de peso no período do nascimento ao desmame em bovinos da raça Nelore. Rev. Bras. Zootec., v. 28, n. 1, p. 55-64, 1999.

PELICIONI, L. C. Polinômios segmentados no ajuste de idade e efeitos da linhagem citoplasmática para características de crescimento e produção de leite em bovinos da raça caracu. 2000. 112 p. Dissertação (Mestrado) - Faculdade de Ciências Agrárias e Veterinárias, Universidade Estadual Paulista, Jaboticabal.

PEREIRA, E. Análise genética de algumas características reprodutivas e de suas relações com desempenho ponderal na raça Nelore. 2001. 64 p. Dissertação (Mestrado) - Faculdade de Zootecnia e Engenharia de Alimentos, USP, Pirassununga.

PERKINS T. L.; GREEN R. D. and HAMLIN K. E. Evaluation of ultrasonic estimates of carcass fat thickness and longissimus muscle area in beef cattle J. Anim Sci. v. 70, p. 1002-1010, 1992a.

PERKINS, T.L.; GREEN, R.D.; HAMLIM, K.E.; et al. Ultrasonic prediction of carcass merit in beef cattle: evaluation of thecnican effects on ultrasonic estimates of carcass fat thickness and longissimus muscle area. J. Anim. Sci., v. 70, p. 2758-2765, 1992b.

PERRY, T. C.; AINSLIE, J. S.; TRAXLER, M. J., FOX, D. G.; STOUFFER, J. $R$. Use of real-time and attenuation ultrasonic measurements to detennine backfat thickness, ribeye area, carcass marbling and yield grade in tive cattle. J. Anim Sci., v. 68, p. 337, 1990.

PRADO, C. S.; PÁDUA, J. T.; SAINZ, R D.; MAGNABOSCO, C. U; COORREA, M. P.; RESENDE, L. S. Comparação de diferentes métodos de avaliação da área de olho-de-lombo e cobertura de gordura em quatro grupos genéticos de bovinos de corte castrados e inteiros suplementados a pasto. In: CONGRESSO BRASILEIRO DE CIÊNCIA E TECNOLOGIA DE CARNES, $1 .$, 2001, São Pedro. Anais... Campinas: ITAL, 2001. p. 367-368.

PRIYANTO, R; JOHNSON, E. R; TA YLOR, D. G. Investigations into the accuracy of prediction of beef carcass composition using subcutaneous fat thickness and carcass weight. I. identifying problems. Meat Sci., v. 46, p. 147-157, 1997. 
QUAAS, R. L.; POLLAK, E. J. Mixed models methodology for farm and ranch beef cattle testing programs. J. Anim. Sci., v. 51, p. 1277-1287, 1980.

RENAND, G.; FISHER, A.V. Comparison of methods for estimating carcass fat content of young Charolais bulls in preformance testing station. Livestock Prod. Sci., v. 51 p. 205-213, 1997.

REVERTER, A., D. J.; JOHNSTON, H. U.; GRASER, M. L.; WOLCOTT, W.; $H$. UPTON. Genetic analyses of live-animal ultrasound and abattoir carcass traits in Australian Angus and Hereford cattle. J. Anim. Sci., v. 78, p. 17861795, 2000.

RIBEIRO, F.G.; BULLE, M.L.M.; LEME, P.R. et al. Correlações entre medidas com ultra-som (in vivo) e diretamente na carcaça (post mortem) em bovinos. In: CONGRESSO DE ZOOTECNIA, 9., 1999, Portugal. Actas... Portugal: APEZ., 1999b. p. 19.

RIBEIRO, P. M. T. Estudo de parâmetros e tendências genéticas de bovinos da raça Santa Gertrudis. 1997. 62 p. Dissertação (Mestrado) Faculdade de Zootecnia e Engenharia de Alimentos, USP, Pirassununga.

RIBEIRO, P. M. T.; DE PAULA, M. G.; DE BARROS, A. J.; FERRAZ, J. B. S.; ELER, J. P. Influência de fatores não genéticos no desenvolvimento ponderal de bovinos da raça Santa Gertrudis. In: REUNIAO ANUAL DA SOCIEDADE BRASILEIRA DE ZOOTECNIA, 33., 1996, Fortaleza. Anais... Fortaleza: SBZ, 1996. p. 152-153.

RILEY D. G.; CHASE JR C. C.; HAMMOND A. C.; WEST R. L.; JOHNSON D. D.; OLSON T. A. and COLEMAN S. W. Estimated genetic parameters for carcass traits of Brahman cattle. J. Anim Sci. v. 80, p. 955-962. 2002.

ROBINSON, D. L.; HAMMOND, K.; McDONALD, C. A. Live animal measurement of carcass traits: estimation of genetic parameters for beef cattle. J. Anim. Sci., v. 71, p. 1128-1135, 1993.

ROBINSON, D. L.; McDONALD, C. A.; HAMMOND, K.; TURNER, J. W. Live animal measurement of carcass traits by ultrasound: Assessment and accuracy of sonographers. J. Anim. Sci., v. 70, p. 1667-1676, 1992.

SAS/STAT. User's guide. v. 8.2. Cary, North Carolina, USA: SAS Institute Inc., 1999.

SCHAEFFER, L. R.; WILTON, J. W. Estimation of variances and covariances for use in a multiple trait beef sire evaluation model. J. Anim. Sci., v. 61, p. 531-538, 1981.

SEARLE, S.R. Linear models. New York: John Wiley \& Sons, 1971. 532 p.

SEARLE, S.R.; CASELLA, G.; McCULLOCH, C.E. Variance components. New York: John Wiley \& Sons, 1992. 501 p. 
SHEPARD, H. H.; GREEN, R. D.; GOLDEN, B. L.; HAMLIN, K. E.; PERKINS, T. L.; DILES, J. B. Genetic parameter estimates of live animal ultrasonic measures of retail yield indicators in yearling breeding cattle. J. Anim. Sci., v. 74, p. 761-768, 1996.

SILVA, J.A. II; ELER, J.P.; FERRAZ, J.B.S.; OLIVEIRA, H.N. Estimação da herdabilidade da probabilidade de prenhez aos 14 meses usando inferência bayesiana. In: REUNIÃO ANUAL DA SOCIEDADE BRASILEIRA DE ZOOTECNIA., 2001, Viçosa. Anais... Viçosa: SBZ, 2001. p. 4.

SILVA, S. L. Estimativa de características de carcaça e ponto ideal de abate por ultra-sonografia, em bovinos submetidos a diferentes níveis energéticos na ração. 2001. 65 p. Dissertação (Mestrado)-Faculdade de Zootecnia e Engenharia de Alimentos, USP, Pirassununga.

SMITH, M. T.; OLTJEN, J. W.; DOLEZAL, H. G.; GILL, D. R.; BEHRENS, B. D. Evaluation of ultrasound for prediction of carcass fat thickness and longissimus muscle area in feedlot steers. J. Anim. Sci. v. 70, p. 29, 1992.

STELZLENI, A. M.; PERKINS, T. L.; BROWN, A. H. et al. Genetic parameters estimates of yearling live animal ultrasonic measurements in Branugs cattle. J. Anim. Sci., v. 80, p. 3150-3153, 2002.

STOUFFER, J.R.; WALLENTINE, M.V.; WELLINGTON, G.A. Development and application of ultrasonic methods for measuring fat thickness and rib-eye area in cattle and rib-eye in cattle and hogs. J. Anim. Sci., v 18, n. 4, p. 759767, 1961.

STOUFFER, J.R.; WALLENTINE, M.V.; WELLINGTON, G.H.; DIEKMANN, A. New techniques for real time ultrasonic evaluations of beef cattle. J. Anim. Sci., v. 67, p. 121, 1989.

SUGUISAWA, L. Ultra-sonografia para predição das características e composição da carcaça de bovinos. 2002. 70 p. Dissertação (Mestrado) Escola Superior de Agronomia Luiz de Queiroz, USP.

SULLIVAN, P. G.; MILLER, S. P. A multiple breed genetic evaluation model for rib eye arca. Disponível em:

http://apsit.aps.uoguelph.ca/pub/97beefres/97bfres9.html Acesso em: 20 out. 2001.

TEDESCHI, L. O. Determinação dos parâmetros da curva de crescimento de animais da raça Guzerá e seus cruzamentos alimentados a pasto, com e sem suplementação. 1996. 140 p. Dissetação (Mestrado) - Escola Superior de Agricultura "Luiz de Queiroz", Universidade de São Paulo, Piracicaba. 
TESS, M. W.; JESKE, K. E.; DILLARD, E. U.; et al. Sire x environment interactions for growth traits of Hereford cattle. J. Anim. Sci., v. 59, p. 14671476, 1984.

THWAITES, C. J. Ultrasonic estimation of carcass composition: review. Austr. Meet Res. Commit., n. 47, 1984. 29 p.

TRUS, D.; WILTON, J. W. Genetic parameters for maternal traits in beef cattle. Can J. Anim. Sci., v. 68, p. 119-128, 1988.

TURNER, J. W.; PELTON, L. S.; CROSS, H. R. Using live animal ultrasound measures of ribeye area and fat thickness in yearling Hereford bulls. J. Anim. Sci., v. 68, p. 3502-3506, 1990.

VAN MELIS, M. H. Utilização do método R na estimação de parâmetros genéticos em gado de corte. 2002. 85 p. Dissertação (Mestrado) Faculdade de Zootecnia e Engenharia de Alimentos, USP, Pirassununga.

WALDNER, D. N.; DIKEMAN, M. E.; SCHALLES, R. R.; et al. Validation of real-time ultrasound technology for predicting fat thickness, longissimus muscle areas, and composition of Brangus bulls from 4 months to 2 years age. J. Anim. Sci., v. 70, n. 3, p. 973-983, 1992.

WILSON, D. E. Real-time ultrasound evaluation of beef cattle. In: Study Guides. Ames: lowa State University, 1995.

WILSON, D. E.; ROUSE, G. H.; GRASER, G. H.; AMIM, V. Prediction of carcass traits using live animal ultrasound. In: Beef research report. Ames: lowa State University, 1998. 7 p.

WILSON, D. E.; WILLHAM,R. L; NORTHCUTT, S. L.; G. H. ROUSE. Genetic parameters for carcass traits estimated from Angus field records. J. Anim Sci., v. 71; p. 2365-2370, 1993. 